Portland State University

PDXScholar

Summer 10-28-2015

\title{
Principal Leadership Practices in High Poverty K-5 Model Schools in Oregon
}

Janice Marie Adams

Portland State University

Follow this and additional works at: https://pdxscholar.library.pdx.edu/open_access_etds

Part of the Educational Leadership Commons, and the Elementary and Middle and Secondary Education Administration Commons Let us know how access to this document benefits you.

\section{Recommended Citation}

Adams, Janice Marie, "Principal Leadership Practices in High Poverty K-5 Model Schools in Oregon" (2015). Dissertations and Theses. Paper 2621.

https://doi.org/10.15760/etd.2617

This Dissertation is brought to you for free and open access. It has been accepted for inclusion in Dissertations and Theses by an authorized administrator of PDXScholar. Please contact us if we can make this document more accessible: pdxscholar@pdx.edu. 
Principal Leadership Practices in High Poverty K-5 Model Schools in Oregon

by

Janice Marie Adams

A dissertation submitted in partial fulfillment of the requirements for the degree of

Doctor of Education

in

Educational Leadership: Administration

Dissertation Committee:

Deborah Peterson, Chair

Pat Burk

Dan Johnson

Yves Labissiere

Portland State University

2015 
(C) 2015 Janice Marie Adams 


\begin{abstract}
Children living in poverty in the United States face some of life's greatest challenges, including achieving academic success in school. Evidence is also emerging of a growing income disparity in America that affects families, communities and local labor markets in ways that can undermine the effectiveness of schools serving disadvantaged populations (Duncan \& Murnane, 2011). Evidence exists, however, that high academic performance is within the reach of all children in high poverty schools, and that principal leadership is a contributing factor.

This study examined principal leadership practices in three high poverty K-5 elementary schools in Oregon identified as Model schools under the Oregon ESEA waiver to No Child Left Behind. This study identified themes of leadership practices including 1) high expectations, 2) meeting children's basic needs, 3) shared leadership and teamwork, 4) use of data, and 5) personal attributes of the principal. Other themes considered important to one or more groups of respondents but not necessarily to all included 1) caring, 2) positive support, 3) addressing biases about children and families in poverty, 4) principal's elementary teaching experience, and 5) pride in the local school. As such, the findings of this study support the knowledge base in educational leadership regarding principal leadership as a factor in schools that impact the academic growth of children (Hallinger, 2005; Hallinger, Bickman, \& Davis, 1996; Hallinger \& Heck, 1998; Hattie, 2009; Jacobson et al., 2004; Leithwood \& Jantzi, 2012; Leithwood \& Louis, 2012; Leithwood et al., 2004; Lyman \& Villani, 2004; Marks \& Printy, 2003; and, Water, Marzano, \& McNulty, 2003).
\end{abstract}


This study has implications for district hiring and planning for principal succession, teacher hiring, resource allocation, community engagement, and district support for schools serving students in high-poverty communities. 


\section{Dedication}

This dissertation is dedicated first and foremost to my parents Jack and Margaret Young, people who grew up poor in America yet still believed in the opportunity for their five children to improve their lives through access to public education. It is also dedicated to my children Nathan Adams and Erica Ediger who teach me something new each day; to my sister Carolyn Schmidt who taught for 40 years in a high-poverty elementary school in Oregon; and to my grandchildren, Jackson, Sydney, Ben, Lucy, and Max who I hope will use the benefits they received and the lessons learned from our family history to help make the lives of all children better in the future. And last but not least, it is dedicated to Sharon Appleman for her lifelong dedication to other peoples' children and for inspiring me to start writing. 


\section{Acknowledgments}

After the first meeting with my advisor and dissertation chair, Dr. Deborah Peterson, I was immediately immersed in a journey of scholarship and authentic practice as Dr. Peterson skillfully guided me to the successful completion of my dissertation. I am deeply grateful for Dr. Peterson's passionate and unconditional encouragement, her commitment to equitable access to education for all children, and her ability to ask deep, meaningful questions that lead learners to construct their own understandings of complex issues.

I am thankful for the committee members who gave me their time, support, and feedback throughout this journey. Dr. Pat Burk, Dr. Dan Johnson, and Dr. Yves Labissiere each brought their own insights and contributions to my study, and their guidance helped me to continuously refine my work as I completed the dissertation.

I want to acknowledge Portland State University and the Graduate School of Education administrators, professors, and instructors I have met and had the privilege to learn from during my years as a student at PSU. The institutional and individual beliefs and values of the university and its faculty have contributed to my work in education being grounded in equity, cultural competence, and research-based practices.

I also want to acknowledge the educators I have worked with over the years who have been wonderful teachers and leaders. Their support helped give me the courage and desire to complete my doctorate.

Finally, I am grateful to the principals, teachers, and parents of the schools in this study for allowing me entry into their schools and lives to examine their practices and 
perspectives while working to understand successful improvement of academic achievement for children in high poverty K-5 Model schools. Their commitment to the lives of children is truly inspiring. 


\section{Table of Contents}

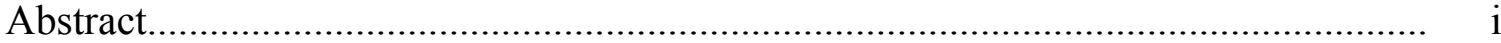

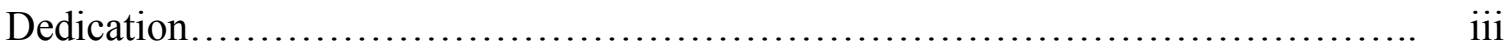

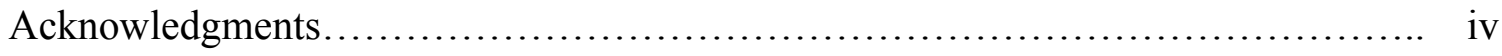

List of Tables ...........................................................................................

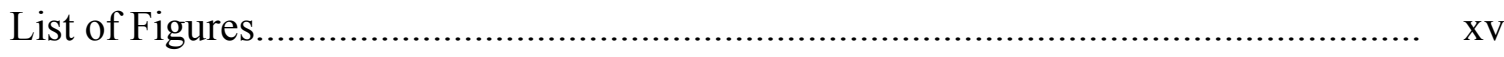

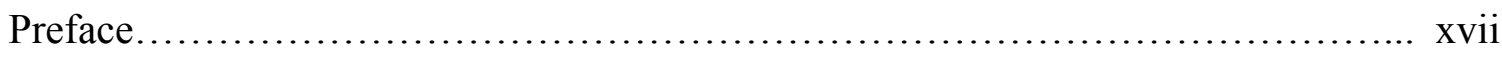

\section{CHAPTER}

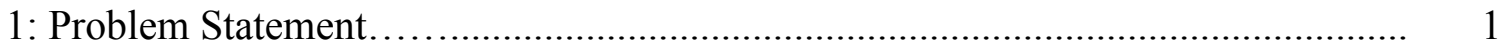

Introduction...................................................... 1

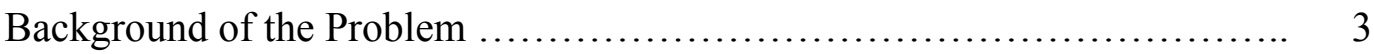

Widening Achievement Gap Between the Rich and Poor................ 5

Childhood Poverty in the United States and Oregon.................... 6

Statement of the Research Problem................................... 12

Purpose of the Study .................................................................. 13

Significance of the Research Problem....................................... 13

Presentation of Methods and Research Questions....................... 15

Methods .................................................... 15

Research Questions....................................... 15

Definition of Key Concepts and Terms ............................................... 16

\section{CHAPTER}

2: Literature Review................................................ 22 
Introduction.......................................................... 22

Theoretical Framework................................................. 23

Review of the Research Literature....................................... 26

Principles and Practices of Teaching and Learning ......................... 27

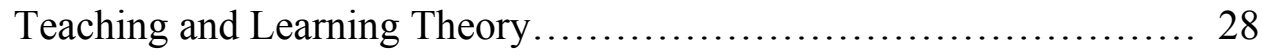

Organizational Leadership Theory and Research in Education............... 34

Organization Theory............................................. 34

Schools as Organizations ..................................... 36

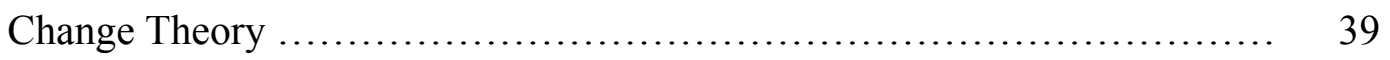

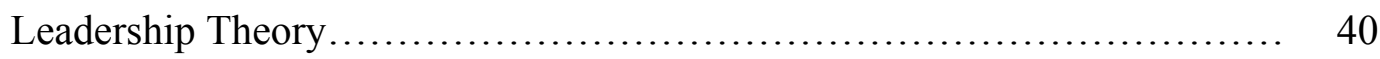

Transactional Leadership ...................................... 41

Transformational Leadership.................................... 41

Instructional Leadership..................................... 42

Balanced Leadership ......................................... 43

Effective Leadership for Schools....................................... 43

Role of the Principal.......................................... 48

Educational Policy and Politics ....................................... 52

Challenges in Oregon Schools.......................................... 55

Synthesis of the Research Literature................................. 57

\section{CHAPTER}

3: Research Methods....................................................... 59

Mixed Methods Multiple-Case Study................................. 60

Participants.......................................................... 63 
National and State School Poverty Information....................... 65

Schools and Students in Oregon K-5 Schools......................... 68

Schools and Students in Oregon K-5 Schools by Geographical Locales....................................................... 69

Number Of Schools and Students in Oregon K-5 Schools by School Size.

Oregon School Report Card Rating Levels....................... 71

Schools..................................................... 72

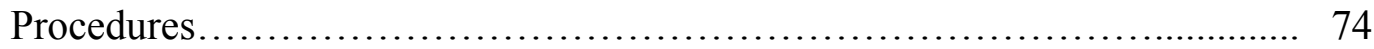

Interviews.................................................... 75

Focus Groups.................................................. 76

Quantitative Survey ...................................... 76

Open-ended Questions ................................ 79

Document Review........................................... 79

Institutional Review Board (IRB) ............................... 80

Data Collection............................................... 80

Interview Respondents.................................. 81

Quantitative Survey Respondents............................ 82

Focus Group Respondents................................ 82

Teacher Focus Group Respondents............................. 82

Parent/Guardian Focus Group Respondents.................... 83

Data Analysis ............................................... 84

Researcher Bias and Assumptions $\ldots \ldots \ldots \ldots \ldots \ldots \ldots \ldots \ldots \ldots \ldots \ldots \ldots . \ldots \ldots$ 
CHAPTER

4: Analysis of Results.............................................. 87

Introduction.................................................. 87

Principal Interview Themes........................................ 87

Addressing Bias Regarding Children Living in Poverty............. 89

High Expectations $\ldots \ldots \ldots \ldots \ldots \ldots \ldots \ldots \ldots \ldots \ldots \ldots \ldots \ldots \ldots \ldots . . \ldots 9$

Shared Leadership....................................... 90

Positive Support....................................... 90

Personal Attributes of the Principal............................ 92

Focus Group Analysis......................................... 93

Focus Group Demographic Data............................ 93

Teacher Focus Group Analysis............................. 94

Meeting Basic Needs................................ 95

Caring............................................. 95

Principal Experience as Elementary Teacher.............. 96

Shared Leadership.................................. 96

Personal Attributes of the Principal...................... 96

Parent/Guardian Focus Group Analysis....................... 97

Meeting Basic Needs............................... 98

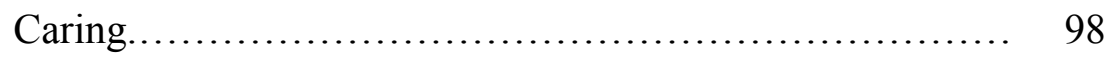

Positive Support.................................. 98

Pride in Local School................................ 99 
Leadership Practices $\quad$ x

Personal Attributes of the Principal....................... 99

Quantitative Survey.......................................... 100

Demographic Data...................................... 100

Means and Standard Deviations for Continuous Variables.......... 103

Pearson Correlation Matrix and Scatterplot................... 104

Vision and Appropriate Model Correlation.............. 106

Vision and Group Goals Correlation.................... 108

Vision and Support Correlation....................... 109

Vision and Intellectual Stimulation Correlation............ 110

Vision and High Expectations Correlation................... 112

Appropriate Model and Group Goals.................... 113

Appropriate Model and Support Correlation............... 114

Appropriate Model and Intellectual Stimulation

Correlation................................................................. 116

Appropriate Model and High Expectations

Correlation............................................ 117

Group Goals and Support Correlation.................... 118

Group Goals and Intellectual Stimulation

Correlation........................................... 120

Group Goals and High Expectations Correlation.............. 121

Support and Intellectual Stimulation Correlation.............. 122

Support and High Expectations Correlation.................. 123

Intellectual Stimulation and High Expectations

Correlation......................................... 125 
Leadership Practices $\quad$ xi

Synthesis of Quantitative Data.................................. 126

Open-ended Survey Question Responses........................ 127

Allocation of Resources............................. 128

Use of Data to Inform Instruction.......................... 130

Principals with Elementary Teaching

Experience......................................... 130

Shared Leadership and Teamwork...................... 131

Document Review............................................. 132

Synthesis of Results......................................... 134

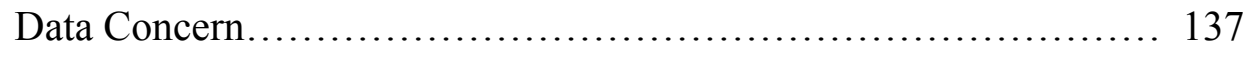

Interpretation of Findings...................................... 138

Limitations of the Study...................................... 140

\section{CHAPTER}

5: Synthesis, Discussion, and Conclusions............................... 142

Synthesis of the Study........................................... 142

Discussion of the Findings....................................... 144

Implications for Practice......................................... 148

Recommendations for Further Research............................... 148

Concluding Remarks................................................. 149

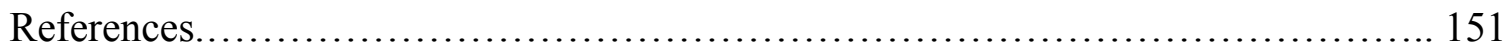


Appendices

A Principal Leadership Questionnaire (PLQ) Survey ................... 168

B Superintendent/Principal Invitation Letter........................ 172

C Letters of Informed Consent..................................... 175

1. Principal Letter of Informed Consent............................ 176

2. Teacher Letter of Informed Consent............................ 178

3. Parent/Guardian Letter of Informed Consent...................... 180

D Principal Interview Protocol................................... 182

E Focus Group Protocols............................................... 184

1. Teacher Focus Group Protocol................................ 185

2. Parent/Guardian Focus Group Protocol.......................... 186

F Parent/Guardian Flyer Announcing Focus Group...................... 187 


\section{List of Tables}

Table $\quad$ Page

12011 NAEP Grade 4 Reading Results Achievement Levels................ 10

2011 NAEP Grade 4 Math Results Achievement Levels..................... 11

3 Social/Political Forces that Impacted Schools 1950s -1970 s.............. 51

4 National Public School Poverty Categories........................... 66

5 Oregon K-5 (All) and K-5 Title I Elementary School Enrollment ............ 69

6 Oregon K-5 (All) and K-5 Title I Elementary Schools and Students by Locale................................................... 70

7 Oregon K-5 (All) and K-5 Title I Schools and Students by Size ............ 71

8 Oregon School Report Card Rating Levels............................ 72

9 Participating Schools ........................................... 74

10 Educational Research Survey Instruments........................... 77

11 Factors Related to Principal Transformational Leadership Characteristics.... 78

12 Strategies for Testing and Confirming Findings in Qualitative Research ..... 85

13 Focus Group Respondents by School............................. 94

14 Number and Percentage of Respondents............................ 101

15 Frequencies and Percentages for Nominal Variables..................... 102

16 PLQ Factors with Corresponding Descriptors.......................... 102

17 Means and Standard Deviations for Continuous Variables................... 104

18 Correlation Matrix Among Vision, Appropriate Model, Group Goals, Support, Intellectual Stimulation, and High Expectations......................... 105

19 Dependent Sample t-Test for Vision and Appropriate Model............... 107 
Leadership Practices xiv

20 Dependent Sample t-Test for Vision and Group Goals..................... 108

21 Dependent Sample t-Test for Vision and Support......................... 110

22 Dependent Sample t-Test for Vision and Intellectual Stimulation............. 111

23 Dependent Sample t-Test for Vision and High Expectations................. 112

24 Dependent Sample t-Test for Appropriate Model and Group Goals........... 114

25 Dependent Sample t-Test for Appropriate Model and Support................ 115

26 Dependent Sample t-Test for Appropriate Model and Intellectual Stimulation.......................................................... 116

27 Dependent Sample t-Test for Appropriate Model and High Expectations...... 118

28 Dependent Sample t-Test for Group Goals and Support....................... 119

29 Dependent Sample t-Test for Group Goals and Intellectual Stimulation........ 120

30 Dependent Sample t-Test for Group Goals and High Expectations............. 122

31 Dependent Sample t-Test for Support and Intellectual Stimulation............. 123

32 Dependent Sample t-Test for Support and High Expectations................. 124

33 Dependent Sample t-Test for Intellectual Stimulation and High Expectations. 125

34 Continuous Variables Found to be Significant Based on a Dependent Sample t-Test............................................. 127

35 Themes of Principal Responses by School.................................. 134

36 Themes of Teacher Responses by School................................ 135

37 Themes of Parent/Guardian Responses by School......................... 137

38 Themes of Open-ended Survey Questions by Respondents and School....... 136

39 All Common Themes by Respondents and School....................... 137 


\section{List of Figures}

Figure $\quad$ Page

1 Percentage of Children in Low-income and Poor Families................. 7

2 Percentage of Children by Parent Education and Employment.............. 8

3 Principal Leadership Practices in High Poverty K-5 Model Schools........... 26

4 Organizational Dimensions of Modernity/Postmodernity.................. 35

5 School Organization and Bureaucratic Tendencies ..................... 36

6 Principal Leadership Responsibilities............................... 46

7 Schools Before and After Creation of the Principal Role............................ 49

8 Principal Practices in the Context of a Single-Case School Site............ 60

9 Study Design.................................................. 62

10 Funneling Sampling Sequence .................................... 68

11 Convergence Model-Multiple Sources of Evidence..................... 75

12 Scatterplot Matrix............................................... 106

13 Mean Of Vision and Appropriate Model.............................. 107

14 Mean of Vision and Group Goals................................... 109

15 Mean of Vision and Support....................................... 110

16 Mean of Vision and Intellectual Stimulation............................. 111

17 Mean of Vision and High Expectations................................ 113

18 Mean of Appropriate Model and Group Goals............................ 114

19 Mean of Appropriate Model and Support............................. 115

20 Mean of Appropriate Model and Intellectual Stimulation.................. 117 
Leadership Practices $\quad$ xvi

21 Mean of Appropriate Model and High Expectations..................... 118

22 Mean of Group Goals and Support................................ 119

23 Mean of Group Goals and Intellectual Stimulation....................... 121

24 Mean of Group Goals and High Expectations........................... 122

25 Mean of Support and Intellectual Stimulation........................... 123

26 Mean of Support and High Expectations............................ 124

27 Mean of Intellectual Stimulation and High Expectations................... 126 


\section{Preface}

As noted by Duncan and Murnane (2011) many generations of Americans gained upward social mobility through education. America was known as the land of opportunity in which a better life for the younger generation could come from the hard work and sacrifices of families. Access to the United States public educational system made it possible for hardworking children from low-income families to graduate from high school and even college (Duncan \& Murnane, 2011). In three decades after 1947, the U.S. economy grew, as did the incomes of people living in poverty. Upward social mobility, particularly for white children, was possible, with many children in the U. S. growing up more financially secure than their parents (Reardon, 2013).

In November 2012, the Public Broadcasting System (PBS) aired a documentary about the Dust Bowl in America in the 1930s (Burns, 2012). I had never really studied the Dust Bowl, but I knew it as the part of the U. S. where my father was born and where my grandfather was a "dirt farmer." The film awakened in me a deeper understanding of the family background that informs my perspective as a researcher.

A view of my family history would not suggest that I could be in my current position in life as an educated, white female with significant privilege in American society. My father was born in Oklahoma in 1922 and he completed only the $8^{\text {th }}$ grade before ending his rides to school on a mule and working in the fields with his father. He migrated with his family to Southern California in the 1930s; they were branded with the societal label of "Okies" and "dirt farmers." The shame of those labels was made clear to me in the Dust Bowl documentary - the immigrants arrived in California impoverished; 
many lived in filth and squalor in tents and shantytowns along the irrigation ditches, treated with contempt by those already living more successfully in the state. My father's opportunity to rise from this station in life was to join the Navy at 16 years old. He survived World War II and completed a 20-year career in the Navy, gaining along the way a GED and skills that prepared him to successfully support a family of five children.

The childhood memories my mother shared with me include those of camping with her parents on the banks of the Willamette River when she was about twelve. They were not camping in the recreational sense: they were white migrant workers following the picking season in Oregon. Her family was already living in poverty when the Great Depression hit, and the financial impact, so devastating to some in America, served only to strengthen their survival skills. She completed high school, but I can imagine her as a young girl entering multiple schools over the years as her family moved from job to job. She did not have nice clothes or shoes as a child, but she learned the importance of appearance for how a person was judged, so she made sure that her children were clean and well dressed. She learned and transmitted the skills and cultural norms that would later help her children fit in to middle-class American society.

My parents moved beyond childhood poverty, worked hard, and raised a family of five children. Though always lower-income, they used their schooling, military training, physical ability to work, and the advantage of being white-skinned (Wise, 2011) to achieve a middle-class existence for their family. They were part of a generation that believed in the "American Dream," a dream that upheld education as a way out of poverty for white families. Their beliefs in education were instilled in my siblings and 
me. School success was a nonnegotiable factor in our household, and their beliefs were realized when I, along with three of my siblings, became first generation college graduates. Their beliefs led to my educational background that includes high school graduation, completion of a Bachelor of Science degree in Business Management, completion of teacher certification and a Masters of Science degree in Educational Administration, and candidacy for the Doctor of Education in Educational Leadership. Their beliefs and experiences in American society, as well as access to a quality public education, created the environment for me to move beyond the lower-income status of my parents. I hope for the same opportunity for other people's children (Delpit, 2006); I question, though, whether the same opportunity for social mobility is available to underserved children today, particularly in light of the additional challenges of American society and culture in the $21^{\text {st }}$ century.

Knowing what we do today about the economy, the income disparities in America, and the historical context of an educational system that has increasingly supported the class system in the nation (Kozol, 1992; Reardon, 2013; Wise, 2011), I question what it will take in our schools to assure that children living in poverty, many of whom are biracial and bicultural, gain access to the American Dream. I question if we, as a society, have the political will to assure that equitable educational opportunity is provided for all children in America.

On the $50^{\text {th }}$ anniversary of Martin Luther King's famous speech at the March on Washington, U. S. Secretary of Education Duncan (2013) stated:

In today's world, freedom means having real opportunities - the kinds of opportunities that come only with a great education. The opportunity to 
find work that will enable you to support yourself, and your family. The opportunity to make decisions about your future. The opportunity to participate fully in our democracy. It's going to take a lot of work before every young person has that kind of opportunity ("Civil rights takes struggle," para. 4).

Duncan (2013) acknowledges that "today, poverty still matters - too much. In a land of opportunity, kids should get a world-class education, even if their parents didn't, and regardless of how much money their family makes" ("Education is the civil rights issue," para. 8).

My perspective as a researcher derives from my family background and thirty years of experience working in Oregon schools. Unlike other times in the history of education in America, when a teaching career of up to thirty years might have resulted in a fairly static work environment, I have experienced the system changes proposed and implemented in Oregon schools over the last three decades. During this time, significant shifts in the economy and in the demographic makeup of communities and schools have occurred in Oregon. Schools are serving more diverse populations and greater numbers of children and families living in poverty. My interest in the topic of this study stems from my experience as a teacher, an administrator and a leadership coach in public schools in Oregon, and also from my growing awareness of barriers to equitable schooling that exist for students attending high poverty schools. 


\section{CHAPTER 1}

\section{Problem Statement}

\section{Introduction}

Children living in poverty in the United States face some of life's greatest challenges, including the challenge of achieving academic success in school. High academic achievement by students in marginalized communities is generally not what occurs in the majority of public schools across the United States (Woods, 2012). Research shows those who live in poverty in the U. S. as children complete fewer years of schooling, work fewer hours, earn lower wages, and are less healthy (Children's Defense Fund, 2012). In the U.S., the richest nation in the world, the poverty rate for young families with children rose from 14.1 percent to 37.3 percent in the years from 1967 to 2010 (Sum \& Khatiwada, 2012). Evidence is also emerging of a growing income disparity in America that affects families, communities and local labor markets in ways that can undermine the effectiveness of schools serving disadvantaged populations (Duncan \& Murnane, 2011).

As stated by Beegle (2007) gender and race have dominated discussions of diversity for more than one hundred years. Reardon (2014) reports that one success story in U. S. education has been a narrowing of racial achievement gaps by roughly 40 percent over the last forty years. This study recognizes that racial factors have long been associated not only with poverty but also with disparities in educational access and attainment in the U. S. Gorski (2013) reflects on the intersectional nature of poverty and class, stating "If we hope to understand and respond to the implications of poverty on childhood and schooling, we must also be willing to consider a wide variety of other 
forms of inequity and how they relate to class" (p. 26). Gorski (2013) further

acknowledges that low-income people vary by race, ethnicity, and nationality; by religion and language; and by political affiliation, vocation, and value systems. For the purposes of this study the researcher will focus on issues of poverty and the impact of poverty on educational outcomes.

Schools in America have historically been more successful educating middle-toupper income and white students than poor students and students of color (Kannapel \& Clements, 2005). There is evidence, however, showing that high academic performance can be achieved for all students in high poverty schools, and one of the contributing factors is principal leadership (Carter, 2000; Edmonds, 1979; Kannapel \& Clements, 2005; Lyman \& Villani, 2004). A growing body of research suggests that school leaders, particularly principals, can have a measurable, though indirect, educationally significant influence on student achievement (Jacobson, Brooks, Giles, Johnson, \& Ylimaki, 2004; Leithwood \& Riehl, 2003).

Hallinger and Heck (1996) find nothing alarming about the fact that leadership effects on school achievement appear to be indirect and note that achieving results through others is the essence of leadership (p. 39). Jacobson et al. (2004) reference Scheerans and Bosker (1997) when stating "there is evidence that high quality leadership is especially important in schools serving low socioeconomic youngsters who have often been at greatest risk for academic failure" (p. 2). The review of empirical research conducted by Hallinger and Heck (1996) leads them to state, "Context, particularly facets 
of the school's socioeconomic environment, appears to influence the type of leadership that principals exercise" (p. 38).

This study examined principal practices in three high poverty K-5 elementary schools in Oregon that have successfully improved growth in academic achievement of children attending these schools. This study was guided by a central research question: What principal leadership practices can be observed in high poverty K-5 Model schools that have improved growth in academic achievement of children attending these schools? The researcher examined principal leadership practices related to (a) program characteristics, (b) resource allocation, (c) shared leadership, and (d) other characteristics revealed by teachers and parents.

Chapter 1 provides the background of this study with a historical discussion of the beginnings of public education in the U. S., changes in the nation's economy, and the value of education in a democracy. It then discusses the researcher's background. Next, Chapter 1 examines the widening income gap in America, childhood poverty data, and academic performance relative to poverty. The problem, purpose and significance of the study are also stated in Chapter 1. This chapter concludes with a presentation of the methods and research questions and the definition of key concepts and terms. Chapter 2 reviews the literature relevant to this study.

\section{Background of the Problem}

Americans have often envisioned education as the "great equalizer" for those from different social and economic realities (Coley \& Baker, 2013; Duncan \& Murnane, 2011; Mann, 1848). Public schooling also has been seen as a cornerstone of democratic 
society. The words and tone of Mann's (1848) $12^{\text {th }}$ Annual Report to the Secretary of the Massachusetts State Board of Education underscores his belief that a democratic society endures through a literate and educated populace.

Education, then, beyond all other devices of human origin, is the great equalizer of the conditions of men - the balance - wheel of the social machinery. It does better than to disarm the poor of their hostility towards the rich; it prevents being poor (para. 6).

Mann (1848) recognized the potential that Massachusetts, at that time rich with capital but densely populated, might fall victim to social divides between the wealthy, educated members of society and those who were ignorant and poor. The work of Mann and others led to proliferation of public schools, beginning in Massachusetts in 1852 and spreading to all states in America by 1930.

Like Mann, Dewey's (1949) passion for democracy and for educating so that all would share in a common life forms the core of the Progressive Movement in education in the 1920s and 1930s (Field, 2005). In arguing for "progressive" rather than "traditional" education, Dewey (1963) supports development of a philosophy of education that springs from learner experience, using "positive and constructive development of purposes, methods, and subject matter ...” (p. 10). Freire (1985) argues in a similar fashion that "educators have to work with the experiences that students, adults, and other learners bring to schools" (Giroux, 1985, Introduction, Section 5, para. 3). Beyond looking at the school from the perspective of the individual, Dewey (1963) emphasized that what society has available for itself should also be available to its future members.

In discussions of public education and its role in a democracy, a number of researchers argue that public schools are a critical and necessary component of 
democratic society that supports the common good while providing for individual social power (Association for Supervision \& Curriculum Development, 1996; Dewey, 1963:

Duncan \& Murnane, 2011; Giroux, 2008; Meier, 2013; Reardon, 2011). The possibilities for social mobility for all grew during the first part of the twentieth century but began showing a decline in the 1960s and 1970s (Hout \& Janus, 2011). As in the 1800 and 1900 s, and maybe even to a greater extent than in the past, the growing income disparities in America present a serious challenge to the possibility of economic, racial and educational equity for every child (Children's Defense Fund, 2012), contributing to “an even more unequal and economically polarized society" (Reardon, 2011, p. 111). As the promise of equal opportunity is diminished, the potential for threats to American democratic society grows greater. As has been true in history, oppression that stems from the inability of individuals or groups to achieve the full potential of what society has to offer can lead to "... increased social conflict and a reduced sense of common purpose" (Duncan \& Murnane, 2011, p. 8).

Widening Income Gap Between the Rich and Poor. Research shows that inequality is a pervasive problem in U. S. education (Duncan \& Murnane, 2011; Gamoran, 2007; Reardon, 2011). The widening income gap that became evident in the years between the 1970s and 2007 shows that family income in the lower $20^{\text {th }}$ percentile rose approximately seven percent while incomes of families in the upper $99^{\text {th }}$ percentile rose 90 percent (Duncan \& Murnane, 2011). Researchers have identified contributing factors to these trends, including outsourcing of jobs to lower-wage countries, advances in technology leading to a demand for higher-skilled workers or the technology itself 
replacing workers, growing numbers of single-parent families, and a decreasing ability of low-income families to afford access to good public schools, to private schools, or to other experiences that enhance school success. One outcome of these factors, tied to competition among families for their children's academic success, is a growing disparity in the extent to which families invest their time and money in their children's education (Kornrich \& Furstenberg, 2013). Kornrich \& Furstenberg (2013) report consensus among scholars and policy makers that acknowledges the advantages in children's development and long-term prospects within families with more human, cultural, and material capital.

Childhood Poverty in the U. S. and Oregon. The National Center for Children in Poverty (NCCP) reports national poverty statistics annually, drawing much of the data from analysis of the American Community Survey (ACS) (n.d.a.). The Census Bureau (n.d.a.) reports U. S. poverty data from several major household surveys and programs. One of those is the American Community Survey (ACS), which provides single and multi-year estimates about communities (ACS, n.d.a.). While this survey is based on relatively small numbers of respondents, information from the survey generates data that help determine how more than $\$ 400$ billion in federal and state funds are distributed each year.

Cauthen and Fass (2008) describe poverty for families and children as the inability to achieve a minimum standard of living that allows for full participation in society. This standard goes beyond basic essentials of food, clothing, and shelter to include education, basic life skills, employment, medical care, and safe neighborhoods (Cauthen \& Fass, 2008). Factors such as living in a single-parent household, low parental 
education levels, residential mobility, being born to a teen mother, and living in households without English speakers are among those considered primary indicators that children will be low-income (Robbins, Stagman, \& Smith, 2012).

Percentages of low-income and poor children in the U. S. also vary by race and ethnicity, with black, American Indian, and Hispanic children being disproportionately low-income and poor as shown in Figure 1 (Jiang, Ekono, \& Skinner, 2015).

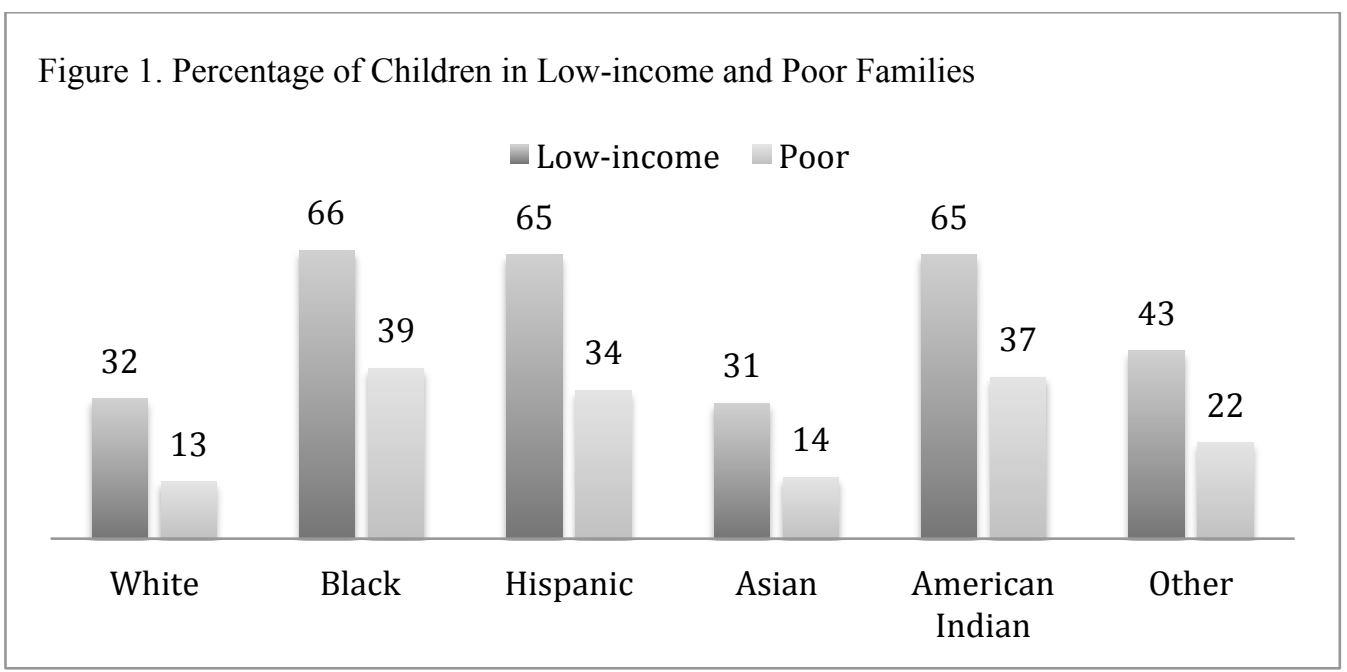

Figure 1. Percentage of children ages six through eleven years in low-income and poor families by race/ethnicity, 2013 (Jiang, Ekono, \& Skinner, 2015).

This study recognizes that racial factors have long been associated not only with poverty but with disparities in educational access and attainment in the U. S. However, for purposes of this study the researcher will focus on issues of poverty and the impact of poverty on educational outcomes.

In a fact sheet published with data from 2013, Jiang, Ekono, and Skinner (2015) report that based on the federal poverty threshold (FPT), children under 18 years account for 23 percent of the population but represent 33 percent of the total number of people in 
poverty. Data published by the National Center for Children in Poverty (NCCP) identifies age groups of children under 18 as (a) infants and toddlers, children under three; (b) young children, ages three to five; (c) middle childhood, ages six to eleven; and (d) adolescent children, ages twelve to seventeen (Jiang et al., 2015). Since this study focuses on children enrolled in K-5 elementary schools, the researcher will use data reported for children in middle childhood, ages six to eleven.

Out of 24 million children in middle childhood in the U. S. in 2012, 45 percent live in low-income families (defined as at or above $200 \%$ of the FPT) (Jiang et al., 2014). As further described by Jiang et al., (2014), within the low-income category, 22 percent of children in middle childhood live in poor families (defined as below $100 \%$ of the FPT) and 23 percent live in near poor families (between 100\% and 199\% of the FPT). Low levels of parental education are an identified risk factor for being low-income (Cauthen \& Fass, 2008). Parental education and levels of parental employment have an impact on middle childhood poverty as shown in Figure 2 (Jiang et al., 2015).

Figure 2. Percentage of Children by Parent Education and Employment

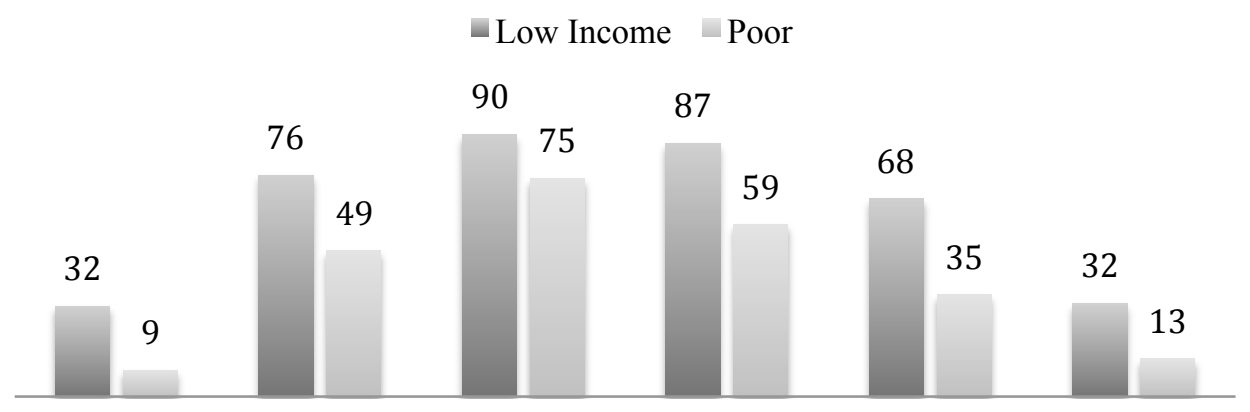

Full-time, Part-time or Not employedLess than high High school Some college year-round part-year school degree degree or more

Figure 2. Percentage of children ages six through eleven years in low-income and poor families by parents' employment and education, 2013 (Jiang et al., 2015). 
According to Gamoran (2007), inequality is a pervasive problem in U. S. education, and "the problem is particularly pronounced for students who face economic disadvantages" (p. 3). Lagging academic achievement, absenteeism, greater disciplinary issues, and general lack of engagement in school life is evident in high poverty elementary schools (Rowan, 2011). Duncan and Murnane (2011) state, "as the incomes of affluent and poor American families have diverged over the past three decades, so too has the educational performance of the children in those families" (p. 15). Reardon (2011) agrees, stating "The educational disparities between children from high- and lowincome families is roughly 30 to 40 percent larger among children born in 2001 than among those born twenty-five years earlier" (p. 1).

A snapshot of U. S. student academic achievement is shown through the findings of the National Assessment of Educational Progress (NAEP), a continuing and nationally representative measure of achievement in various subjects over time at the fourth- and eighth-grade levels (National Center for Educational Statistics, 2011). In the Oregon Statewide Report Card (2011-12) the NAEP is distinguished from Oregon's Assessment of Knowledge and Skills (OAKS) in that it (a) does not provide individual scores for students, (b) is a paper-pencil test and not a computer adaptive test, and (c) provides valid and reliable estimates of what students know and do in the content area only when the scores are aggregated for groups. NAEP results serve to provide some statistical data showing the fourth grade reading and math achievement disparities in Oregon and the U. S. relative to the difference between all students and those identified as economically disadvantaged. 
Table 1 shows the 2011 fourth grade reading results for all students and for those economically disadvantaged, as measured by eligibility for free and reduced lunch (NCES, 2011).

Table 1

2011 NAEP Grade 4 Reading Results Achievement Levels

\begin{tabular}{|l|l|c|c|c|c|}
\hline \multicolumn{2}{|l|}{ Students } & $\begin{array}{c}\text { Advanced } \\
\%\end{array}$ & $\begin{array}{c}\text { Proficient } \\
\%\end{array}$ & $\begin{array}{c}\text { Basic } \\
\%\end{array}$ & $\begin{array}{c}\text { Below } \\
\text { Basic } \\
\%\end{array}$ \\
\hline \multirow{3}{*}{ All Students } & Oregon* & 7 & 23 & 32 & 37 \\
\cline { 2 - 6 } & United States & 7 & 25 & 34 & 34 \\
\hline \multirow{2}{*}{$\begin{array}{l}\text { Economically } \\
\text { Disadvantaged }\end{array}$} & Oregon & 3 & 16 & 31 & 50 \\
\cline { 2 - 7 } & United States & 2 & 16 & 34 & 48 \\
\hline
\end{tabular}

*numbers provided do not add up to $100 \%$

In both reading and math NAEP scores for 2011, a smaller percentage of economically disadvantaged students in Oregon and in the U. S. demonstrated Advanced performance, while a greater percentage of economically disadvantaged students in Oregon and the U.S. were identified as Below Basic in performance (Oregon Statewide Report Card, 2011-12). Table 2 displays data for the 2011 fourth grade NAEP results for math, showing results for all students and for those economically disadvantaged (NCES, 2011). 
Table 2

2011 NAEP Grade 4 Math Results Achievement Levels

\begin{tabular}{|l|l|c|c|c|c|}
\hline \multicolumn{2}{|l|}{ Students } & $\begin{array}{c}\text { Advanced } \\
\%\end{array}$ & $\begin{array}{c}\text { Proficient } \\
\%\end{array}$ & $\begin{array}{c}\text { Basic } \\
\%\end{array}$ & $\begin{array}{c}\text { Below } \\
\text { Basic } \\
\%\end{array}$ \\
\hline \multirow{3}{*}{ All Students } & Oregon & 6 & 30 & 41 & 23 \\
\cline { 2 - 6 } & United States* & 6 & 33 & 42 & 18 \\
\hline \multirow{2}{*}{$\begin{array}{l}\text { Economically } \\
\text { Disadvantaged }\end{array}$} & Oregon & 2 & 20 & 45 & 33 \\
\cline { 2 - 6 } & United States* & 2 & 22 & 48 & 27 \\
\hline
\end{tabular}

*numbers provided do not add up to $100 \%$

The economic recession that hit the nation and the state of Oregon in 2008 had a significant impact on educational funding at the same time as the accountability for higher student achievement was increasing. Job losses and house foreclosures drove people from the state, so student enrollment numbers, as well as tax revenues, dropped over the years from 2008-2012. At the same time, the number of students identified as homeless grew from $2.83 \%$ to $3.65 \%$ of total enrollment, and the number of elementary students in Oregon schools eligible for Free or Reduced Lunch (FRPL) grew from 51.2\% to $57 \%$ (Public Education in Oregon, 2013).

In spite of the challenges that exist in high poverty elementary schools, researchers continue to find examples of schools that are high-performing in spite of being high poverty schools (Barth et al, 1999; Carter, 2000; Comer, 1988; Kannapel \& Clements, 2005; Rowan, 2011). Kannapel and Clements (2005) state the following relative to their study of high poverty, high performing schools in Kentucky: 
Although public schools are responsible for educating all students, they historically have had greater success educating middle-to-upper income and white students than poor and minority students. Nearly all the worst performing schools in Kentucky and across the nation are high poverty schools. But there are also striking exceptions to the pattern of low income/low performance. There are enough schools that defy the trend to prove that the background of the student body does not have to determine achievement results (p. 2).

\section{Statement of the Research Problem}

There is a growing body of research on the widening educational disparities between the rich and the poor in America (Duncan \& Murnane, 2011; Gorski, 2008:

Reardon, 2011, 2013; Sandefur \& Wells, 1999) and the impact of poverty on academic achievement and educational attainment (Coley \& Baker, 2013; Jensen, 2009; Nelson III \& Sheridan, 2011; Rowan, 2011). A large body of research exists to describe the construct of effective principal leadership relative to school improvement, but the evidence does not clearly show what principal leadership practices are effective in schools that serve high poverty students and communities. As acknowledged by Leithwood, Louis, Anderson, and Wahlstrom (2004):

There is still much to be learned about how leaders can successfully meet the educational needs of diverse student populations. But there has been a great deal of research concerning both school and classroom conditions that are helpful for students from economically disadvantaged families and those with diverse racial and ethnic backgrounds. The major shortcoming in much of this research, however, is that it does not identify leadership practices that are successful in improving conditions in the school and classroom suggested by this research, nor does it help unpack the skills.

Considering the challenges to teaching, learning, and leadership that are often reported as being present in high poverty schools, and evidence that principal leadership makes a 
difference in student achievement, principal leadership practices in high performing, high poverty K-5 elementary schools in Oregon provide a resource for further research.

Purpose of the Study. The purpose of this study was to explore principal leadership practices in three high poverty K-5 Model schools in Oregon. A literature review of schools successful in increasing academic growth of children in high poverty schools identified numerous findings about isolated aspects of the impact of poverty on educational attainment, a school's leadership characteristics, or a school's program characteristics (Carter, 2000; Coley \& Baker, 2013; Jacobson, 2008; Jensen, 2009; Lyman \& Villani, 2004; Ramirez, 2011). This study collected qualitative and quantitative data from principals, teachers, and parents in three schools identified as Model schools by the Oregon Department of Education (ODE) as part of the Elementary and Secondary Education Act (ESEA) Waiver (ODE, 2012). The data were analyzed in order to reveal and propose insights about principal leadership practices effective in high poverty K-5 Model schools in Oregon.

\section{Significance of the Research Problem}

Poverty is an economic reality that sweeps across all racial, cultural, ethnic and gender populations in the U.S. There is a national pride connected to America being the "land of opportunity" where hard work and personal sacrifice can improve the futures of succeeding generations (Duncan \& Murnane, 2011). However, despite decades of legislative reforms, school improvement reforms, and outcries for social justice, students of different social backgrounds continue to attain varying educational outcomes (Gamoran, 2007). Pervasive inequalities are evident across states, from district to district, 
and even within districts for students who live in poverty and attend high poverty schools (Duncan \& Murnane, 2011, 2014; Gamoran, 2007; Lyman \& Villani, 2004).

As Reardon recently reported (2011), trends in the nation's social history in the last 50 years reveal some reasons why family resources have become more unequal, resulting in the growing income achievement gap: a) there has been a rapid growth in income inequality; b) a slower economic growth pattern, coupled with the income inequalities, makes upward social mobility less certain than in the past; c) jobs that provided a middle-class wage for those without a college degree have largely disappeared; and, d) the changes in U. S. family characteristics are more closely correlated with family income (e.g., single parent households, parents with only a low level of education). The U. S. education system faces the demand that all students learn the skills and values they need for work and informed citizenship in a rapidly changing world (Wagner, 2002). Social changes relative to the current knowledge-based economy, the resultant need for a learning society, and the need for serving diverse populations of students have driven the public and political outcry for radical changes in schools.

Researchers have studied the connection between school leadership and student performance and have found that not only does school leadership matter but also it is second only to teaching in its impact on student learning (Leithwood et al., 2004). Branch, Hanushek, and Rivkin (2013) observe that the demands of leading high poverty schools, including but not limited to higher teacher turnover, fewer financial resources, and less than desirable working conditions, increase the importance of having an effective leader. 


\section{Presentation of Methods and Research Questions}

Methods. This study used a multiple-case mixed methods study design (Yin, 2014) to investigate principal leadership practices in three high poverty K-5 elementary schools in Oregon identified as Model schools by ODE. Mixed methods research involved collecting and analyzing both qualitative and quantitative data in one study (Creswell, 2003). This typical multiple-case study included (a) basic demographic information about each of the principals, written in narrative format, (b) the histories of the schools, (c) document analyses related to each of the schools, (d) interview data, and (e) focus group data (Lunenburg \& Irby, 2008). A multiple item likert-scale survey was administered to the principal, teachers, and parents from each school. The multiple sources of evidence in this study allowed the researcher to triangulate the data, making the case study findings more convincing and accurate (Yin, 2014).

Research Questions. This study examined the phenomena of principal leadership practices of three high-poverty K-5 elementary schools in Oregon identified as Model schools by ODE through the analysis of qualitative and quantitative data (Lunenburg \& Irby, 2008, p. 96). This study was guided by a central research question (Creswell, 2003, p. 105): What principal leadership practices can be observed in high poverty K-5 Model schools that have improved growth in academic achievement of children attending these schools? Related questions were designed to narrow the focus of the study while still leaving open the questioning (Creswell, 2003). The related questions for this study were as follows:

1. How do principal practices support programs improving growth in academic achievement of children in high poverty K-5 Model schools? 
2. How do principals allocate school and district resources to support programs and instruction improving growth in academic achievement of children in high poverty K5 Model schools?

3. How do principals share leadership in high poverty K-5 Model schools where growth in academic achievement of children is improved?

4. What other practices do principals put to use in high poverty K-5 Model schools that have improved academic achievement of children?

\section{Definition of Key Concepts and Terms}

Adaptive challenges are those that force the organization to learn new ways and to change and are accomplished by leadership for the change needed (Heifetz \& Linksy, 2002).

Adequate Yearly Progress $(A Y P)$ is the measure by which schools, districts, and states are held accountable for student performance under ESEA, reauthorized in 2001 as the No Child Left Behind (NCLB) Act. The requirement is that schools, districts, and the state make AYP toward the goal of having all students meet rigorous state academic standards. In Oregon, the standards are measured by the Oregon Assessment of Knowledge and Skills (OAKS) (ODE, 2012).

Culturally responsive teaching (CRT) teaches to and through the strengths of ethnically diverse students by using the cultural knowledge, prior experiences, frames of reference, and performance styles that make learning more relevant and effective for them (Gay, 2010).

Deficit thinking is a term used to describe the negative interpretation of differences in those who are culturally, racially, or ethnically diverse (Ford, 2010). 
Ecological perspective applies the ecological principles from biology to social settings, allowing studies of organizations and leadership to evolve from the industrial biases of the past that focus on the predominance of the leader and the mechanistic characteristics of the organization to better understand the "complexity of the systems and the adaptive challenges to which each organization must respond" (Wielkiewicz \& Stelzner, 2005, p. 336).

Economically disadvantaged is the term used by the National Center for Educational Statistics (NCES) to describe students who are eligible for the Free and Reduced Lunch Program (NCES, 2011).

Educational disparities is a term used to describe differences in educational outcomes that may result from (a) differential or biased treatment of ethnic and racial minority students within the educational system, (b) differences in socioeconomic status, and (c) different responses to educational systems or different sets of educational needs (American Psychological Association, 2012).

Elementary and Secondary Education ACT (ESEA) is legislation passed in 1965 as part of the "Great Society" goals of President Johnson (ESEA, n.d.a.). The law emphasizes equal access to education and establishes high standards and accountability. The law authorizes federally funded education programs that are administered by the states.

ESEA Flexibility Waiver is the means by which the USDE offered individual states the opportunity to replace specific requirements of NCLB in exchange for rigorous 
and comprehensive state plans to improve the educational outcomes for all students. Oregon applied for and was granted the initial waiver in 2012 (USDE, 2011).

Federal Poverty Threshold (FPT) is a measure of need updated annually for inflation using the Consumer Price Index for All Urban Consumers (CPI-U). Poverty thresholds are the dollar amounts used to determine poverty status. Thresholds vary based on family size and ages of family members and are intended to provide a statistical guideline for poverty. (United States Census Bureau, n.d.a.).

Free and Reduced Price Lunch Program (FRPL) is a federally funded meal program provided to children whose families live at or below the poverty level (United States Department of Agriculture, n.d.a.).

High poverty schools in Oregon are defined under Title I-A as schools with $40 \%$ or more students from low-income families (ODE, 2009).

Human capital describes the education and skills needed by individuals to achieve earnings that support a decent standard of living for themselves and their families (Haskins, 2012).

Model schools are identified in Oregon as part of the 2012 ESEA Waiver through a rating system that identifies Priority, Focus and Model schools. Priority and Focus schools are the lowest performing Title 1 schools in the state, and Model schools are the highest, in one of two categories: 1) The highest-performing Title 1 schools that are making AYP for all subgroups in the school without significant educational disparities; and, 2) high-progress schools that are among the top $10 \%$ of Title 1 schools that are 
making the most progress in improving performance of the all students group in reading and mathematics (ODE, 2012).

No Child Left Behind (NCLB) is the 2001 reauthorization of ESEA. Designed to reduce inequality in education, the act focused on in particular on increasing achievement of student in demographic subgroups (Gamoran, 2007).

Oregon Assessment of Knowledge and Skills (OAKS) is the standardized assessment Oregon administers to measure the progress of students from 3rd grade to 8th grade, and 10th grade. OAKS is aligned to Oregon state standards, which define what students should learn each year. The Oregon Statewide Assessments are summative assessments, which are assessments of learning generally carried out at the end of an instructional period. Summative assessments are typically used for program accountability and to assign achievement level scores to students (ODE, 2012). The tests are given as follows:

- 3rd and 6th Grades: OAKS tests in reading and math.

- 4th and 7th Grades: OAKS tests in reading, math, and writing.

- 5th and 8th Grades: OAKS tests in reading, math, and science.

- 10th Grade: OAKS tests in reading, math, writing, and science.

Poverty is a complex concept that is defined by Jensen (2009) as "a chronic and debilitating condition that results from multiple adverse synergistic risk factors and affects the mind, body, and soul" (p. 6). Jensen (2009) identified different types of poverty, including the following that are pertinent to this study: 
- Generational poverty--observed in families where at least two generations have been born into poverty, resulting in the families lacking the tools to move them out of their situations;

- Situational or episodic poverty--caused by a sudden crisis or loss like a severe health issue, job loss, or a divorce and is often temporary;

- Urban poverty -found in metropolitan areas with populations over 50,000 people. Issues like crowding, violence, and noise combine leading to chronic stressors for the urban poor; and

- Rural poverty - found in nonmetropolitan areas with populations below 50,000. Job opportunities may be limited, there are more single-guardian households, and families may have less access to services and quality education opportunities.

Poverty Measurements include (a) The Poverty Rate, which is the percentage of the U.S. population that falls below the official poverty line, a figure set in the 1960 s based primarily on food consumption that is updated annually based on the inflation factor; (b) Supplemental Poverty Measure, developed in 2011 to more accurately account for consumptions items other than food, such as medical and housing costs; (c) Relative Poverty, a measure that takes into account the poverty threshold as a share of median income and tracks changes in income inequality within the bottom half of the income distribution on poverty; and (d) extreme poverty, representing people who live at $50 \%$ or less of the official poverty line (Mishel et al., 2012).

Technical challenges are those that can be resolved by applying current knowledge and procedures, usually by someone in authority in the organization (Heifetz \& Linsky, 2002).

Title I of the Elementary and Secondary Education ACT (ESEA) of 1965, now titled Improving the Academic Achievement of the Disadvantaged, mandates that all 
children have a fair, equal, and significant opportunity for a high-quality education and reach, at a minimum, proficiency on challenging State academic achievement standards and state academic assessments (USDE, 2013).

Title I-A is the part of ESEA that provides federal funds to local educational agencies (LEAs) and schools with high numbers or high percentages of children from low-income families to ensure that all children meet challenging state academic standards; funds are allocated through statutory formulas that are based primarily on census poverty estimates and the cost of education in each state (USDE, 2013).

Widening academic achievement gap describes the relationship between the academic achievements between children in high- and low-income families relative to the widening of the income gap between high- and low-income families (Reardon, 2011).

Widening income gap describes the gap in income between high-income and lowincome families resulting in high-income families having far more resources, relative to low-income families, to invest in their children's development and schooling (Reardon, 2013). 


\section{CHAPTER 2}

\section{Literature Review}

\section{Introduction}

In Chapter 1, the researcher provided the background of the problem related to the statement of the research purpose. Researchable questions and a brief review of the methods framed the research process for the study. Chapter 2 draws on empirical research as well as relevant literature to support the case for a study that examines principal leadership practices in three high poverty K-5 Model schools in Oregon that have increased growth in academic achievement of children in the schools.

Educational researchers have studied the constructs of principal leadership and leadership effects on student achievement for a number of decades. Current statistics and research about the effects of poverty on student academic achievement and life-long challenges for health, employment and social mobility call for a moral imperative to identify the leadership characteristics and practices that improve learning and achievement in high poverty schools. The research suggests there are additional challenges for principals in high poverty schools (Lyman \& Villani, 2004).

A broad range of resources related to the research problem were examined by the researcher including (a) handbooks and encyclopedias, (b) abstracting and index services, (c) government documents, and (d) public search engines (Lunenburg \& Irby, 2008). The researcher used search terms including leadership theory, learning theory, principal leadership, high poverty high-performing schools, leadership for school improvement, 
leadership for student achievement, poverty in the U. S., and poverty and educational attainment to seek relevant resources for this study.

\section{Theoretical Framework}

An ecological perspective frames this study of schools striving to guarantee the promise of an equitable education to all children. This study seeks to build upon the existing body of research by examining principal leadership practices effective within a contextual landscape of high poverty K-5 Model schools in Oregon that are improving academic achievement for children attending the schools.

With the emphasis on accountability in public schools today, school principals are faced with the challenge of ensuring high quality education for all, and reducing educational disparities between high- and low-performing students. High poverty schools present additional challenges to principals. Factors contributing to the problems for schools where high-percentages of children live in poverty include lagging academic achievement; high rates of student absenteeism; higher student and teacher mobility; and, the challenge of students being less engaged in school life in general (Rowan, 2011). Less money in the community equates to fewer financial resources available to the schools in the community. These multiple layers of forces that work against student success in school create a challenging milieu for moving schools from low- to high-performing.

Gould (2007) observes that children are at the heart of a complex educational system that is subjected to political, economic, and social forces. The framework for this study is an ecological theory perspective. Ecological theory, with a foundation in the biological sciences, provides a framework that accounts for multiple layers of interaction 
in a world of complex overlapping systems (Gould, 2007). The essence of Gould's (2007) argument is that an ecological framework, or context-based framework, is useful to address the need for exploring critical issues within the education system that impact student educational attainment.

Duncan and Murnane (2011) use an ecological framework to explore the relationships between income inequality, families, neighborhoods and local labor markets, leading to the potential for residential segregation by income, limited political influence, and the depletion of other community resources that may lead to the decline in school quality. Growing income inequality further serves to decrease children's educational attainments due to the lack of money poor families have to invest in their children compared to wealthier families (Duncan \& Murnane, 2011; Reardon, 2013). Important to the understanding of the impact of the interdependent contexts identified in their research is that as more disadvantaged groups suffer the compounding effects of poverty, "Social and economic inequalities become more entrenched and limit social mobility” (Duncan \& Murnane, 2011, p. 8).

In applying the ecological perspective to this study on principal practices that accelerate growth in academic achievement of children in high poverty K-5 elementary schools, the researcher suggests the context for children and families living in poverty can be improved through educational attainment. Haskins (2012) identifies four major types of programs that the U.S. uses to develop human capital: preschool programs, K-12 education, post-secondary education, and employment and training programs. Factors such as lack of proper housing, unemployment or underemployment, poor or nonexistent 
medical care, poor environmental factors, and lack of access to social benefits cast a heavy burden on children and families living in poverty. It is impossible for schools to compensate for all of those factors; however, it is possible for schools to invest the resources necessary to help children succeed academically, with the principal playing a key role as described by Louis, Leithwood, Wahlstrom, and Anderson (2010):

School leadership, from formal and informal sources, helps to shape school conditions (including, for example, goals, culture, and structures) and classroom conditions (including the content of instruction, the size of classrooms, and the pedagogy used by teachers). Many factors within and outside schools and classrooms help to shape teachers' sense of professional community. School and classroom conditions, teachers' professional communities, and student/family background conditions are directly responsible for the learning of students.

Figure 3 draws upon the works of Duncan and Murnane (2011) and Louis et al., (2010) to place principal leadership practices in high poverty K-5 Model schools in context with other conditions and influences impacting the academic success of children in high poverty schools. 
Figure 3. Principal Leadership Practices in High Poverty K-5 Model Schools
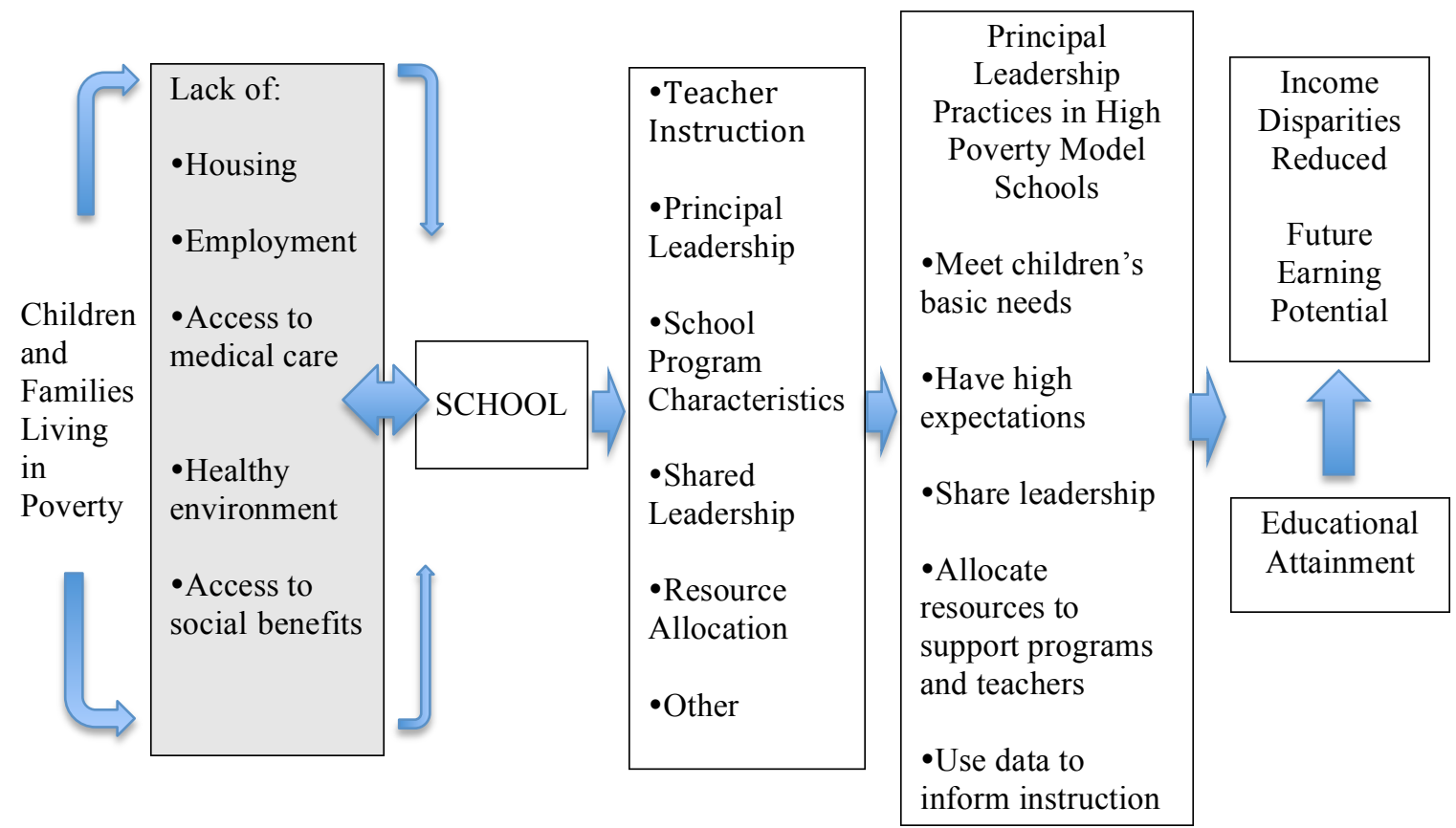

Figure 3. Conceptual framework applied to this study of principal practices in high poverty K-5 Model schools in Oregon, adapted from Duncan \& Murnane, 2011, p.8.

\section{Review of the Research Literature}

Pertinent to this research study is the existing body of research on principles and practices of learning, organizational and leadership theory, and educational policy and politics. School principals today work in an environment of high accountability driven by federal and state policy at the same time they are embroiled in the daily operations of a school. The roles and responsibilities of the principal include being an employer, a supervisor, and a leader, while they themselves are also employees within a larger bureaucratic system (Rousmaniere, 2013). Given the breadth of the roles and responsibilities of the principal as well as the multiple levels of complexity in which a principal works, it is important to consider the role within a theoretical framework as well 
as with an understanding of the principles of teaching and learning, organizational and leadership theory, and educational policy and politics

\section{Principles and Practices of Teaching and Learning}

Theories and conceptions of learning and its relationship to teaching practices have evolved from the early 1900s to today. While psychology theorists including Dewey (1949), Piaget (1969), Skinner (1954), Vgotsky (1978), Bruner (1960), Maslow (1943), Bloom (1956), and Gardner (1993), among others, have all contributed to the depth of understanding about human learning, recent theorists rightfully place these constructs within the framework of culturally responsive teaching (CRT). To understand the framework of CRT, the researcher will begin with an overview of psychology theorists. Their philosophical perspectives and models of learning influence educational practices and models of teaching that evolve in concert with the paradigm shifts in scientific understandings of human learning and with changing technologies that influence teaching and learning.

Knowledge and application of the principles and practices of learning is a critical consideration for schools in helping all learners achieve and is even more important in schools serving children living in poverty and children of color. Empirical evidence shows many factors that impact the education of children living in poor families in high poverty neighborhoods, varying from health issues to brain development to economic issues. The factors may result in disruptions to brain and early skill development that can lead to weaker attention skills and cognitive self-regulation, negative effects of behavior problems and mental health issues, poor environmental factors that lead to more physical 
health issues, lower rates of high school and college graduation, and higher chances of being economically disadvantaged throughout their lifetime (Duncan \& Murnane, 2011; Nelson III \& Sheridan, 2011; Reardon, 2011).

Many schools serving poor children and poor children of color have observed school-related factors that may contribute to the further decline of childhood and future adulthood opportunities to achieve social mobility and to actively participate in the best of what American society has to offer. These factors include teachers and other adults who are not highly skilled and who hold low expectations for these children (Duncan \& Murnane, 2011), unsafe learning environments, limited access to current technology and high-quality materials, lack of curricula and instruction that can appropriately intervene to address academic disparities, frequent turn-over of teachers, and fewer resources in general compared to schools in richer neighborhoods (Comer, 1988; Gorski, 2008; Kozol, 1992). However, as reported by ODE (2009), there is a growing body of evidence showing that it is possible to create schools where all students achieve to high standards, even when most students in the school are poor or disadvantaged. The characteristics these schools share include:

- A clear focus.

- High expectations for students and staff.

- An environment focused on learning.

- Strong leadership.

- Curriculum, instruction, and assessments aligned with standards.

- High-quality professional development.

- A collaborative spirit and collaborative structures.

- Meaningful parental involvement.

- A commitment to continuous review and improvement. 
Teaching and Learning Theory. Teaching and learning are complex, deeply entwined human endeavors. The practice of teaching draws upon the scientific study of children and developmental psychology (Cunningham, 2007). The theoretical perspectives addressed here are but part of a larger body of research that grows from the field of psychology and that informs the changing political, social, and disciplinary conditions of education (Case, 1996).

Early twentieth century learning theories derive from the British empiricist position that knowledge is acquired first when sensory organs detect stimuli and the mind connects the patterns within the stimuli (Case, 1996). Educational learning theories developed from that beginning to have a more scientific approach, largely influenced by Skinner (1954) who suggests that scientific research in the field of learning can be brought to bear upon practical problems in education. Many theories about teaching and learning are used to guide the work of policy makers, schools of education, instruction and curriculum developers, and school leaders. Learning theories that have influenced the development of educational practice and are pertinent to this study include (a) behaviorism, (b) cognitivism, (c) constructivism, and (d) connectivism.

Behavioral theories of learning focus on explaining the behavior of individuals using a stimulus-response framework (Schuell, 2006). These theories see learning as something that happens outside of the learner and results in a theory of operant conditioning, leading to teaching practices that rely on reinforcement, feedback, and practice; this results in learning by rote memorization. After decades of educational practice grounded in behavioral psychology, theorists began to respond to new research 
in cognitive learning. Bloom (1956) designed a taxonomy of learning in order to promote higher forms of thinking in education rather than just rote learning.

Cognitive theorists view learning as an active pursuit by the learner. As one of the preeminent psychologists in cognitive development theory, Piaget (1969) places the context for learning within the framework of a child's development stages, knowledge of which supports guided discovery instruction. Critical responses to Piaget grew from theories that children's knowledge structures were domain-specific and considered external factors in determining the rate of cognitive growth (Case, 1996). These responses combined to form the constructivist tradition of learning theory, providing an explanation for how knowledge is constructed in the human being when information comes into contact with existing knowledge that is developed by experience.

Although constructivism is by no means an entirely new conceptualization of learning (its roots can be traced to Dewey (1949) and other progressive educators, to Piaget (1969) and Vygotsky (1978), and to Bruner (1960) and discovery learning), constructivist perspectives on learning become increasingly influential from the 1970s on and represent a paradigm shift in the epistemology of knowledge and theory of learning (Applefield, Huber, \& Moallem, 2000). Constructivist theories recognize the role children exhibit in constructing their own knowledge structures (Astington \& Pelletier, 1996). Cognitive constructivism emphasizes interaction with the physical environment while social constructivism emphasizes the learner's interaction with other people (Astington \& Pelletier, 1996). Vgotsky's (1978) Social Development Theory is a cognitive theory that forms the foundation for early constructivist thinking. Key to his 
theory is the idea that full cognitive development requires social interaction (McLeod, 2007). The zone of proximal development identified with Vgotsky is an assessment construct useful for teachers as they seek to understand a child's maturing higher cognitive processes, allowing them to "engage the child in problems that are just above his or her independent problem solving" (Gredler, 2011, p. 118).

As reported by Siemens (2004), the development of behaviorism, cognitivism, and constructivism, and their resulting applications in education happened at a time when learning was not impacted by technology. He further states, "Behaviorism, cognitivism, and constructivism (built on the epistemological traditions) attempt to address how it is that a person learns" (Background, para 3). Connectivism accounts for the fact that new information is continually being acquired, that learning can reside outside of the learner, and that the learning process is impacted by shifting elements not entirely under the control of the individual (Siemens, 2004). A new metaphor suggested by Bereiter and Scardamalia (1996) is that of "mind as pattern recognizer," wherein "the mind acquires abilities and dispositions to recognize and respond in various ways to various patterns, but the patterns are not in the mind" (p. 489-490).

According to Hattie (2009), "the art of teaching requires deliberate interventions to ensure that there is cognitive change in the student" including " . . having sufficient understanding of the student's understanding as he or she comes to the task ..." (p. 23). Darling-Hammond (1997) observes that teachers must have a pedagogical content knowledge that enables them to make ideas accessible to others as well as having the knowledge to encourage students' social, physical and emotional growth, and understand 
"differences in children that may arise from culture, language, family, community, gender, prior schooling, and the other factors that shape people's experiences" (p. 295). Furthermore, Giroux (1988) adds a Freirian lens to pedagogical practice by suggesting "forms of experience in which teachers and students display a sense of critical agency and empowerment “(p. 87). Giroux (1988) reminds us that schools, as political forms of power, allow some individuals and groups to interpret for others how they might live, resist, affirm, and participate in developing their own identities. Following Freire's view of education, Giroux (1988) frames the power of education as a referent for change:

Education is that terrain where power and politics are given a fundamental expression, where the production of meaning, desire, language, and values engage and respond to the deeper beliefs about what it means to be human, to dream, and to name and struggle for a particular future and form of social life (p. 110)

For children of color and those who live in poverty, theories of teaching and learning come together within the construct of CRT. While CRT does not ignore the underpinnings of the educational programs and practices that exist in schools, it requires that teachers become "orchestrators of social contexts for learning ... and make teaching processes compatible with the sociocultural context and frames of references of ethnically diverse students" (Gay, 2010, p. 45). The researcher assumes Gay's reflection on the needs of diverse students to include those underserved students who also live in poverty. Understanding the learning needs and assets children bring to the classroom is critical for providing effective instruction for all children, and especially for children marginalized by race, ethnicity, and social class.

While the principles and practice of learning guide instructional practices, the reality is that unless children's basic needs are met, they cannot thrive under any theory 
of learning (Maslow, 1943). Economic, family support and education policies need to be part of a comprehensive national strategy to close the economic achievement gap (Reardon, 2013). It is unrealistic to believe that schools alone can solve the problems of educational disparities that exist for children living in poverty. Schools, however, do have a role to play in reducing the gap. Reardon (2013) suggests steps that can contribute to that role: (a) states and school districts could devote a greater share of their resources and efforts to the earliest grades in order to eliminate, in the long run, the self-perpetuating educational disparities; (b) districts could increase time in school (e.g., extended days and/or years); if used effectively, this may help to narrow academic achievement gaps; and, (c) states and school districts can do more to provide all students with equal access to high-quality teachers, quality curriculum and instruction, and adequate school resources.

While the researcher agrees that Reardon's (2013) suggestions are key technical solutions that will help solve issues of inequity in schooling, the researcher also believes that some of the issues are so politically and culturally embedded in the U. S. system of education that solutions leading to equity for all children requires leaders who will take on the challenges of adaptive change (Heifetz \& Linsky, 2002). Given the strong presence teachers and learners have in the complex processes of schooling, what role does the school principal have for improving growth in academic achievement of children representing diverse racial, ethnic and sociocultural backgrounds? Research continues to affirm that troubled schools cannot be turned around without intervention by a strong leader (Leithwood et al., 2004). Leadership is the catalyst that makes it possible for 
teachers to do their best, but it is also often the main reason that teachers come to and remain in challenging schools. Leithwood and Riehl (2003) state that the effects of leadership on student learning are small but educationally significant.

\section{Organizational Leadership Theory and Research in Education}

According to Etzioni (1964), "we are born in organizations, educated by organizations, and most of us spend much of our lives working for organizations" (p. 1). The term "organization" captures a broad construct of social units or human groupings arranged for the purpose of achieving specific goals (Etzioni, 1964). Literature relative to organizational theory has an important place in understanding organizations, including schools, as a key social construct in human existence and endeavors.

Organization Theory. Classic organization theory as applied in America can be traced to the beginnings of the factory system in Great Britain in the eighteenth century (Shafritz \& Ott, 1992). Theories of organizations changed in the following decades in response to changes in production technologies, understanding of human behaviors, outcomes associated with organizational functions, and power and influence from forces outside the organization.

The modern organization developed in response to social factors associated with industrialization, among them, "a rise in educational standards and achievements, the spread of political consciousness, secularization, the rapid growth of science, the decline

of the family, and increase in social mobility" (Etzioni, 1964, p. 105). Bureaucracy in its rational-legal form grew slowly, beginning in the Middle Ages and exerting its greatest influence in the twentieth century (Perrow, 1986). The bureaucratic model provided 
organizational efficiency and a rational means of dealing with people. In bureaucracies, power is centralized and control maximized by asking people to respond primarily to the needs of an organization and to subject themselves to the authority of the organizational leader (Clegg, 1990; Perrow, 1986). An ideal bureaucracy affords organizations a social tool that "legitimizes control of the many by the few, despite the formal apparatus of democracy" (Perrow, 1986, p. 5); however, this ideal form does not account for all the variations in people and needs that are inherent in society. As organizations grew larger, more complex, and pervasive in society, new theories developed around management and leadership, efficiency, worker productivity, specialization of tasks, job satisfaction, and concepts of organizations as systems.

Postmodern organizational realities demand more rapid transformation strategies than those informed by the rigid, rational thinking that previously informed organizational structure (Burnes, 2004; Clegg, 1990). External demands, internal conflict, varying technologies, and power interact within complex cultural systems that share common symbols, values, and cause-and-effect beliefs (Shafritz \& Ott, 1992). The shifts that occur in the understanding of organizational development in response to social, economic and cultural shifts from the modern to the postmodern tendencies (Clegg, 1990) are seen in Figure 4.

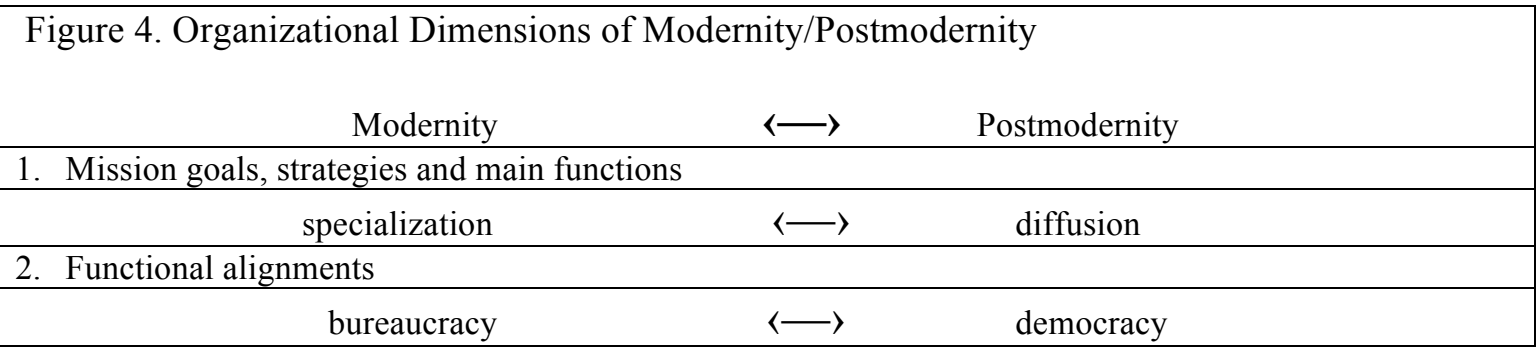




\begin{tabular}{|c|c|c|}
\hline hierarchy & $\langle\longrightarrow$ & market \\
\hline \multicolumn{3}{|l|}{ 3. Co-ordination and control } \\
\hline \multicolumn{3}{|c|}{ in organizations } \\
\hline disempowerment & $\langle\longrightarrow$ & empowerment \\
\hline \multicolumn{3}{|c|}{ around organizations } \\
\hline laissez-faire & $\langle\longrightarrow$ & industry policy \\
\hline \multicolumn{3}{|l|}{ 4. Accountability and role relationships } \\
\hline extra-organizational & $\langle\longrightarrow$ & intra-organizational \\
\hline \multicolumn{3}{|l|}{ 5. Skill formation } \\
\hline inflexible & $\langle\longrightarrow$ & flexible \\
\hline \multicolumn{3}{|l|}{ 6. Planning and communication } \\
\hline short-term techniques & $\langle\longrightarrow$ & long-term techniques \\
\hline \multicolumn{3}{|l|}{ 7. Relation of performance and reward } \\
\hline individualized & $\langle\longrightarrow$ & collectivized \\
\hline \multicolumn{3}{|l|}{ 8. Leadership } \\
\hline mistrust & $\longleftrightarrow \longrightarrow$ & trust \\
\hline
\end{tabular}

Figure 4. Organizational dimensions of modernity/postmodernity. Source: Clegg, 1990, p. 203.

Bolman and Deal (2008) identify key characteristics of organizations that illuminate challenges leaders may face, including (a) organizations are complex ... open systems that operate within changing environments, (b) organizations are surprising ... the solution to previous problems may lead to future obstacles, (c) organizations are deceptive ... processes and/or people act to camouflage mistakes, and, (d) organizations are ambiguous ... figuring out what is really going on is not always easy. Bolman and Deal (2008) use a four-frame approach looking at structural, human resource, political and symbolic perspectives to help managers and leaders respond to the complexity, ambiguity, value dilemmas, political pressures, and multiple constituencies they face in organizations. 
Schools as Organizations. There is value in viewing schools as organizations, especially through the lens of past attempts to use organizational theory to improve schools. Shifts from the modern to postmodern organizational reality can be seen in the U.S. education system. The unique characteristics of school organizations, especially in light of the major reform and restructuring demands for which people in schools are accountable, make it difficult to directly translate all of the theories and literature from the corporate world into an educational environment. It is important, though, to understand the application of theories from the corporate world in order to understand the traits that also exist in the structure of schools.

Schools as organizations evince many of the "bureaucratic tendencies" as described by Weber (Clegg, 1990). Figure 5 shows correlates between some of those tendencies and some of the organizational characteristics of schools.

\begin{tabular}{|c|c|}
\hline \multicolumn{2}{|c|}{ Figure 5. School Organization and Bureaucratic Tendencies } \\
\hline Bureaucratic Tendencies & School Organization Correlates \\
\hline Specialization of personnel based on tasks & Administration, Licensed Staff, Support Staff \\
\hline Authorization of organizational action & $\begin{array}{l}\text { Functions of each personnel role have specific } \\
\text { levels of authority commensurate with their duties }\end{array}$ \\
\hline $\begin{array}{l}\text { Hierarchization, stemming from tasks and } \\
\text { personnel being functionally separated }\end{array}$ & $\begin{array}{l}\text { Hierarchy of functions ranging from } \\
\text { administrative, to teaching, to classified, etc. }\end{array}$ \\
\hline $\begin{array}{l}\text { Contractualization of organizational relationships } \\
\text { that specifies duties, rights, obligations and } \\
\text { responsibilities }\end{array}$ & $\begin{array}{l}\text { Each employee unit has precise contracts of } \\
\text { employment }\end{array}$ \\
\hline $\begin{array}{l}\text { Credentialization that is used to measure } \\
\text { qualifications }\end{array}$ & $\begin{array}{l}\text { Administrators, teachers, specialists and } \\
\text { paraprofessionals have licenses or credentials } \\
\text { commensurate with their contracts }\end{array}$ \\
\hline $\begin{array}{l}\text { Careerization is based on differentially stratified } \\
\text { credentials }\end{array}$ & $\begin{array}{l}\text { Career structure and promotion from one rung of } \\
\text { the hierarchy to another is based on appropriate } \\
\text { credentials and experience }\end{array}$ \\
\hline $\begin{array}{l}\text { Stratification of status among personnel in the } \\
\text { organization. }\end{array}$ & $\begin{array}{l}\text { Pay and compensation differentials are structured } \\
\text { through contracts and define employee status }\end{array}$ \\
\hline $\begin{array}{l}\text { Specific rights of control are held by } \\
\text { superordinates. }\end{array}$ & $\begin{array}{l}\text { Specific configurations of authority maintain } \\
\text { various layers of subordinates-Superintendent to } \\
\text { District Office Personnel, to Principals, to } \\
\text { Teachers, etc. }\end{array}$ \\
\hline
\end{tabular}




\begin{tabular}{|l|l|}
\hline $\begin{array}{l}\text { Formalization of rules that justify and produce } \\
\text { legitimate action. }\end{array}$ & $\begin{array}{l}\text { Functional separation of roles/tasks and } \\
\text { hierarchical relations within district and schools } \\
\text { are rule-bound (State regulations, Board Policy, } \\
\text { Administrative Regulations) }\end{array}$ \\
\hline Standardization & $\begin{array}{l}\text { Files of written documents are held in } \\
\text { administrative offices with access limited for } \\
\text { others based on role }\end{array}$ \\
\hline Centralization & $\begin{array}{l}\text { Communication, co-ordination and control are } \\
\text { routed through the administrative offices, forming } \\
\text { a central hub for the school organization }\end{array}$ \\
\hline
\end{tabular}

Figure 5. School organizational characteristics that correlate with bureaucratic tendencies. Source: Clegg, 1990

Bureaucratic structures in the past effectively provided the same efficiencies for schools as for other types of organizations that needed to respond to economic, political and social changes brought about by industrialization. They are characteristics that adhere to the tenets of a different century in schooling, but they are strongly embedded in the culture of American educational institutions and are difficult to change. Sergiovanni (1990) argues that the purpose of schooling, that of teaching and learning, can be displaced due to bureaucratic rules, administrative convenience, contract provisions, and interests of teachers. Deal (1990) emphasizes that "at the very least, we need to treat educational organizations as complex social organisms held together by a symbolic webbing rather than as formal systems driven by goals, official roles, commands, and rules" (p. 7). Understanding the bureaucratic structures that still exist in the educational system today is important for leaders as they work to create school environments focused on teaching and being responsive to the learning needs of all children.

A common response to those who might impose business standards on schools is that schools don't produce "widgets." The researcher agrees that it is not the work of schools to produce widgets, but it is not always clear to others exactly what schools are 
responsible for producing. Does everyone agree that the purpose of schools is to prepare students to participate in a democratic society? Is it the job of schools to prepare young people to be productive workers? Are schools responsible for preparing children to be lifelong learners? Are schools responsible for mitigating the factors of poverty and opening the doors of social mobility to all children? The paradigm shift to a societal value of cultural human diversity suggests that the answer to each of those questions is "yes" and that there is the need for dialogue and decision making in schools and among policy makers that ensures educational success for all students in the $21^{\text {st }}$ century (Williams, 1999).

\section{Change Theory}

All organizations, including schools, exist in environments that are shaped by internal and external forces. Changes may occur due to natural events, to new technologies, the skill sets of workers, the vision of different leaders, or through planned change efforts (Burke, Lake, \& Paine, 2009). Acknowledging the changes in education in the 1960s, Bennis (1966) observed a significant increase within three decades in numbers of people attending not only high school but also college. Bennis (1966) describes three areas of philosophical change occurring in the 1960s; the researcher finds that the resulting insight into organizational transformations is still relevant today:

1. A new concept of human based on increased knowledge of humans' complex and shifting needs, which replaces the oversimplified, innocent push-button idea of the human.

2. A new concept of power, based on collaboration and reason that replaced a model of power based on coercion and fear. 
3. A new concept of organizational values, based on humanistic-democratic ideals, that replaces the depersonalized mechanistic value system of bureaucracy.

Chin and Benne (1967) reinforce this perspective in their reflection that the introduction of planned change should be based on behavioral knowledge of change.

Like the forces that shift over time and shape change in manufacturing organizations, information organizations, and governmental agencies, social, economic and political forces drive pressure for change in education systems. Fullan (1999) notes that the best organizations are those that have a connection with their wider environments, further acknowledging that changes in school cultures may require more sophisticated leadership than has previously existed in schools (2005).

\section{Leadership Theory}

Scholars have debated the concept and definition of leadership for many years (Mees, 2008). Leadership is commonly understood to be a process by which a person influences others to accomplish an objective and directs the organization in a way that makes it more cohesive and coherent (Avolio, 1999; Bolman \& Deal, 2008; Fullan, 2005; Perrow, 1986). Viewing leadership as a process allows for exploration of the context in which it occurs, the characteristics of followers, the historical times in which it is set, and the timing of events that have an impact on organizations and those who lead them (Avolio, 1999). Leadership cannot operate in a vacuum; the context of the organization or social system in which leaders diagnose what is happening, make decisions, and take action to resolve identified problems creates the environment in which leadership plays out (Heifetz et al., 2009). 
There is a broad range of leadership theory evident in the research and literature on organizations, much of which has been applied to educational leadership. It is often distinguished from authority, power, and influence, which are tools that leaders may use but that do not automatically result in acts of leadership (Bolman \& Deal, 2008; Heifetz et al., 2009). There is often a direct contrast in the literature between management and leadership, with management seen as attending to the nuts and bolts of the organization and leadership viewed as a process of visioning, networking and building relationships, often for purposes of effecting change.

Transactional Leadership. Transactional leadership describes a relationship in which leaders and followers exchange needs and services for the purpose of accomplishing independent objectives (Sergiovanni, 1990). The extrinsic needs of both groups are met through a system of barter- " positive reinforcement for good work, merit pay for increased performance, promotion for increased persistence, a feeling of belonging for cooperation" (Sergiovanni, 1990, p. 31). Transactional leadership actions align closely with manager or leader actions in a bureaucracy.

Transformational Leadership. According to Bass (1990), in many cases transactional leadership may be "a prescription for mediocrity" (p. 20). In addition, leaders may not have control of the organizational rewards or penalties that might motivate employees (Bass, 1990). Transformational leadership moves beyond bureaucratic notions to build "upon followers' need for meaning and institutional purpose" (Maxcy, 1991, p. 37). The focus of transformational leadership is to inspire human potential, motivating both leader and follower to higher levels of organizational 
commitment and performance (Sergiovanni, 1990). Transformational leaders achieve results in one or more of the following ways: 1) they may be charismatic in providing vision and sense of mission; 2) they communicate high expectations and inspire those around them; 3) they are individually considerate, paying attention to differences among employees; and 4) they may provide intellectual stimulation (Bass, 1990). This type of leadership inspires energy and moral purpose so that collaboratively members of the organization overcome obstacles and achieve ambitious goals (Hattie, 2009). While recognizing that transformational leadership is not a panacea - in fact, there are circumstances that warrant transactional processes-Bass (1990) argues that transformational characteristics are critical in leaders whose organizations require renewal and change.

The nature of the world in the $21^{\text {st }}$ century with rapid changes in technology and with significant political and economic complexities have shaped a more updated vision of transformational leadership than that first described by James McGregor Burns in 1978 and later by Bass and others (Liontos, 1992). Especially as it applies to schools, Sagor (1992) states:

The issue is more than simply who makes which decision ... it is finding a way to be successful in collaboratively defining the essential purpose of teaching and learning and then empowering the entire school community to become energized and focused. In schools where such a focus has been achieved, we found that teaching and learning became transformative for everyone (p. 13).

Instructional Leadership. Instructional leadership provides a focus on ensuring a learning environment free of disruption, a system of teaching objectives that is clear, and high teacher expectations for themselves and for their students (Hattie, 2009). The power 
of instructional leadership has been shown to be greater than that of transformative leadership in schools in terms of the positive effects on student achievement (Hattie, 2009). The power of the instructional leader is the ability to maintain the focus of school processes on student achievement through their influence on the organizational conditions and instructional quality in the school (Marzano, Waters, \& McNulty, 2005; Mora-Whitehurst, 2013).

Balanced Leadership. Balanced leadership is a framework grounded in over 30 years of research that moves beyond abstract ideas to the concrete knowledge, responsibilities, practices, strategies, tools, and resources that school principals and other leaders need to be effective (Waters, Marzano, \& McNulty, 2003). In their development of the balanced leadership framework, Waters et al. (2003) compiled findings from studies that contributed to the multiple components of the framework. Of the twenty-one key leadership responsibilities identified in their study, Waters et al. (2003) found that it was important for leaders to have the understanding for (a) identifying first and second order change characteristics that determines the magnitude or order of change, (b) selecting the appropriate leadership practices depending on the order of change, and (c) developing the experiential, declarative, procedural, and contextual knowledge to know when and how to address the 21 leadership responsibilities reported in the framework.

\section{Effective Leadership for Schools}

Leadership is viewed as important to the success of organizations, including schools (Avolio, 1999; Clegg, 1990; Bolman \& Deal, 2008; Fullan, 2005; Heifetz, Grashow \& Linsky, 2009; Heifetz \& Linsky, 2002; Leithwood, Begley and Cousins, 
1992; Marzano et al., 2005; Perrow, 1986; Rice, 2012; Sergiovanni, 1990, 1996; Wagner, 2006). The theoretical underpinnings of leadership are applicable to all organizational contexts, and leadership methods in business and in education have more in common now than in the past. A large body of organizational management and leadership literature is frequently used to provide insight about educational leadership roles. General management theories and perspectives have contributed a sound base for informing school leadership, particularly in the areas of helping to think through problems, clarifying issues and finding solutions (Sergiovanni, 1996).

Theorists and professionals in the field of education began, in the 1990s, to evaluate schools as different types of places that require specialized knowledge on the part of leaders that may not be provided through the corporate or business management perspective. The complexities of the school environment must be taken into account in order to adequately prepare people for leadership roles in schools (Fullan, 1997). Levine (2005) states, "The job of school leader has been transformed by extraordinary economic, demographic, technological and global change" (p. 11). Lyman and Villani (2012) assert, "School leaders, particularly in urban areas, find large percentages of their students and families living in poverty" (p. 1). Bolman and Deal (2008) capture the challenges by saying, "Good managers and leaders sustain a tension-filled poise between extremes." (p. 436). Those extremes demand that managers and leaders have a commitment to their core beliefs, while at the same time they are able to respond to the "vortex of forces" pulling and pushing the organization in different directions (Deal, 2008, 436). 
The challenges reflected here are only some of the factors that result in school leaders having to " ... engage in continuous evaluation and school improvement, create a sense of community, and build morale in a time of transformation" (Levine, 2005, p. 12). Sergiovanni (2000) agrees when he writes about the context for schooling and the need for moral leadership as the framework for getting things done in schools.

Schools need special leadership because schools are special places. Sure, schools share with other enterprises common managerial requirements that ensure basic levels of organizational purpose, competence, reliability, structure, and stability. But schools must respond as well to the unique political realities they face. After all, schools belong to parents and children, interact with the needs of local businesses, churches, and other community groups, and have a unique relationship with state governments. These "stakeholders" don't always agree, and it takes a high level of political skill for school leaders to bring about the necessary consensus and commitment to make schools work well for everyone (pp. 165-166).

The cultural perspective especially makes sense for illuminating some of the deeply held values and beliefs that underlie school systems and individual school communities; this knowledge becomes even more valuable in the environment of accountability for change in which schools and their leaders exist (Deal, 1990). Reeves (2009) believes, given that change constitutes risk, loss, and fear for those within the prevailing culture, leaders must "Make the case for change compelling, and associate it with moral imperatives rather than compliance with external authority" (p. 93).

In their synthesis of the research, Marzano et al. (2005) worked to answer the question, "What does the research tell us about school leadership?" (p. 9). The authors drew each of the responsibilities listed in Figure 6 from several studies ranging in number from four studies (Intellectual Stimulation) to 44 (Focus), and the relationship each 
responsibility had with student achievement was quantified in their meta-analysis. The listing of these responsibilities in alphabetical order does not indicate the statistical significance of the individual responsibilities on student achievement but their inclusion on the list indicates that all are important.

\begin{tabular}{|c|c|}
\hline \multicolumn{2}{|c|}{ Figure 6. Principal Leadership Responsibilities } \\
\hline RESPONSIBILITY & EXTENT TO WHICH THE PRINCIPAL: \\
\hline Culture & Fosters shared beliefs and a sense of community and cooperation \\
\hline Order & Establishes a set of operating procedures and routines \\
\hline Discipline & $\begin{array}{l}\text { Protects teachers from issues and influences that would detract from their teaching time } \\
\text { and focus }\end{array}$ \\
\hline Resources & $\begin{array}{l}\text { Provides teachers with the materials and professional development necessary for the } \\
\text { successful execution of their jobs }\end{array}$ \\
\hline $\begin{array}{l}\text { Curriculum, instruction, } \\
\text { assessment }\end{array}$ & $\begin{array}{l}\text { Is directly involved in the design and implementation of curriculum, instruction and } \\
\text { assessment }\end{array}$ \\
\hline Focus & Establishes clear goals and keeps those goals in the forefront of the school's attention \\
\hline $\begin{array}{l}\text { Knowledge about } \\
\text { curriculum, instruction, } \\
\text { assessment }\end{array}$ & Is knowledgeable about curriculum, instruction and assessment practices \\
\hline Visibility & Has quality contact and interactions with teachers and students \\
\hline Contingent rewards & Recognizes and rewards individual accomplishments \\
\hline Communication & Establishes strong lines of communication with teachers and among students \\
\hline Outreach & Is an advocate and spokesperson for the school to all stakeholders \\
\hline Input & Involves teachers in the design and implementation of important decisions and policies \\
\hline Affirmation & Recognizes and celebrates school accomplishments and acknowledges failures \\
\hline Relationship & Demonstrates an awareness of the personal aspects of teachers and staff \\
\hline Change agent & Is willing to actively challenge the status quo \\
\hline Optimizer & Inspires and leads new and challenging innovation \\
\hline Ideals/beliefs & Communicates and operates from strong ideals and beliefs about schooling \\
\hline Monitors/evaluates & Monitors the effectiveness of school practices and their impact on student learning \\
\hline
\end{tabular}




\begin{tabular}{|l|l|}
\hline Flexibility & $\begin{array}{l}\text { Adapts his or her leadership behavior to the needs of the current situation and is } \\
\text { comfortable with dissent }\end{array}$ \\
\hline Situational awareness & $\begin{array}{l}\text { Is aware of the details and undercurrents in the running of the school and uses this } \\
\text { information to address current and potential problems }\end{array}$ \\
\hline Intellectual stimulation & $\begin{array}{l}\text { Ensures that faculty and staff are aware of the most current theories and practices and } \\
\text { makes the discussion of these a regular aspect of the school's culture }\end{array}$ \\
\hline
\end{tabular}

Figure 6: Principal leadership responsibilities. Adapted from Marzano et al., 2005.

Review of the literature on schools successful in fostering student learning reveals a relationship between school leadership and student learning (Edmonds, 1979; Hallinger, 2005; Hallinger \& Heck, 1998); Leithwood et al., 2004; Lyman \& Villani, 2004; Wallace Foundation, 2013). Current research demonstrates that "effective principals are responsible for establishing a school wide vision of commitment to high standards and the success of all students" (Wallace Foundation, 2013, p. 6). Elmore (2000) argues for principal leadership that focuses on instructional improvement. Waters et al., (2003) emphasize the balanced leadership framework, combining 21 research-based principal responsibilities with the knowledge necessary to lead first and second order change in schools. Hattie's (2009) review of 11 meta-analyses of 491 studies regarding principals and school leaders identified type of principal leadership as a moderator on the effects of principal on student outcomes and specifically identified two major forms of leadership: instructional leadership and transformational leadership (p. 83). Hattie (2009) draws a conclusion from the meta-analyses that instructional leadership has more power than transformational leadership in its effect on student outcomes.

Leithwood et al., (2004) conducted a review of the research on how leadership influences student learning and concluded "present evidence led us to the conclusion that leadership is second in strength only to classroom instruction" (p. 70). In their review of 
the works of Hallinger and Heck (1999), Conger and Kanungo (1998), Leithwood (1996), and Waters, Marzano, and McNulty (2003), each of which identified categories of leader practices, Leithwood et al. (2004) went so far as to suggest, "These categories of leadership practices closely reflect a transformational approach to leadership which Bass (1997) claims has proven to be useful in many different cultural and organizational contexts" (p. 23) and that has proven useful for educational organizations.

Role of the Principal. The school principal has always been expected to perform a variety of roles that include political, managerial, and instructional roles (Hallinger, 2005). Understanding the history of the school principal helps to understand what the role looks like today and how it evolved. Rousmaniere's (2013) historical examination of the role presents a picture of complex and contradictory responsibilities in the evolution of this important figure in the educational system in the U. S. Roles and responsibilities run the gamut of employer, supervisor, professional figurehead, and inspirational leader, while daily serving as the link between "a large bureaucratic system and the individual daily experiences of a large number of children and adults" (Rousmaniere, p. 3). At the same time, the role is often seen as one with the primary task of providing instructional leadership and creating optimal learning environments for students (Ornstein \& Levine, 1989).

The creation of the principal role in the late $19^{\text {th }}$ century changed internal power relations in schools (Rousmaniere, 2013), as visualized by the researcher in Figure 7. 
Figure 7. Schools Before and After Creation of the Principal Role

Before

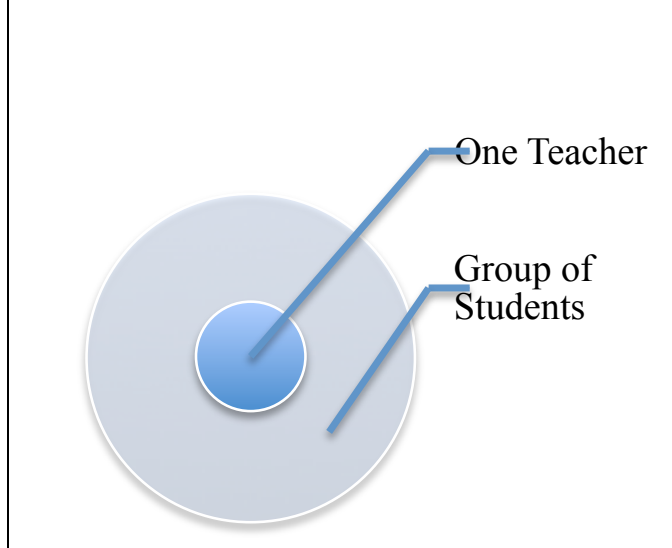

After

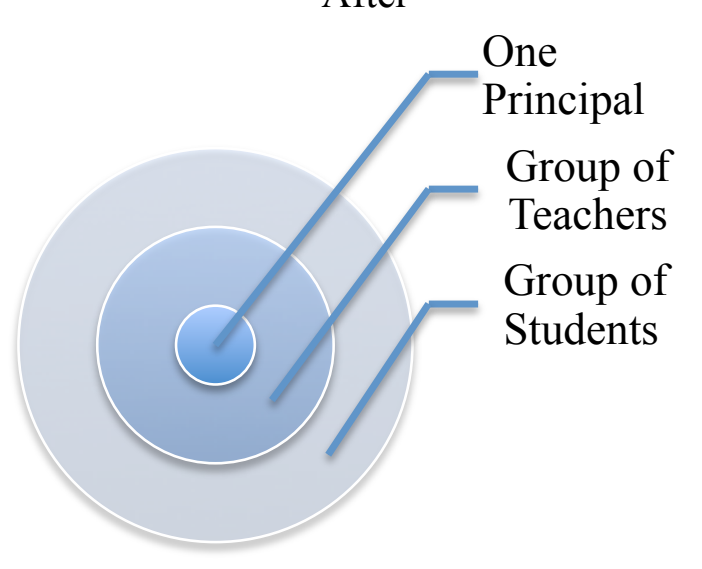

Figure 7. Change in internal organization of schools before and after creation of the principal role in the late $19^{\text {th }}$ century as informed by Rousmaniere, 2013.

The divide between principals and teachers was further emphasized when office space was dedicated to the position. The growth of school administration was informed by a group of educational reformers who saw the bureaucratization of school organizations as the means for improving learning (Rousmaniere, 2013). At the same time that authority moved from the classroom to the principal's office, the principal became a pivotal cog in the machinery of public education. Similar to the roles of middle managers in corporate bureaucracy, principals were conduits between central office administration and the school for implementing newly designed school systems at the beginning of the twentieth century (Rousmaniere).

The history of schooling in the U. S. is contradictory in both the beliefs of the purpose of education, and the beliefs of who should benefit from education. This divide is exhibited in part in the differences between "administrative progressives who advocated for the development of school systems driven by the values of fiscal economy and 
organizational accountability, and pedagogical progressives who promoted a childcentered, humanistic approach to education" (Rousmaniere, 2013, p. 58).

Rousmaniere (2013) describes how the philosophy of John Dewey guided progressive educational thinkers to see how democratic practices in school would assist students in understanding how to understand and participate in a democratic society. Within this frame of thinking, the idea of democratic practice extended to inclusion of the community, especially during the post-depression era in the U. S. In spite of principals' work at the school and community level, "the language and priorities of democracy were tempered by the language and priorities of educational management" (Rousmaniere, $p$. $60)$.

The post-World War II years led to even greater changes in educational systems and in the role of the principal stemming from (a) more state and federal involvement in schools, (b) union organization of teachers, (c) parent activism, (d) an oppositional youth popular culture, (e) an increase in racial, ethnic, and class conflict, and (f) the expansion of bureaucratic procedures that developed in response to modern society (Rousmaniere, 2013). Table 3 shows a number of the social and political forces post-World War II through the 1970s that impacted public schools and created demands for new policies, leading to principals' work focused primarily on understanding and applying system guidelines (Rousmaniere, pp. 89-110). 
Table 3

Social/Political Forces that Impacted Schools 1950s - 1970s

\begin{tabular}{|c|c|c|}
\hline Time Period & Social/Political Force & Impact on Schools \\
\hline 1954 & $\begin{array}{l}\text { U. S. Supreme Court decision Brown } \\
\text { v. Board of Education }\end{array}$ & $\begin{array}{l}\text { Separate educational facilities were ruled } \\
\text { inherently unequal. }\end{array}$ \\
\hline 1955 & Brown II & $\begin{array}{l}\text { The Supreme Court provided a plan for } \\
\text { dismantling the dual system of education in the } \\
\text { South. }\end{array}$ \\
\hline 1958 & $\begin{array}{l}\text { After the launch into space of the } \\
\text { Sputnik satellite, the National Defense } \\
\text { Education Act (NDEA) was passed. }\end{array}$ & $\begin{array}{l}\text { Federal funding provided for science and } \\
\text { technology education and other topics that would } \\
\text { contribute to the nation's military and economic } \\
\text { power. }\end{array}$ \\
\hline 1958 & $\begin{array}{l}\text { FBI director J. Edgar Hoover } \\
\text { identified a rebellious youth culture as } \\
\text { a "menace" }\end{array}$ & $\begin{array}{l}\text { More aggressive discipline policies were } \\
\text { implemented in schools and discipline procedures } \\
\text { were assigned to administrators. }\end{array}$ \\
\hline Early 1960s & $\begin{array}{l}\text { Legal authorization of public-sector } \\
\text { unions }\end{array}$ & $\begin{array}{l}\text { By the end of the } 1970 \text { s, the majority of teachers } \\
\text { belonged to collective bargaining units, } \\
\text { complicating relationships between teachers and } \\
\text { principals. }\end{array}$ \\
\hline 1965 & $\begin{array}{l}\text { Elementary and Secondary School } \\
\text { Act (ESEA) }\end{array}$ & $\begin{array}{l}\text { Federal funding was provided to schools for } \\
\text { enrichment programs for poor children (Title I) }\end{array}$ \\
\hline 1966 & $\begin{array}{l}\text { The Equality of Educational } \\
\text { Opportunity Report (commonly } \\
\text { known as the Coleman Report) was } \\
\text { published }\end{array}$ & $\begin{array}{l}\text { The report challenged concepts that funding, } \\
\text { teacher preparation, curriculum development or } \\
\text { educator professionalization had an impact on } \\
\text { students more than background and } \\
\text { socioeconomic status. }\end{array}$ \\
\hline $1968 / 1974$ & $\begin{array}{l}\text { Bilingual Education Act was passed, } \\
\text { followed by the } 1974 \text { Supreme Court } \\
\text { decision Lau v. Nichols }\end{array}$ & $\begin{array}{l}\text { Schools were required to provide assistance for } \\
\text { children with limited English proficiency. }\end{array}$ \\
\hline 1969 & $\begin{array}{l}\text { Supreme Court decision Tinker v. Des } \\
\text { Moines }\end{array}$ & $\begin{array}{l}\text { The decision supported constitutional rights to } \\
\text { freedom of speech and expression for students } \\
\text { and teachers. }\end{array}$ \\
\hline 1975 & $\begin{array}{l}\text { Education for All Handicapped } \\
\text { Children Act }\end{array}$ & $\begin{array}{l}\text { Schools were responsible for the education of } \\
\text { children with disabilities. }\end{array}$ \\
\hline $1960 s-1970 s$ & Civil Rights Initiatives & $\begin{array}{l}\text { Racial integration of schools, support of minority } \\
\text { cultures and achieving equity led to tensions, with } \\
\text { school principals in the middle of the conflict. }\end{array}$ \\
\hline
\end{tabular}

Source: Rousmaniere, 2013, pp. 89-110.

The call for changes in public schools continued into the 1980s. The publication

of $A$ Nation at Risk was a response to "the widespread public perception that something is

seriously remiss in our educational system" (National Commission of Excellence in

Education, 1983). Many reform initiatives followed, ranging from more accountability 
through standardized assessment systems, programs of school choice meant to challenge the large bureaucracy of schooling and bring free-market competition into public education, and charter school legislation (Rousmaniere, 2013). All of the ensuing expectations "were added to [the] principal's ongoing work of mediating educational, legal, fiscal, and cultural dynamics" (Rousmaniere). Eighteen years after publication of $A$ Nation at Risk, ESEA was reauthorized as the No Child Left Behind (NCLB) Act of 2001, linking federal funding to student achievement and holding schools accountable for closing the achievement gap (Gamoran, 2007).

The challenges inherent in the expectations of the principal's role in school improvement are further complicated by the fact that the job still holds many of the same tasks and managerial components as it did many years ago, in spite of the changes in the broader context of education as it exists today (Rousmaniere, 2013). The complexities as well as the core purpose of the principal's role are captured in the quote from Rousmaniere reflecting on the changes throughout the twentieth century.

Modern principals came to have less to do with student learning and more to do with upholding administrative structures and responding to public pressures. Yet by the nature of their background and role as educators, principals have always been concerned with student learning, and principals across time have played a pivotal role in shaping the educational culture of schools (p. 5).

\section{Educational Policy and Politics}

The concept of educational equity for all children, irrespective of their socioeconomic status, skin color or ethnicity, has been a cornerstone of the American cultural, political and economic belief systems since the inception of the Common School movement in the mid-1 $9^{\text {th }}$ century. Edwards (1949) observes, "More than any other of 
our institutions ... our schools and colleges and universities have been an authentic expression of the core values that lie at the base of our way of life" (p. 71). Described by Downs (1974) as a missionary for public education, Mann responded to resistance by those he observed as wealthy and in power by accumulating findings of the connection between education and the wealth of a nation. The Common School movement was grounded in his belief that universal education "could counteract the trend toward domination of capital and the servility of labor" (Downs, 1974, p. 116). Mann argued that all citizens, regardless of race or economic status, should have equal access to a tuitionfree, tax-supported public school system and that such a system must be responsive to all races, and be nonsectarian if society was to achieve the liberating status of a true democracy (Cremin, 2013).

Mann's support for public education is seen by many historians as lying within the American liberal tradition, while more recent scholars have viewed his work in a conservative mode (Messerli, 1971). Understood through a critical lens, his premise that education be paid for and controlled through public systems, as well as his pedagogical stances on moral education, citizenship education, and his support of a professional teaching force could be viewed as laying the foundation for the "sometimes mindnumbing establishmentarian bureaucracy" that is the public school system today (Messerli, 1971, p. xii). While his efforts may be viewed as supporting an educational system content with class domination as articulated through his thoughts on the connections between schooling and industrial productions, researchers taking into account the history of the era in which he worked view Mann's contributions to the 
political and social foundations of American education as an attempt at positive solutions to social problems associated with a poor, uneducated populace (Cremin, 2013; Downs, 1974; Filler, 1965; Messerli, 1971).

The standard way of thinking and writing about education in America is that it is an essential feature of a free, democratic society built on a strong foundation of pluralism and individual freedom (National Commission of Excellence in Education, 1983). While formal school opportunities increased for many members of American society in the mid1800s, public education failed to effectively serve Native Americans, African Americans, non-English speakers and children living in poverty until the 1960s. It was in the 1960s that "a new era of consciousness about the real meaning of equal opportunity and alleviating conditions associated with poverty" (Gelbrich, 1999, Part 8, para. 6) became a focus of public education policy.

A wave of school reform legislation, movements and reports ensued. First, ESEA was passed in 1965 as a part of the "War on Poverty" (ESEA, 1965). Next came the new sociology of education in the early 1970s, posing criticisms of traditional schooling that were Freirian in nature: "How does one make education meaningful in a way that makes it critical and, hopefully, emancipatory?" (Giroux, 1985). Following that, the 1983 report $A$ Nation at Risk was commissioned in response to the perception that America could not continue to compete as a world power in a global market without a highly educated work force. The report declared,

Each generation of Americans has outstripped its parents in education, in literacy, and in economic attainment. For the first time in the history of our country, the educational skills of one generation will not surpass, will not equal, will not even approach, those of their parents (p. 19). 
Next, the federal No Child Left Behind (NCLB) Act of 2001, a reauthorization of ESEA, was signed into law on January 8, 2002. Most recently, ESEA Flexibility Waivers, allowing each state to apply for flexibility with the NCLB provisions while providing plans to improve educational outcomes for all students, were made available to states in 2011.

Complex trends in societal support for public schools have persisted since the publication of $A$ Nation at Risk in 1983. As the decade of the 1990s evolved, ASCD (1996) acknowledged that charter schools began gaining ground, tuition vouchers became part of a national debate, and homeschooling increased. In concert with what was perceived as poor performance by public schools, as demonstrated by measures reported as part of NCLB, ASCD (1996) observed that public education was itself in jeopardy. NCLB generated hope yet also garnered significant criticism after its passage in 2001 . The premise of this reauthorization of the ESEA was to assure that every child had access to a high quality education regardless of race, gender, ethnicity or wealth, but the democratic values inherent in the act were undermined largely by a lack of funding for teacher professional development and the focus on a single measure of standardized testing for evaluating student annual progress (NCLB, 2001).

\section{Challenges in Oregon Schools}

Public K-12 schools in Oregon in the $21^{\text {st }}$ century present significant challenges for educational leaders. Enacted in 1991, The Oregon Educational Act for the $21^{\text {st }}$ Century (HB 3565) called for sweeping changes in the Oregon education model while providing few additional resources. At the same time, a statewide property tax measure 
significantly reduced funding for public schools and shifted funding decisions from local communities to the state. The compression of funding has created budgetary shortfalls impacting school districts even today.

The educational reforms mandated by NCLB placed further demands on the Oregon educational system. Under this legislation, schools were rated each year on adequate yearly progress (AYP) toward all students meeting rigorous state academic standards by the 2013-2014 school year. In September 2011, the USDE invited states to request flexibility regarding specific requirements of the No Child Left Behind Act of 2001 in exchange for rigorous and comprehensive state-developed plans designed to improve educational outcomes for all students, reduce educational disparities, increase equity, and improve the quality of instruction (USDE, 2011). Oregon submitted a request and was granted the waiver in 2012. The evidence that this policy implementation is positively affecting student achievement is not yet clear.

Beyond the mandates, the tensions, and the social debates that have long swirled around public schools in the U. S., many Americans today still tend to believe that education provides for all children the equitable opportunity to become economically self-sufficient, to participate in society as responsible citizens, to promote cultural unity, and to enhance individual lives (Reardon, 2013). But the reality of American education as equitable for all children does not reflect these facts. Children underserved by education in America, primarily children who are poor and of color, have lower academic scores and are the least likely to gain the skills necessary for jobs in today's economy (Comer, 1988). As reported by the Children's Defense Fund (2012): 
There are 16.4 million poor children in rich America, 7.4 million living in extreme poverty. Children under five are the poorest age group in America and one in four infants, toddlers and preschoolers are poor during the years of greatest brain development. A majority of public school students and more than three of four Black and Hispanic children, who will be a majority of our child populations by 2019 , are unable to read or compute at grade level in the fourth or eighth grade and will be unprepared to succeed in our increasingly competitive global economy (p. 1).

\section{Synthesis of the Research Literature}

Poverty by itself does not necessarily lead to the disenfranchising school experiences of poor children. "Stereotypes about the poor and widespread misconceptions about poverty have influenced educators and permeate our society" (Lyman \& Villani, 2004, p. 4). A body of research conducted in the 1970s and 1980s responded to a collection of stereotypes identified as "a culture of poverty" and sought to debunk the myth that poor people share monolithic and predictable beliefs, values, and behaviors" (Gorski, 2008). It is simply not true, yet the concept that poor people lack motivation and have poor work ethics, that they do not value education, that they are linguistically deficient, and that they tend to abuse drugs and/or alcohol, is pervasive in American mainstream thinking, and actually distracts from the real culture of classism that leads to deficit thinking relative to poor students in schools (Gorski, 2008).

The number of children living in poverty and attending high poverty schools continues to increase in Oregon (OCPP, 2013). Because the research identifies educational disparities relative to high poverty schools (Lyman \& Villani, 2004; Reardon, 2011) and because there is evidence that leadership makes a difference in student achievement (Branch et al., 2013; Hallinger, Bickman \& Davis, 1996; Jacobson, 2008; Marzano et al., 2005; Wallace Foundation, 2013), a significant area of study for 
educational leadership is principal leadership that accelerates growth in academic achievement of children living in poverty. This area of research would benefit from a study in which both qualitative and quantitative data are analyzed in order to identify what principal leadership practices exist in high poverty K-5 Model schools in Oregon effective in improving growth in academic achievement of students. 


\section{CHAPTER 3}

\section{Research Methods}

Chapter 2 reviewed literature relevant to isolated aspects of the impact of poverty on educational attainment, the construct of effective principal leadership relative to school improvement, a school's leadership characteristics, and a school's instructional practices or program characteristics. Chapter 3 describes the research methods used in this study, data collection procedures, data analysis, and researcher bias.

This dissertation studied the central research question: What principal leadership practices can be observed in high poverty K-5 Model schools that have improved growth in academic achievement of children attending these schools? The researcher used a mixed methods multiple-case study design (Yin, 2014) to examine the central research question and the following related research questions:

1. How do principal practices support programs improving growth in academic achievement of children in high poverty K-5 Model schools?

2. How do principals allocate school and district resources to support programs and instruction improving growth in academic achievement of children in high poverty K5 Model schools?

3. How do principals share leadership in high poverty K-5 Model schools where growth in academic achievement of children is improved?

4. What other practices do principals put to use in high poverty K-5 Model schools that have improved academic achievement of children?

This chapter is organized into six sections: (a) mixed methods multiple-case study description and rationale, (b) selection of participants, (c) instrumentation, (d) data collection, (e) data analysis, and (f) researcher bias. Analysis of the combined data from the three schools in the study is presented in Chapter 4. 


\section{Mixed Methods Multiple-Case Study}

This study examined principal leadership practices in high poverty K-5 Model schools in Oregon effective in improving growth in academic achievement of children using a mixed methods multiple-case design (Miles et al., 2014). The researcher employed a typical multiple-case study design to examine principal leadership practices in high poverty K-5 Model schools within the context of three schools, with each school site considered a single case (Yin, 2014). The researcher visualized this design feature as shown in Figure 8.

Figure 8. Principal Practices in the Context of a Single-Case School Site

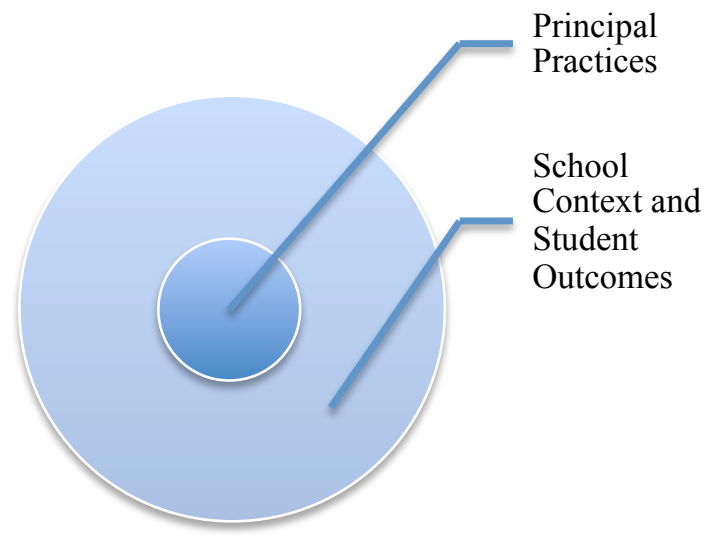

Figure 8. Principal practices situated in the context of a single-case school site.

The researcher used case study methods to examine "a phenomenon of some sort occurring in a bounded context" (Miles et al., 2014). The case study is a type of qualitative research that provides a thorough investigation of a single setting or subject, a single repository of documents, or a particular event, it does so within the real-world context, is bounded by time and activity, and uses a variety of data sources (Baxter \& Jack, 2008; Bogdan \& Biklin, 1998; Creswell, 2003; Fraenkel \& Wallen, 1996; Yin, 
2014). The procedures in case study research are the same as those central to all types of research methods, including "protecting against threats to validity, maintaining a chain of evidence, and investigating and testing rival explanations (Yin, 2014, pp. 3-4).

Lunenberg and Irby (2008) describe a typical case as one in which the researcher "would select to typify the norm when describing a group or program" (p. 96). As with other types of research, there are strengths and limitations to using case study methodology. Case study research provides an advantage in situations where "how" or "why" questions are being asked about a contemporary issue or set of events (Yin, 2014). The unique strength of the case study method is "its ability to deal with a full variety of evidence - documents, artifacts, interviews, and observations - ...” (Yin, 2014, p. 12). This research method is suited to research that occurs in settings where relevant behaviors cannot be manipulated, as with the examination of principal leadership practices that accelerate growth in academic achievement of children in a high poverty school.

This study examined principal leadership practices in three high poverty K-5 Model schools in Oregon effective in improving growth in academic achievement of children. Examining three purposively selected cases allowed the researcher to explore principal leadership practices using literal replication logic across the three schools (Yin, 2014). Cross-case analysis of the three school cases allowed the researcher to deepen understanding and to enhance the ability to make analytic generalizations of principal leadership practices in high poverty K-5 Model schools in Oregon effective in improving growth in academic achievement of children (Miles et al., 2014). This typical multiple- 
case study included (a) basic demographic information about each of the principals, written in narrative format; (b) archival histories of the schools; (c) survey data; (d) interview and focus group data; and (e) document analyses related to each of the schools; (Lunenburg \& Irby, 2008).

This study used mixed methods research in order to enable the researcher to collect a richer array of evidence than could be done by a single method alone (Yin, 2014). As stated by Maxwell and Loomis (2003), "mixed methods data analysis allows the researcher to use the strengths of both quantitative and qualitative analysis techniques so as to understand phenomena better" (p. 255). The purpose of qualitative research "is to obtain an in-depth understanding of purposively selected participants from their perspective" (Lunenburg \& Irby, 2008, p. 177). A quantitative approach enabled the researcher to use strategies of inquiry "such as surveys to collect data on predetermined instruments that yield statistical data" (Creswell, 2003, p. 18).

The benefit of this study design is the findings of one phase of the study inform the next through a "process of working back and forth between inductive and deductive models of thinking" (Creswell, 1994, p. 178) As displayed in Figure 9, this study alternated qualitative and quantitative data collection, which enabled the researcher to provide analytic texture to the work (Miles et al., 2014, p. 44).

Figure 9. Study Design

Qualitative
(exploration) $\quad \rightarrow \quad \begin{gathered}\text { Quantitative } \\ \text { (survey) }\end{gathered} \quad \rightarrow \quad \begin{gathered}\text { Qualitative } \\ \text { (deepen, test findings) }\end{gathered}$

Figure 9. Illustrative design linking qualitative and quantitative data. Adapted from Creswell, 1994. 
Using a mixed methods research design, data collected from document reviews, interviews, surveys, and focus groups were analyzed. The multiple sources of evidence in this study allowed the researcher to triangulate the data, making the case study findings more convincing and accurate (Yin, 2014). Triangulation allowed the researcher to " seek convergence and corroboration of results from different methods studying the same phenomena" (Maxwell and Loomis, 2003, p. 255). Three types of triangulation were used in this study: data source, data type and method (Miles et al., 2014, p. 299). Triangulation by data source included data from diverse people, roles, and locations. Triangulation by data type included the use of qualitative and quantitative data. Triangulation by method included interviews, focus groups, surveys, and document review. This approach allowed the researcher in this study to assert "pragmatic knowledge claims" relative to principal leadership practices in three high poverty K-5 Model schools in Oregon effective in improving growth in academic achievement of children (Creswell, 2003, p. 19).

\section{Participants}

The participants in this investigation were drawn from the population of K-5 Title I elementary schools in the state designated as Model schools in 2012, 2013, and 2014 under the Oregon ESEA waiver (ODE, 2012, 2013). Model schools are the highest performing Title 1 schools, in one of two categories: 1) The highest-performing Title 1 schools that are making AYP for all subgroups in the school without significant educational disparities; and, 2) high-progress schools that are among the top 10\% of Title 1 schools that are making the most progress in improving performance of the all students group in reading and mathematics (ODE, 2012). This study used purposive criterion 
sampling to select three high poverty K-5 elementary schools in Oregon meeting specific criteria for the document review portion of the study (Peterson, 2012). Criteria included:

1. The schools were identified as Model schools by ODE in 2012, 2013, and/or 2014;

2. More than $70 \%$ of the students in the Model school were eligible for Free or Reduced Lunch;

3. A range of geographical locales of K-5 Title I elementary schools was represented; and,

4. A range of small ( $<250$ students), medium (250-499 students), and/or large K-5 Title I elementary schools (500+ students) was represented.

This study used a multiple-case design in which the study as a whole covered several schools (Yin, 2014). The researcher considered the number of potential schools in the purposive sample of Oregon K-5 Model schools to decide upon the selection of two or more cases believed to be literal replications. Three schools would provide adequate representation for the qualitative dimension of this study, as analytic conclusions independently arising from two or more cases comprise a stronger case study (Yin, 2014). These three schools would be the subject of all four sections of the study: document review, interview, quantitative survey, and focus groups.

Public elementary schools in Oregon represent a wide range of grade level configurations, from pre-K through the sixth grade. A typical configuration in districts might include kindergarten through fifth grade (elementary school), sixth grade through eighth grade (middle school), and ninth through twelfth grade (high school). The researcher conducted a search of the National Center for Education Statistics (NCES) 
public school search tool that revealed data for school years 2010-2011 and 2011-2012 showing configurations of kindergarten-first grade, kindergarten-second grade, kindergarten-third grade, kindergarten-fourth grade, kindergarten-fifth grade, and kindergarten-sixth grade (USDE, 2013).

The researcher focused this study on elementary schools in Oregon with a K-5 grade level configuration as that configuration included the largest number of public elementary school in the state. Identifying this population, within which K-5 Title I elementary schools were a subset, enabled the researcher to explore representativeness of the three K-5 Title I schools identified as Model schools in 2012, 2013, and/or 2014 that would be studied. The three schools in the study represented a range of school size, locale, student numbers, and percentage of poverty found in the larger population of K-5 non-Title I and K-5 Title I schools in Oregon.

This section includes a descriptive background of national and state school poverty designations, the number of schools and students in both non-Title I and Title I K-5 schools in Oregon, the number and percentages of schools and students in both nonTitle I and Title I K-5 schools by geographical locale, and the number and percentages of schools and students in both non-Title I and Title I K-5 schools by size of student enrollment. These statistics were used to support the researcher's rationale for the selection of the three high poverty K-5 elementary schools participating in the study.

National and state school poverty information. National poverty guidelines, updated and published annually by the federal government, are used as eligibility criterion by a number of federal programs (Department of Health and Human Services, 
2014). The National School Lunch Program, a food and nutrition assistance program provides low-cost or free lunches to students in public and non-profit private schools (USDA, n.d.a.). Free lunches are available to children in households with incomes at or below 130 percent of poverty and reduced-price lunches are available to children in households with incomes between 130 and 185 percent of poverty (USDA, n.d.a.). These programs help address the needs of schools and districts with high concentrations of poverty as the evidence reveals that the level of poverty in a school can affect academic outcomes (Rumberger, 2007).

High poverty public schools are identified in the U. S. according to the percentage of students eligible to participate in Free-or-Reduced Price Lunch programs (FRPL), providing an approximate measure of the concentration of low-income students within a school (Aud et al., 2013). As shown in Table 4 the USDE defines low-poverty, mid-low poverty, mid-high poverty, and high poverty public schools according to the following percentages of students available for FRPL (Aud et al., 2013). These data are applicable to Oregon schools as they follow the national guidelines. For purposes of this study, one of the criteria for a school to be included was that they have $70 \%$ or more of students eligible for FRPL, placing them in the mid-high to high poverty category.

Table 4

National Public School Poverty Categories

\begin{tabular}{|c|c|}
\hline Poverty Category of Public Schools & $\%$ of Students Eligible for FRPL \\
\hline High poverty & $>75 \%$ Students \\
\hline Mid-high poverty & $51-75 \%$ Students \\
\hline Mid-low Poverty & $26-50 \%$ Students \\
\hline Low-Poverty & $<25 \%$ Students \\
\hline
\end{tabular}


Title I-A is the part of ESEA that provides federal funds to local educational agencies (LEAs) and schools with high numbers or high percentages of children from low-income families, with the intent to ensure that all children meet challenging state academic standards; funds are currently allocated through statutory formulas that are based primarily on census poverty estimates and the cost of education in each state (USDE, 2013). Each school district in Oregon has the option of choosing what rate of poverty (FRPL) is used to determine that a school is eligible for Title I status and funding (ODE, n.d.a.), which may result in a wider range of poverty within Title I schools than in other states.

The schools identified for this study represented a purposive sample (Miles et al., 2014) as they were drawn from a list of Oregon K-5 Title I elementary schools identified by ODE in 2012, 2013, and or 2014 as Model schools under the Oregon ESEA waiver. Model schools are defined as high poverty schools that are rated in the top 5\% (approximately) of Title I Schools in the state based on the new rating formula (ODE 2012, 2013).

ODE identified a total of 28 different K-5 Title I elementary schools as Model schools in the three years since the ESEA waiver was approved (ODE 2012, 2013, 2014). Model schools included schools from every level of school, pre-k through $12^{\text {th }}$ grade, as well as schools from each of the NCES-identified school locales throughout Oregon (city, suburb, town and rural). Thirty Oregon Title I schools were identified as Model schools in 2012. While in 201326 schools were on the list, 12 schools that were also identified in 2012 were still on the list and 14 schools were newly identified. The other 18 schools 
that were identified as Model schools in 2012 were not on the list in 2013. In 2014, the list of 28 Model schools included 13 schools also identified in 2013.

Schools and students in Oregon K-5 schools. The number of schools and students in both non-Title I and Title I K-5 schools in Oregon Model schools exist within the larger context of K-5 non-Title I and K-5 Title I elementary schools in Oregon. The researcher used a funneling sampling sequence suggested by Erickson (1986), shown in Figure 10, to show representation of the sample schools in the context of K-5 elementary schools in Oregon.

Figure 10. Funneling Sampling Sequence

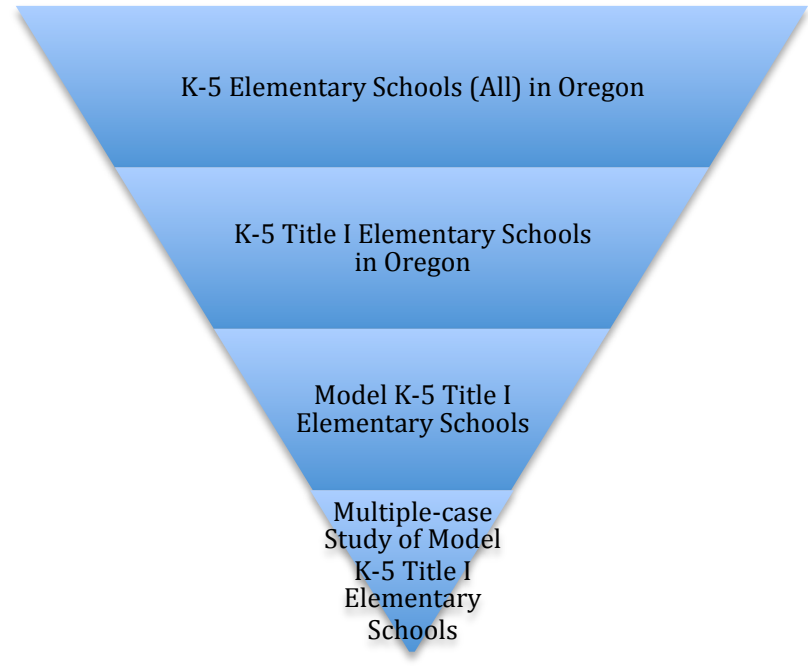

Figure 10. Funneling sampling sequence used to situate the sample schools in the overall context of K-5 elementary schools in Oregon. Adapted from Erickson, 1986.

The NCES database (2013) listed data for the years 2010-2011 and 2011-2012 relative to Oregon K-5 elementary schools. The researcher used spreadsheets downloaded from the NCES database (2013) to identify (a) all public K-5 elementary schools in Oregon, (b) how many of the schools qualified as Title I schools, (c) how many students 
were enrolled the schools, and (d) how many students in the schools were eligible for FLRP. Table 5 shows that out of 427 K-5 elementary schools, 310 of the schools were Title I schools. Based on the number of students enrolled in Title I schools out of the number of students enrolled in K-5 Elementary Schools (All), the percentage of students enrolled in K-5 Title I schools in Oregon is $74 \%$.

Table 5

Oregon K-5 (All) and K-5 Title I Elementary School Enrollment

\begin{tabular}{lcccc}
\hline \# of Schools & \# of Students & $\begin{array}{c}\text { \# of Students } \\
\text { Free/Reduced } \\
\text { Lunch }\end{array}$ & $\begin{array}{c}\% \text { of Students } \\
\text { Free/Reduced } \\
\text { Lunch }\end{array}$ \\
\hline K-5 Elementary & 427 & 166,644 & 93,516 & $56 \%$
\end{tabular}

Schools (All)

$\begin{array}{llll}\text { K-5 Title I } & 310 & 122,713 & 80,770\end{array}$

Schools

Source: NCES database (2013).

Schools and students in Oregon K-5 schools by geographical locales. Public K-5 elementary schools in Oregon range in size based on numbers of students enrolled and are situated in different geographical locales as defined by NCES (2013). The NCES data revealed that the greatest number of all K-5 elementary schools and students (nonTitle I and Title I) are found in cities, while the greatest number of Title I schools and students are located in towns, as displayed in Table 6. 
Leadership Practices

Table 6

Oregon K-5 (All) and K-5 Title I Elementary Schools and Students by Locale

\begin{tabular}{|c|c|c|c|c|c|}
\hline Descriptor & $\begin{array}{c}\text { Definitio } \\
\mathrm{n}\end{array}$ & $\begin{array}{l}\text { \# and \% } \\
\text { of Oregon } \\
\text { K-5 } \\
\text { Elementary } \\
\text { Schools } \\
\text { (All) }\end{array}$ & $\begin{array}{l}\# \text { and } \% \text { of } \\
\text { Oregon } \\
\text { K-5 } \\
\text { Elementary } \\
\text { Students } \\
\text { (All) }\end{array}$ & $\begin{array}{c}\# \text { and } \% \text { of } \\
\text { Oregon Title I } \\
\text { K-5 } \\
\text { Elementary } \\
\text { Schools }\end{array}$ & $\begin{array}{c}\text { \# and } \% \text { of } \\
\text { Oregon } \\
\text { K-5 Elementary } \\
\text { Students in Title } \\
\text { I Schools }\end{array}$ \\
\hline $\begin{array}{l}\text { City } \\
\text { Large, Mid- } \\
\text { sized } \\
\text { or Small }\end{array}$ & $\begin{array}{l}\text { Territory } \\
\text { inside an } \\
\text { urbanized } \\
\text { area and } \\
\text { inside a } \\
\text { principal } \\
\text { city }\end{array}$ & $\begin{array}{c}129 \\
(30 \%)\end{array}$ & $\begin{array}{l}54,474 \\
(33 \%)\end{array}$ & $\begin{array}{c}76 \\
(25 \%)\end{array}$ & $\begin{array}{r}32,875 \\
(27 \%)\end{array}$ \\
\hline $\begin{array}{l}\text { Suburb } \\
\text { Large, Mid- } \\
\text { sized } \\
\text { or small }\end{array}$ & $\begin{array}{l}\text { Territory } \\
\text { outside a } \\
\text { principal } \\
\text { city and } \\
\text { inside an } \\
\text { urbanized } \\
\text { area }\end{array}$ & $\begin{array}{c}93 \\
(22 \%)\end{array}$ & $\begin{array}{c}42,330 \\
(25 \%)\end{array}$ & $\begin{array}{c}64 \\
(21 \%)\end{array}$ & $\begin{array}{c}29,550 \\
(24 \%)\end{array}$ \\
\hline $\begin{array}{l}\text { Town } \\
\text { Distant, } \\
\text { Fringe } \\
\text { or Remote }\end{array}$ & $\begin{array}{l}\text { Territory } \\
\text { inside an } \\
\text { urban } \\
\text { cluster }\end{array}$ & $\begin{array}{c}126 \\
(30 \%)\end{array}$ & $\begin{array}{l}48,838 \\
(29 \%)\end{array}$ & $\begin{array}{c}113 \\
(36 \%)\end{array}$ & $\begin{array}{l}43,927 \\
(36 \%)\end{array}$ \\
\hline $\begin{array}{l}\text { Rural } \\
\text { Distant, } \\
\text { Fringe } \\
\text { or Remote }\end{array}$ & $\begin{array}{l}\text { Census- } \\
\text { defined } \\
\text { rural } \\
\text { territory }\end{array}$ & $\begin{array}{c}79 \\
(18 \%)\end{array}$ & $\begin{array}{l}21,002 \\
(13 \%)\end{array}$ & $\begin{array}{c}57 \\
(18 \%)\end{array}$ & $\begin{array}{l}16,361 \\
(13 \%)\end{array}$ \\
\hline
\end{tabular}

Source: NCES database (2013).

Number of schools and students in Oregon K-5 schools by school size. For

purposes of this study the researcher identified K-5 elementary schools in Oregon as small, medium or large, based on student enrollment. School size was a statistic of interest to the researcher given that state general fund resources are allocated to Oregon districts primarily based on student enrollment (ODE, n.d.a.). The decision to classify schools as small, medium, or large, as shown in Table 7, served three purposes: 
1. The researcher was able to consider representativeness of the schools in the study to the larger population of K-5 elementary schools in Oregon.

2. The researcher was able to consider school size as a possible factor in principal leadership practices in high poverty K-5 Model schools in Oregon effective in improving growth in academic achievement of children.

3. School size provided a context for the researcher to better understand resource allocation for the schools.

Table 7

Oregon K-5 (All) and K-5 Title I Schools and Students by Size

\begin{tabular}{lccccc}
\hline Descriptor & Definition & $\begin{array}{c}\text { \# of Oregon } \\
\text { K-5 } \\
\text { Elementary } \\
\text { Schools (All) }\end{array}$ & $\begin{array}{c}\text { \% of Oregon } \\
\text { K-5 } \\
\text { Elementary } \\
\text { Students } \\
\text { (All) }\end{array}$ & $\begin{array}{c}\text { \# of Oregon } \\
\text { Title I } \\
\text { K-5 } \\
\text { Elementary } \\
\text { Schools }\end{array}$ & $\begin{array}{c}\text { of Oregon } \\
\text { K-5 } \\
\text { Elementary } \\
\text { Students in } \\
\text { Title I } \\
\text { Schools }\end{array}$ \\
\hline Small & $<250$ Students & 75 & $7 \%$ & 44 & $6 \%$ \\
Medium & $\begin{array}{l}250-499 \\
\text { Students }\end{array}$ & 249 & $57 \%$ & 196 & $61 \%$ \\
Large & $500+$ Students & 103 & $36 \%$ & 70 & $33 \%$ \\
\hline
\end{tabular}

Source: NCES database, 2013.

Oregon school report card rating levels. Under the ESEA waiver, ratings are given to schools each year through an annual report card (ODE, 2012). The ratings are based on measures that include academic achievement, academic growth and subgroup growth for elementary and middle schools, with graduation rates and subgroup graduation rates calculated in addition for high schools. Schools receive an overall rating of Level 1 through 5, displayed in Table 8, based on how well they are doing in each of these areas (ODE, 2012, 2013). 
Table 8

Oregon School Report Card Rating Levels

\begin{tabular}{|l|l|}
\hline \multicolumn{1}{|c|}{ LEVEL } & \multicolumn{1}{|c|}{ STATUS } \\
\hline $\begin{array}{l}\text { Level 1 = Falls into the bottom 5\% of } \\
\text { schools }\end{array}$ & Below Average \\
\hline $\begin{array}{l}\text { Level 2 } \\
\text { schools }\end{array}$ & Falls between 5\% and 15\% of \\
\hline $\begin{array}{l}\text { Level 3 }=\text { Falls between 15\% and 44\% of } \\
\text { schools }\end{array}$ & Below Average \\
\hline $\begin{array}{l}\text { Level 4 = Falls between 44\% and 90\% of } \\
\text { schools }\end{array}$ & Average to Above Average \\
\hline Level 5 = Falls into the top 10\% of schools & Above Average \\
\hline
\end{tabular}

In addition, the new accountability system provides new designations for Title 1 schools that receive federal funds to help meet the needs of at-risk and low-income students (Oregon School Boards Association, 2013). Priority Schools are those in the bottom 5\% of all Title I schools based on Oregon's new report card rating formula. Focus Schools are in the bottom $15 \%$ of all Title I schools, and Reward Schools (identified as Model schools in the Oregon Waiver) are in the top 5\% of all Title I schools. Priority and Focus Schools identified in 2012 will retain that status through the 2015-16 school year, while Model schools have the potential to change each year based on overall achievement and growth of schools within the state (ODE, 2012, 2013).

Schools. To identify the potential Oregon K-5 Title 1 Elementary Schools included in the study, the researcher conducted a search of the ODE public web page in August 2014. The search revealed a report identifying Priority, Focus, and Model schools as required under the ESEA waiver (ODE, 2012). The researcher first compiled a list of all Oregon schools identified as Model schools in 2012 and 2013, and then added to the list when the Priority, Focus, and Model school list was published by ODE in October 
2014. The researcher referenced the NCES website and identified the locale code, type of school, size of school, and percentage of students receiving free or reduced meals. This information was added to the list with names of the districts and names of Model schools. The researcher then created a list of Oregon Model schools based on the following characteristics:

- District Name;

- School Name;

- Locale Code;

- Type of School (grade levels taught);

- $\quad$ Size of School; and

- $\quad$ Percentage of FRPL.

Of these schools, ten schools were identified by NCES (2013) as having rates of poverty greater than $70 \%$, based on FRPL participation. From that population, superintendents of seven schools that met all of the established criteria were contacted for permission to conduct the study. The superintendents of three districts responded to the researcher's requests and granted permission for the researcher to contact the principals of their respective Model schools. The researcher contacted the principals of the three schools by email and by phone and they all agreed to participate in the study. The three Model schools identified for the study represented 100\% of Oregon K-5 Title I schools relative to size of school, and $40 \%$ of students in Oregon K-5 Title I schools relative to geographical locale. For purposes of confidentiality, the schools were not named but were identified as Atlas Elementary, Brighton Elementary, and Camden Elementary. 
Demographics for each of the schools are displayed in Table 9.

Table 9

Participating Schools

\begin{tabular}{|l|c|c|c|c|}
\hline $\begin{array}{l}\text { Model K-5 Title I } \\
\text { Elementary School }\end{array}$ & $\begin{array}{c}\text { Size of } \\
\text { School }\end{array}$ & $\begin{array}{c}\text { Locale of } \\
\text { School }\end{array}$ & FRPL \% & $\begin{array}{c}\text { Year Identified as } \\
\text { a Model School }\end{array}$ \\
\hline Atlas Elementary & $\begin{array}{c}\text { Small } \\
(<250)\end{array}$ & Rural (Fringe) & $74 \%$ & 2013 \\
\hline $\begin{array}{l}\text { Brighton } \\
\text { Elementary }\end{array}$ & $\begin{array}{c}\text { Medium } \\
(250-499)\end{array}$ & City (Small) & $71 \%$ & $2013 / 2014$ \\
\hline $\begin{array}{l}\text { Camden } \\
\text { Elementary }\end{array}$ & $\begin{array}{c}\text { Large } \\
(>500)\end{array}$ & City (Large) & $76 \%$ & 2014 \\
\hline
\end{tabular}

Sources: NCES database (2013) and ODE (n.d.a.)

\section{Procedures}

The researcher used specific methods, both qualitative and quantitative, for collecting data (Miles et al., 2014). The most important underlying construct of this study was principal leadership practices in high poverty K-5 Model schools in Oregon effective in improving growth in academic achievement; therefore, prior instrumentation reflected this factor while still allowing the researcher to explore the construct in the context of each school (Miles et al., 2014). The argument for a lot of prior instrumentation was supported by the fact that the researcher was conducting a multiple-case study that could lead to an overload of data, thereby compromising "the efficiency and power of the analysis" (Miles et al., 2014, p. 39).

The methodology the researcher identified was a multi-method design with quantitative data included (Miles et al., 2014). Figure 11 represents the convergence of multiple sources of evidence identified in this study to provide confidence to the researcher that the study rendered the construct accurately (Yin, 2014). 
Figure 11. Convergence Model-Multiple Sources of Evidence

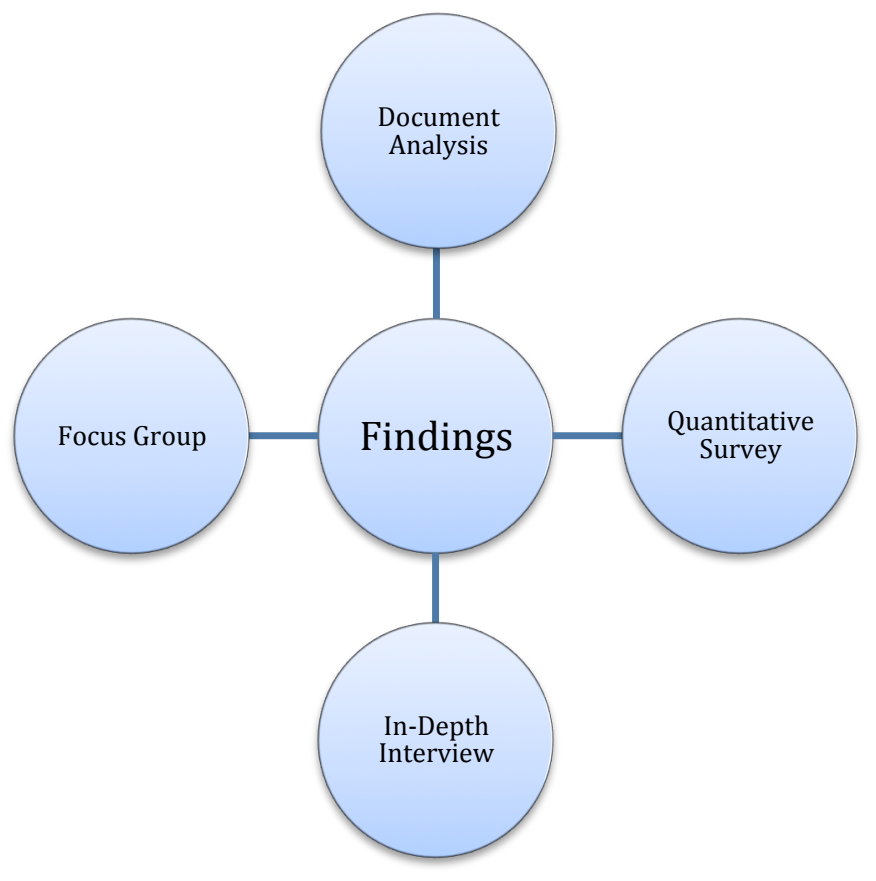

Figure 11. Convergence model of multiple methods of evidence (Yin, 2014).

Interviews. As described by Bogden and Biklin (1998) the interview enables the researcher to develop insights into participants' interpretations or perspectives of some piece of the world. The researcher conducted in-depth interviews with the principals of the three schools to collect descriptive data in the participant's own words (Bodgen \& Biklen, 1998). The interview protocol (Appendix D) followed a line of inquiry that explored each principal's leadership practices in the context of their leadership of a high poverty K-5 Model school in Oregon effective in improving growth in academic achievement of children. Interview questions were modified from research conducted by Lyman and Villani (2008) and were used with permission of the author. The interviews were guided by questions similar to those used in the focus groups with teachers and parents (Appendix E). The interviews took place in the principals' offices with the 
researcher taking verbatim notes, asking clarifying questions as needed, and recording the interviews on audiotape.

Focus Groups. The researcher facilitated short, one-hour focus groups with teachers and parents at each school. Focus groups are group interviews that are structured a particular way and have specific, well-defined goals (Bogdan \& Biklen, 1998, p. 100). They can provide the researcher with useful insights into the world of the subjects being studied (Bogdan \& Biklen, 1998). In a mixed-methods study, this qualitative method helps to ensure that the "study is robust, valid, and reliable" (Lunenburg \& Irby, 2008, p. 104). The focus group protocol (Appendix E) built upon the teacher survey findings, enabling the researcher to triangulate the data and strengthen the construct validity of the study (Yin, 2014). Focus group questions were modified from research conducted by Lyman and Villani (2008) and were used with permission of the author.

Quantitative Survey. A quantitative survey allows the researcher to obtain numeric descriptions of trends, attitudes, or opinions of a population (Creswell, 2003). There have been numerous investigations of leadership behaviors that allow principals to create positive school cultures and learning environments (Bulach, Boothe, \& Pickett, 2006). Table 10 shows the results of an online search for survey instruments for assessing principal leadership, which revealed a wide array of instruments and purposes. 
Table 10

Educational Research Survey Instruments

\begin{tabular}{ll}
\hline \multicolumn{1}{c}{ Author(s) } & \multicolumn{1}{c}{ Survey Instruments } \\
\hline Bass and Avolio, 2004 & Multifactor Leadership Questionnaire (MLQ) \\
Gruenert and Valentine, n.d.a. & School Culture Survey (SCS) \\
Hallinger, n.d.a. & $\begin{array}{l}\text { Principal Instructional Management Rating Scale } \\
\text { (PIMRS) }\end{array}$ \\
Jantzi and Leithwood, 1996 & $\begin{array}{l}\text { Principal Leadership Questionnaire (PLQ) } \\
\text { Marzano, Waters, and McNulty, 2005 }\end{array}$ \\
University of Washington \& Seattle Public & Staff Assessment Questionnaire (SAQ) \\
Schools, n.d.a. & \\
Valentine and Bowman, 1988 & Audit of Principal Effectiveness \\
\hline
\end{tabular}

The researcher used the Principal Leadership Questionnaire (PLQ) as adapted from Jantzi and Leithwood (1996) by the Middle Level Leadership Center (MLLC) (n.d.a.) with permission from the authors. This survey instrument was used in previous research, enhancing the potential to increase the validity and reliability of the findings and "to improve explanations or predictions, and to make recommendations about practice” (Miles et al., 2014, p. 39). As pointed out by Jantzi and Leithwood (1999), a transformational approach to leadership basically aims to promote capacity development and higher levels of personal commitment to organizational goals on the part of leaders' colleagues. Ryan (2007) used the PLQ in his doctoral research and concluded:

Being mindful of how daily leadership decisions not only fit within the transformational leadership constructs, but more importantly, how they affect good classroom teaching practices, should help principals plan and initiate strategies and programs that create a campus atmosphere more conducive to comprehensive learning (p. i). 
The PLQ (Appendix A) was administered to the principals and the teachers at each school to gather quantitative data regarding the principal's transformational leadership characteristics. The PLQ consisted of 24 Likert-type questions with response options: strongly disagree, disagree, slightly disagree, slightly agree, agree, and strongly agree. This instrument yielded data representative of the characteristics identified in the literature review as principal leadership practices that positively impact student achievement. The factors of the PLQ with their corresponding internal consistency coefficients are listed in Table 11.

\section{Table 11}

Factors related to Principal Transformational Leadership Characteristics.

\begin{tabular}{|c|c|c|}
\hline PLQ Factor & Description & Reliability Coefficient \\
\hline $\begin{array}{l}\text { Identifying and } \\
\text { articulating a vision }\end{array}$ & $\begin{array}{l}\text { Behavior on the part of the principal aimed at } \\
\text { identifying new opportunities for his or her } \\
\text { school staff members and developing, } \\
\text { articulating, and inspiring others with his or her } \\
\text { vision of the future }\end{array}$ & Chronbach's alpha of .88 \\
\hline $\begin{array}{l}\text { Providing an } \\
\text { appropriate model }\end{array}$ & $\begin{array}{l}\text { Behavior on the part of the principal that sets an } \\
\text { example for the school staff members to follow } \\
\text { consistent with the values the principal espouses }\end{array}$ & Chronbach's alpha of .86 \\
\hline $\begin{array}{l}\text { Fostering the } \\
\text { acceptance of group } \\
\text { goals }\end{array}$ & $\begin{array}{l}\text { Behavior on the part of the principal aimed at } \\
\text { promoting cooperation among school staff } \\
\text { members and assisting them to work together } \\
\text { toward common goals }\end{array}$ & Chronbach's alpha of .80 \\
\hline $\begin{array}{l}\text { Providing } \\
\text { individualized support }\end{array}$ & $\begin{array}{l}\text { Behavior on the part of the principal that } \\
\text { indicates respect for school staff members and } \\
\text { concern about their personal feelings and needs. }\end{array}$ & Chronbach's alpha of .82 \\
\hline $\begin{array}{l}\text { Providing intellectual } \\
\text { stimulation }\end{array}$ & $\begin{array}{l}\text { Behavior on the part of the principal that } \\
\text { challenges school staff members to reexamine } \\
\text { some of the assumptions about their work and } \\
\text { rethink how it can be performed }\end{array}$ & Chronbach's alpha of .77 \\
\hline $\begin{array}{l}\text { Holding high } \\
\text { performance } \\
\text { expectations }\end{array}$ & $\begin{array}{l}\text { Behavior that demonstrates the principal's } \\
\text { expectations for excellence, quality, and high } \\
\text { performance on the part of the school staff }\end{array}$ & Chronbach's alpha of .73 \\
\hline
\end{tabular}

Source: Middle Level Leadership Center, 2009 
The survey was available in an online format using SurveyMonkey. Data collected online was automatically entered into an Excel spreadsheet. Survey responses provided categorical and quantitative data. Statistical analysis of the quantitative data was completed using Statistics Solutions Pro version v1.15.02.16 (2014). Statistical tests for mean, maximum score and standard deviation were run to describe any spread that exists within the distributions (Fraenkel \& Wallen, 1996). Tests for correlation were run to examine the relationship among the variables (Fraenkel \& Wallen, 1996). Just as superintendents who have research departments that do the technical side of data analysis with the superintendent directing the questions that need to be answered by data analysis, the researcher enlisted the services of Statistics Solutions (2014) to conduct the statistical tests.

Open-ended questions. The researcher added three open-ended questions to the survey to elicit further information relative to the research questions. Open-ended questions were asked of the principal and teachers regarding their perceptions of principal leadership practices in these high poverty K-5 Model schools in Oregon effective in improving growth in academic achievement of children.

Document review. This study included a review of public documents including school and district web page information, school improvement plans, meeting agendas, professional development plans, state report cards, articles in local and regional newspapers, school newsletters, and a web search for other information. Yin (2014) describes documents as evidence that allows the researcher to access specific details for corroborating information from other sources and making inferences that can serve as 
clues for further investigation. Document analysis in qualitative research is a technique related to the "critique or analysis of documents for significance, meaning and relevance within a particular context and phenomenon" (Lunenburg \& Irby, 2014, p. 94).

\section{Institutional Review Board (IRB)}

In accordance with Portland State University (PSU) and the Graduate School of Education Doctoral Dissertation guidelines, the researcher completed all compliance features of the IRB. The researcher submitted required documentary evidence of all data collection procedures and protocols for assuring the rights and welfare of all subjects participating in the study to the PSU Human Subjects Research Review Committee (HSRRC). HSRRC was satisfied that provisions for protecting the rights and welfare of all subjects participating in the research were adequate, and the project is approved. No data collection began until the approval process was complete. The researcher conducted the research according to the plans and protocols submitted to the HSRRC, which approved all procedures, protocols, survey instruments, consent forms or cover letters.

\section{Data Collection}

Data was collected in this study using both qualitative and quantitative methods, beginning in summer 2014 and continuing through winter 2015. Qualitative data was collected in the initial and last stage of this study through a review of public documents including school and district web page information, school improvement plans, meeting agendas, professional development plans, state report cards, articles in local and regional newspapers, school newsletters, and a web search for other information (Yin, 2014). 
The researcher followed a traditional model of research, differentiating the researcher from the participants (Miles et al., 2014). Participants in the study included a) the principal of each school, b) teachers in each of the schools, and c) parents/guardians of students attending the schools. All individuals participating in the study were assured that the researcher would take steps to protect their identities throughout the process of data collection, data analyses, and report writing (Bogdan \& Biklen, 1998). Informed consent (see Appendix B) was provided for all subjects and signed approval forms were obtained from all participants. Participants were provided study products to provide member checks on "the accuracy of descriptions, explanations, and interpretations" (Miles et al., 2014). The researcher collected and maintained all data on a personal laptop computer, an external hard drive, and in paper files in a home office.

Interview Respondents. The researcher met with each of the three principals of the schools identified for the study after contacting them by phone and email and arranging for meetings that met their schedules. The principals received a copy of the interview protocol in advance of the interview by email. The researcher and principals met at the schools in the principals' offices for the interview. The principal each granted permission for the researcher to record the interview on a digital recorder.

The researcher reviewed the purpose of the study, the procedures and the timelines, and described the process of informed consent (Appendix C.1). The three principals signed the informed consent form before the interviews started. The researcher later made a photocopy of the signed informed consent forms, kept a copy for the research files and presented a copy to the principal at a later meeting. The researcher 
provided the principals with contact information in case there was any reason to contact the researcher at any time during the study.

Quantitative Survey Respondents. The researcher attended a staff meeting at each of the schools to review the purpose of the study and to describe the study activities to the teachers. The principals left the meetings before the description of the study was provided to the teachers. The researcher reviewed the reason for informed consent (Appendix C.2) and the practices that would be taken to protect teachers choosing to participate in the survey. Teachers were assured that there would be no negative outcomes for them if they chose not to participate. In addition to getting signed permission forms from the teachers, the researcher collected email addresses in order to send the SurveyMonkey survey link to the emails of the teachers' choice. Teachers were told the timeline for when the survey link would be sent to them. The researcher provided each teacher at the meeting with contact information in case there was any reason to contact the researcher at any time during the study. The researcher provided light refreshments to the teachers at the meetings.

Focus Group Respondents. Teachers were informed of the opportunity to participate in a focus group during the staff meeting attended by the researcher. Parents were communicated about the opportunity to participate in a focus group through a flyer provided by the researcher and through communications from the principals.

Teacher Focus Group Respondents. The researcher met with teachers at the three schools on schedules and locations decided upon by the teachers. All three groups wanted to meet during their lunch times; the researcher provided a light meal for each of the 
teacher groups. Teachers were provided a copy of the focus group protocol (Appendix E.1). The researcher reminded the teachers of the assurances of protection afforded to them by the informed consent. The researcher made a copy of the forms signed at an earlier meeting and provided each teacher participant with their copy. The teachers granted permission for the researcher to digitally record the focus group. After reviewing the procedures and answering any questions presented by the teachers, the interviewer conducted the focus group. Each focus group took approximately one hour to complete. The principal was not present during the focus group.

Parent/Guardian Focus Group Respondents. The researcher met with parents/guardian at the three schools on schedules and locations decided upon by the parents. One of the groups met in the morning before school and two of the groups met in the evening. All of the focus groups took place in the schools. Parents were provided a full description of the study purpose and activities. The researcher reviewed the letter of informed consent with each group. Parent/guardian signatures on the informed consent letters were obtained prior to the beginning of the focus group. Parents/guardians at each site gave permission for the researcher to digitally record the focus group. After reviewing the procedures and answering any questions presented by the parents, the interviewer conducted the focus group. Each focus group took approximately one hour to complete. The participants were provided information about how to contact the researcher for further questions or to withdraw from the study. The principal was not present at the meetings. 


\section{Data Analysis}

This study to investigate principal leadership practices in high poverty K-5 Model schools in Oregon effective in improving growth in academic achievement of children used qualitative and quantitative research methods to collect data relevant to the research questions. The researcher employed a method of analyzing data concurrently with data collection (Miles et al., 2014). The inductive mode of qualitative research methods provided an emerging approach to the data for best understanding of the research problem (Creswell, 2003). Qualitative information was compiled in the form of documents or other print or digital artifacts, handwritten or typed field notes, and audio recordings of interviews and focus groups (Miles et al., 2014). The deductive mode of the quantitative survey provided for descriptive and inferential analysis of data that the researcher used to help explore the emerging qualitative themes (Creswell, 2003).

Creswell (2003) describes data analysis and interpretation in a concurrent study as combining the quantitative and qualitative data to seek convergence among the results. Quantifying the qualitative data enables the researcher to compare quantitative results with the qualitative data (Creswell, 2003). Steps in the process of qualitative data analysis as suggested by Creswell (2003) include (a) organizing and preparing the data for analysis, (b) gaining a general sense of the information by reading through all of the data, (c) coding the material into categories, using a descriptive term to label the topics, and (d) using the coding process "to generate a description of the setting or people as well as categories or themes for analysis" (p. 193). Assuring trustworthiness of the research compels the researcher to take steps to check for accuracy and validity of the study 
findings. Creswell's (2003) recommendations for checking accuracy include (a) triangulating different data sources of information in order to build a coherent rationale for themes, (b) using member checks to determine the accuracy of the qualitative findings, (c) using rich description to convey the findings, and (d) clarifying the bias the researcher brings to the study.

\section{Researcher Bias and Assumptions}

The researcher's previous experience as a public high school principal in schools with high rates of poverty created the potential for the "...prejudices and attitudes of the researcher to bias the data" (Bogdan \& Biklin, 1998, p. 33). Miles et al., (2014) describe personal bias as a personal agenda that may skew the researcher's "ability to represent and present fieldwork and data analysis in a trustworthy manner" (p. 294). The researcher was also aware that personal history of family poverty could increase sensitivity to intentional or unintentional practices that disadvantage poor children in schools. To address this potential, the researcher used methods meant to provide objectivity in the process of collecting and analyzing data, including the strategies for testing and confirming findings listed in Table 12 (Miles et al., 2014).

Table 12

Strategies for Testing and Confirming Findings in Qualitative Research

\begin{tabular}{|l|l|}
\hline TACTIC & PURPOSE \\
\hline $\begin{array}{l}\text { Check for Representativeness } \\
\text { Check for Researcher Effects } \\
\text { Triangulate data/ Weight the Evidence }\end{array}$ & Assess Quality of Data \\
\hline $\begin{array}{l}\text { Check the Meaning of Outliers/ Follow up Surprises } \\
\text { Look for Negative Evidence }\end{array}$ & Test Conclusions about a Pattern \\
\hline $\begin{array}{l}\text { Make If-Then Tests } \\
\text { Rule out Spurious Relations/ Check out Rival Explanations } \\
\text { Get Feedback from Participants }\end{array}$ & Test Explanations \\
\hline
\end{tabular}

Source: Miles et al., 2014. 
Knowing how to conduct research ethically assisted the researcher in avoiding bias (Yin, 2014). The researcher had knowledge of public schools in Oregon yet had no power or influence over the participants in the study, whether principal, teachers or parents, and was not known in the identified schools. Participants were afforded respect as individuals and as subjects within the context of a school. Informed consent required that the nature and the purpose of the research study be clearly explained and participants were informed of their rights throughout the study (Miles et al., 2014). In addition to methodology that helped provide the researcher with objectivity, the purpose of this study was to generate understanding of principal leadership practices that accelerate growth in academic achievement of children in high poverty elementary schools, and the researcher sought only "to add to the knowledge, not to pass judgment on a setting" (Bogdan \& Biklin, 1998, p. 34).

Assumptions regarding the nature, analysis, and interpretation of the data (Lunenburg \& Irby, 2008) made in this study included (a) principals and other participants would answer interview, survey, and focus group questions truthfully, (b) the schools participating in this study represented the identified populations, and (c) the public documents available to the researcher were an accurate portrayal of the schools in the study. 


\section{CHAPTER 4}

\section{Analysis of Results}

\section{Introduction}

Chapter 4 presents analysis of the data related to the central research question for this study: What principal leadership practices can be observed in high poverty K-5 Model schools that have improved growth in academic achievement of children attending these schools? Related questions were designed to narrow the focus the study while still leaving open the questioning (Creswell, 2003). The related questions for this study were as follows:

1. How do principal practices support programs improving growth in academic achievement of children in high poverty K-5 Model schools?

2. How do principals allocate school and district resources to support programs and instruction improving growth in academic achievement of children in high poverty K5 Model schools?

3. How do principals share leadership in high poverty K-5 Model schools where growth in academic achievement of children is improved?

4. What other practices do principals put to use in high poverty K-5 Model schools that have improved academic achievement of children?

The study included collection and analysis of data from four sources in each of the three schools in the study: a) a principal interview; b) a quantitative survey with three open-ended questions administered to principals and teachers; c) two focus groups in each school comprised of teachers and parents; and d) a document review.

\section{Principal Interview Themes}

The researcher conducted a face-to-face interview with the principals of each of the three schools. The interviews were conducted in their offices. The following principal 
interview questions were modified from research conducted by Lyman and Villani (2008) and they were used with permission of the author.

1. What do you think educators need to do to assist children in poverty to succeed academically?

2. Share with me one success story without which any description of this school would be incomplete? (with a particular child, about learning, with a family, etc.)

3. What three words best describe your leadership? In what ways does your leadership support children's success in school?

4. What do you find to be the most challenging, or the hardest part about leading in a high poverty school?

5. What else do I need to consider about principal leadership practices or other factors that accelerate growth in academic achievement for children in this school?

The researcher compiled the responses from each question of the principal interview protocol individually, looking for patterns and trends in the response data in order “. . . to develop a coding system to organize data" (Bogdan \& Biklin, 1998, p. 171). Coding categories or themes were developed and the researcher pulled words and quotes from the data to test the usefulness of the categories (Bogdan \& Biklin, 1998). Common themes emerged through this process, allowing the researcher to complete an analysis and summary of the themes from the principal interviews.

Five common themes emerged from the principal interviews. The themes were 1) addressing biases and prejudices about poverty and its effects on children, 2) high expectations for students and teachers, 3) shared leadership, 4) positive support, and 5) personal characteristics. 


\section{Addressing biases regarding children living in poverty and academic}

achievement. The first theme was the importance of addressing obstacles and biases preventing children in poverty from accessing education. Addressing obstacles for children included meeting their basic needs. The principal in one school described this in response to Question 1:

Children adapt survival skills to hide their issues. The trick is to identify what their needs are. You have to use all your senses when you first meet them-do they have adequate or clean clothing, are they hungry, do they complete homework, what is their pattern of attendance? Then you can start to pull in the resources that will help get the basic needs met.

Another principal recognized that her own personal competitive drive to move each child forward in their learning sometimes required taking a step back in order to meet the basic needs of the child before teaching them reading and math.

In one school, the principal noted the importance of addressing obstacles that children living in poverty sometimes faced, confronting the personal biases she has about people in poverty. In response to Question 1, a principal at one of the schools stated:

The most important thing educators can do to help children succeed academically is to examine their own beliefs around children in poverty and examine their own roadblocks in the belief that all children can succeed.

One of the other principals conducted a book study with the staff using Jensen's Teaching with poverty in mind: What being poor does to kids' brains and what schools can do about it (2009) as a way of helping them better understand the students in their classrooms who were living in poverty.

High Expectations. A common theme among all three principals was high expectations for children. One principal reflected that the number one thing educators can 
do to assist children in poverty to succeed academically is to have high expectations. Another principal shared that in addition to having high expectations, it is important to communicate those expectations to children and to parents. In all three schools, the principals commented on having high expectations for themselves and for the teachers, in addition to the children. One principal, however, noted that a number of teachers in the school have no children of their own and that sometimes they can have expectations that are too high for some children that are experiencing particularly negative home situations.

Shared Leadership. The third major theme that emerged from the data was the importance of shared leadership. The first principal expressed the concept as intentionally finding as many ways as possible to share leadership with teachers. This includes working side-by-side with them in the classroom. This principal learns from others and believes that "collective action will find the answers." The second principal has a strong vision for the school and knows that building shared leadership is the how and why the really hard work of teaching children in a high poverty school is successful. The leadership style of the third principal is "looking for opportunities for all to lead together." This creates an environment in which all have the ability to vent, discuss, share problems, and be part of the solutions.

Positive support. The fourth common theme all principals identified was providing positive support to teachers and the rest of the staff, and maintaining morale. One part of that support is showing appreciation for the work of the teachers and classified staff. A principal in one school described support in the following way. 
This staff is amazing. It is a team. Classified staff gets just as much credit as anyone else. The custodian is amazing and does things to support the kids. When you are a building leader, have a vision, and have a staff that supports you with it, things are so much easier. I don't micromanage but I oversee everything. The teacher's goals are my goals.

A second principal relates the support to having been a teacher for a long time and has a goal to keep that lens. This lens helps the principal support teachers by prioritizing between supporting district initiatives and providing the support for teachers to face everything they are already doing. This principal and the third principal used the same phrase in describing their support for teachers-helping teachers let go of things that are not in their control. All three principals shared that they are transparent about the issues that face the teachers working with children in poverty, and they also celebrate the successes, whether large or small.

Related to support for teachers and staff was ensuring that morale stayed high. All of the principals acknowledged that keeping staff morale up is one of the most challenging parts of leading a high poverty school. The high poverty rate in each of the school communities, due to unemployment, results in housing issues and homelessness that leads to the highly transient nature of families and children in all three schools in the study. High student mobility represents a constant "one step forward, two steps back" reality for teachers as they work with students to fill the gaps in their learning, only to see them leave the school. In addition, financial resources are limited in each school and parent involvement is low. The principal in one school summarized her support in this way:

I am constantly looking for moments with staff to keep the morale up and keep things for students moving forward. Sometimes it is just little acknowledgements 
that they are valued--I wish I had a pool of money to buy every staff member a school sweatshirt. Because my job is $60 / 40$ (60\% principal, $40 \%$ district work), I am not always here. If they are having a tough day, not being here represents a lost moment to jump in and support them.

Personal Attributes of the Principal. The principals of these three schools are all women. Two of them have been in the job for more than five years and one is in the first year as a principal. Two of the principals lived in poverty themselves, albeit situational and not generational poverty, and grew up in the neighborhoods and school district where they currently work, while the other grew up in an Oregon community similar in demographics to the school in which she now works. This theme-personal attributes of the principal — emerged during the interviews. Some of the responses were later echoed by teachers and parents.

One principal described herself as driven, as evidenced by the investment of her own family time to the school, and has a "never stop, never give up" attitude to keep the school going strong. Another described herself as tenacious and unwavering, with strong convictions about never giving up when you believe that things can change. The third principal stated

I am highly competitive-I love any type of competition. I compete with myself first, not against other schools but to keep my school first.

Other attributes that emerged from the data relative to this theme included being 1) reflective, 2) resourceful, 3) transparent in decision-making, 4) a good listener, and 5) visible to teachers, students and families. 


\section{Focus Group Analysis}

The researcher compiled the answers from each question of the focus groups individually in order to determine trends and patterns within a particular field of inquiry. For example, all the responses for Question \#1 were coded at one time, analyzed together, and then summarized. The researcher used the comments to generate a thread of recurring themes and concepts using axial coding. Axial coding relies on inductive and deductive coding (Strauss \& Corbin, 1990). After identifying the concepts and determining relationships between them and the context of the concept, the researcher used selective analysis to identify specific comments that seemed to belong together to identify related concepts. Next, the researcher looked for relationships between the categories and the respondents who identified the categories. The researcher then wrote a summary of the findings for each question. After completing an analysis and summary of each question, the researcher wrote an analysis and summary of all themes of the focus groups.

Focus Group Demographic Data. The researcher conducted six focus groups in three schools with a total of 66 participants. The participants included $4.5 \%(n=3)$ respondents of color and $95.5 \%(n=63)$ White respondents. Camden Elementary had the highest number of participants and Atlas Elementary the smallest. The number of respondents corresponded closely with the size of school, as Camden Elementary was the largest school, Brighton Elementary was the medium-sized school, and Atlas Elementary was the small group in the study. Table 13 shows the characteristics of the focus group participants by school. 
Table 13

Focus Group Respondents by School

\begin{tabular}{|l|c|c|c|}
\hline \multicolumn{1}{|c|}{ School } & Total & Teachers & Parents/Guardians \\
\hline Atlas Elementary & 16 & 11 & 5 \\
\hline Brighton & 20 & 16 & 4 \\
Elementary & 30 & & \\
\hline $\begin{array}{l}\text { Camden Elementary } \\
\text { Total }\end{array}$ & $\begin{array}{c}66 \\
(100 \%)\end{array}$ & $\begin{array}{c}49 \\
(74 \%)\end{array}$ & 8 \\
\hline
\end{tabular}

Teacher Focus Group Analysis. The following questions were asked during the teacher focus groups at all three schools.

1. What do you think educators need to do to assist children in poverty to succeed academically?

2. Share with me one success story without which any description of this school would be incomplete? (with a particular child, about learning, with a family, etc.)

3. What three words best describe the principal's leadership? In what ways does his or her leadership support children's success in school?

4. What do you find to be the most challenging, or the hardest part about teaching in a high poverty school?

5. What else do I need to consider about principal leadership practices or other factors that accelerate growth in academic achievement for children in this school?

Five common themes emerged from the teacher focus group data. The themes were 1) meeting basic needs of students, 2) caring, 3) principal experience as an elementary teacher, 4) shared leadership, and 4) personal characteristics. 
Meeting basic needs of students. Teachers in one school acknowledged the importance of providing basic needs that children in poverty might not get at home, including meals, coats, toothbrushes, and shoes. Teachers in another school expressed the need for mental health services for both children and families, and the need for the school to provide family advocates and counseling services. In response to Question 1, a teacher in one school stated:

There is a need to accommodate basic needs before we can teach anything. They may be hungry, their clothing may be dirty, they may have head lice. We cannot take it for granted that parents know the children need to be bathed at night. We often provide alarm clocks to the children because they become responsible for getting themselves to school on time.

Caring. A strong sense of caring for children in high poverty schools by teachers and principals was a second theme revealed in the teacher focus groups. Teachers in two of the school expressed the importance of personalizing school for children, meaning that adults in the school know children well and know their struggles. A teacher in one of the schools expressed this concept in the following way.

Knowing students well means knowing them academically as well as personally. All of us have a strong ethic around knowing their academic abilities - we gather information about our students that allows us to appropriately group them, push them, and advocate for them. We have a firm belief that no matter where kids come from, they can learn and we will take them as far as we can.

Question 3 of the teacher focus group elicited words that teachers used to describe principal leadership practices at these three high poverty elementary schools where student achievement has been improved. Teacher responses revealed two themes in addition to those of addressing basic needs of children and caring. One theme was experience as an elementary teacher and the other theme was personal attributes. 
Principal Experience as an Elementary School Teacher. This theme was a factor identified in each of the teacher focus groups as important to their work in the classroom. A teacher in one of the schools described it in this way:

The current principal has been where we (teachers) are. The principal has so much background experience, having spent 25 years in the classroom. Having taught the new curriculum, the principal knows the pressures and the experience the principal brings is relevant and real.

A teacher in another school reflected on working over the years with five different principals with the current principal being the first one that comes from the elementary level.

Shared Leadership. Teachers in all three schools reacted to the researcher's focus group question, "What three words best describe the principal's leadership?" in almost identical ways.

A teacher in one school said "we are all leaders here." A teacher from a second school indicated the belief that in spite of poor leaders in the past, the staff always pulled things together for the students. Another teacher in that school described a sense of equality between the principal and teachers.

Personal Attributes of the Principal. Teachers in all three schools had descriptions of the principals' personal attributes that resulted in this being identified as a theme. One theme that emerged from the teacher focus groups was that principals in the three schools are each visible and hands-on. One teacher stated that the principal is supportive and gets "into the trenches" with teachers. In another school, teachers agreed that the principal doesn't ask anything of them that the principal isn't willing to do also. A teacher in another school described the principal as good at building on the strengths of 
the staff. The principal is a "doer" but doesn't take away from what the teachers can do. Teachers in two of the schools also described the principals as "driven," mirroring a word used by principals and parents in each of the schools.

Parent Focus Group Analysis. The parent focus group questions varied slightly from those asked in the principal interview and in the teacher focus group. Teachers were asked, "What do you find to be the most challenging, or the hardest part about working in a high poverty school?" and principals were asked, "What do you find to be the most challenging, or the hardest part about leading in a high poverty school?" Parents were asked the following questions:

1. What do you think educators need to do to assist children in poverty to succeed academically?

2. Share with me one success story without which any description of this school would be incomplete? (with a particular child, about learning, with a family, etc.)

3. What do you think educational leaders can do for children who live in poverty?

4. What three words best describe the principal's leadership? In what ways does his or her leadership support children's success in school?

5. What else do I need to consider about principal leadership practices or other factors that accelerate growth in academic achievement of children in this school?

The parent focus group questions across all three schools revealed four common themes related to what educators and principals can do to assist children attending high poverty schools: 1) address basic needs of the children in addition to the academic part of school; 2) care for the children; 3) provide positive support; and 4) encourage pride in their local school. 
Meeting basic needs. The theme of meeting the basic needs, seen as important for the ability of children to "fit in," was consistently strong throughout the discussions. In response to Question 1, a parent at one school stated:

It is attentiveness to things that may be taken for granted in more affluent schools - nutrition, sleep, hygiene, etc. They (educators) come alongside the child and make accommodations for the basic needs.

A parent at a second school recognized how skillfully staff works with children who need this care.

They grab the children the minute they see them and help them wash up and get ready for the day. If they haven't eaten, they get breakfast before class starts so they can focus in the classroom. It is done in a way that is discreet; the children feel they are being taken care of and loved, but they are not shamed.

Caring. The second common theme in parent focus groups flowed directly from the first: the sense of caring for the children by the teachers and the principal. The concept of caring arose in relation to four of the questions asked in the focus groups. Parents noted that every child comes to school with a different struggle, and that children know when educators are really there for them. This fact motivates the children to want to learn. Parents in one school described how children might spend more time with the teachers than with their own parents and that the encouragement they receive at school is key if or when they don't get it at home.

Positive support. The third common theme was one of positive support. Parents describe this differently than caring. Positive support as described by parents in these schools included understanding if children come to school with incomplete homework and providing time in school to complete work, being able 
to look at individual strengths and see where a child needs to grow, and not isolating children or singling them out for what they cannot do. Parents in one school described this support in the following way:

The school might be the only positive influence children have in their lives. When the school motto of Be Safe, Be Responsible and Be Respectful was adopted, this school added Be Positive. The school addresses the negative but always rewards the positive.

Pride in Local School. Pride in the local school was another common theme revealed by parents in response to Question 2. The pride at one school was associated with how welcoming the principal and the office staff were to them when they came to the school. Parents in another school expressed pride in the school building, noting it was the newest in the district and in the county. One of the schools was almost closed until the principal, teachers and the community rallied to keep it open. Parents from another school noted pride in how parent needs are addressed immediately at that school compared to other schools in the area.

Question 4 of the parent focus group elicited words that parents used to describe principal leadership practices at these three high poverty elementary schools where student achievement has been improved. Themes of providing basic needs for children, caring, providing positive support, and pride in the local school revealed through other questions in the parent focus groups were repeated. An additional theme revealed was personal attributes of the principal.

Personal Attributes of the Principal. This theme was described in various ways. One consistent concept was revealed by use of the word "driven" in parent responses to this question. A parent in one school described the principal this way: 
The principal is focused-driven by a goal to see success in kids. The principal wants success for each and every person. In this school, there is no child left behind. There is no person left behind.

A parent in another school reflected that the school's last few principals have all worked a tremendous number of hours, including being involved in after school and community events. Parents in a third school agreed with the following description:

The principal is relentless, tireless. There is no 9 to 5 for this principal. The principal works until the job is done. A lot is done behind the scenes that people will never know about.

Parent focus group Reponses included other themes that were not common across

all respondents, including a) belief in the kids, the teachers, and the community, b) taking charge and follow through, and c) being a role model.

\section{Quantitative Survey}

Quantitative data for this study was collected from principals and teachers by administering the Principal Leadership Questionnaire (PLQ) as adapted from Jantzi and Leithwood (1996) by the Middle Level Leadership Center (MLLC) (n.d.a.). The researcher selected this instrument based on the literature review indicating the principal leadership practices in the survey were shown to positively impact student achievement. The surveys were administered online through a Survey Monkey (n.d.a.) account maintained by the researcher. StatisticsSolutions Pro version v1.15.02.16 (2014) was used for data analysis and narrative interpretation.

Demographic Data. The degree of confidence with which the results of this study could be applied to the general population of high poverty K-5 elementary schools in Oregon required a sample size of 30 surveys so that the "distribution of sample means is very nearly normal, even if the population is not normally distributed" (Fraenkel \& 
Wallen, 1996, p. 207). The researcher received a total of 40 surveys from three schools as displayed in Table 14, reaching the desirable

sample size for the overall study. However, there were less than 30 respondents in each of the schools so generalizations by school must be made carefully based on the sample size.

Table 14

Number and Percentage of Respondents

\begin{tabular}{|l|c|c|}
\hline School & Number Received & Percentage of Total Respondents \\
\hline Atlas Elementary & 8 & 78 \\
\hline Brighton Elementary & 12 & 79 \\
\hline Camden Elementary & 20 & 86 \\
\hline
\end{tabular}

The researcher was sensitive to concerns of the teachers that their relatively small numbers would make it easy to identify them based on number of years teaching, position in the school, and gender for the males since their numbers were particularly small. The researcher revised the demographic questions prior to administering the survey in response to those concerns. In spite of that concern, $78 \%$ of Atlas Elementary teachers responded to the survey, $79 \%$ of Brighton Elementary teachers responded, and $86 \%$ of Camden Elementary teachers completed the survey. All three principals completed the survey. The majority of participants fell into the category of Regular Education Teacher for Position $(\mathrm{n}=30,77 \%)$. The majority of participants fell into the category of 0-9 years for Years at School ( $\mathrm{n}=25$, $63 \%$ ). The majority of participants fell into the category of Female for Gender ( $\mathrm{n}=34$, $85 \%)$. The majority of participants fell into the category of White for Race $(\mathrm{n}=38,95 \%)$. Frequencies and percentages for nominal variables are displayed in Table 15. 
Leadership Practices

Table 15

Frequencies and Percentages for Nominal Variables

\begin{tabular}{lrc}
\hline Variables & $n$ & $\%$ \\
\hline Position & & \\
$\quad$ Principal & 3 & 8 \\
Regular Education Teacher & 30 & 77 \\
Specialist (ESL, SpED, & 6 & 15 \\
Years at School & & \\
0-9 years & 25 & 63 \\
10-19 years & 11 & 28 \\
20+ years & 4 & 10 \\
Gender & 34 & 85 \\
Female & 6 & 15 \\
Male & & 3 \\
Race & 1 & 3 \\
Asian & 1 & 95 \\
Black or African American & 38 & \\
White & & \\
\hline
\end{tabular}

Note: Due to rounding error, percentages may not add up to 100 .

Based upon how well they applied to the principal they worked with, survey respondents assessed 24 statements on a six-point likert scale from Strongly Disagree to Strongly Agree. Table 16 categorizes descriptors for some of those statements into what Jantzi and Leithwood (1996) described as PLQ factors. These factors were used as continuous variables for purposes of data analysis.

Table 16

PLQ Factors with Corresponding Descriptors

\begin{tabular}{|l|l|}
\hline PLQ Factors & $\begin{array}{l}\text { Principal commands respect } \\
\text { Principal excites faculty with visions of what can be } \\
\text { accomplished } \\
\text { Principal makes faculty feel and act like leaders }\end{array}$ \\
\hline
\end{tabular}




\begin{tabular}{|l|l|}
\hline Appropriate Model & $\begin{array}{l}\text { Principal leads by doing } \\
\text { Principal provides good models for faculty to follow }\end{array}$ \\
\hline Group Goals & $\begin{array}{l}\text { Principal encourages faculty to work toward same goals } \\
\text { Principal provides resources to support implementation of } \\
\text { school goals } \\
\text { Principal works toward whole faculty consensus to } \\
\text { establish goals }\end{array}$ \\
\hline Support & $\begin{array}{l}\text { Principal treats each teacher as an individual } \\
\text { Principal takes individual opinions into consideration } \\
\text { Principal is thoughtful of each teachers personal needs }\end{array}$ \\
\hline Intellectual Stimulation & $\begin{array}{l}\text { Principal challenges teachers to reexamine basic } \\
\text { assumptions about the work } \\
\text { Principal stimulates teachers to think about what is being } \\
\text { done for students } \\
\text { Principal provides information that supports my } \\
\text { implementation of goals }\end{array}$ \\
\hline High Expectations & $\begin{array}{l}\text { Principal insists on best performance from faculty } \\
\text { Principal shows that there are high expectations for faculty } \\
\text { as professionals } \\
\text { Principal does not settle for second best }\end{array}$ \\
\hline
\end{tabular}

Means and Standard Deviations for Continuous Variables. Continuous

variables included Vision, Appropriate Model, Group Goals, Support, Intellectual

Stimulation, and High Expectations. For Vision, observations ranged from 4.00 to 6.00 , with an average observation of $4.85(S D=0.64)$. For Appropriate Model, observations ranged from 4.00 to 6.00 , with an average observation of $5.00(S D=0.79)$. For Group Goals, observations ranged from 3.80 to 6.00 , with an average observation of $4.77(S D=$ 0.65). For Support, observations ranged from 4.00 to 6.00 , with an average observation of $4.78(S D=0.62)$. For Intellectual Stimulation, observations ranged from 3.00 to 6.00, with an average observation of $4.68(S D=0.84)$. For High Expectations, observations ranged from 4.00 to 6.00 , with an average observation of $5.09(S D=0.77)$. Means and standard deviations for continuous variables are displayed in Table 17. 
Table 17

Means and Standard Deviations for Continuous Variables

\begin{tabular}{lcl}
\hline Variable & $M$ & $S D$ \\
\hline Vision & 4.85 & 0.64 \\
Appropriate Model & 5.00 & 0.79 \\
Group Goals & 4.77 & 0.65 \\
Support & 4.78 & 0.62 \\
Intellectual Stimulation & 4.68 & 0.84 \\
High Expectations & 5.09 & 0.77 \\
\hline
\end{tabular}

Pearson Correlation Matrix and Scatterplot. A Pearson correlation matrix was created among Vision, Appropriate Model, Group Goals, Support, Intellectual Stimulation, and High Expectations. Since each variable was used five times, a Bonferroni correction to the alpha level was used; thus the new alpha level is .010 (.050/ 5). A significant positive correlation indicates that as one variable tends to increase, the other variable also tends to increase. It was shown that Vision was significantly positively correlated with Appropriate Model, Group Goals, Support, Intellectual Stimulation, and High Expectations. Appropriate Model was significantly positively correlated with Group Goals, Support, Intellectual Stimulation, and High Expectations. Group Goals was significantly positively correlated with Support, Intellectual Stimulation, and High Expectations. Intellectual Stimulation was significantly positively correlated with High Expectations. Support is not significantly correlated with Intellectual Stimulation or with High Expectations, Table 18 shows the full correlation matrix. Figure 12 shows the scatterplot matrix among the variables. 
Leadership Practices

Table 18

Correlation Matrix Among Vision, Appropriate Model, Group Goals, Support, Intellectual Stimulation, and High Expectations

$\begin{array}{lllll}1 & 2 & 3 & 4 & 5\end{array}$

1) Vision

2) Appropriate

Model

3) Group

Goals

4) Support

5) Intellectual

Stimulation

6) High

$.64 *$

$.58 *$

$.50 *$

Expectations

Note. ${ }^{*} p \leq .010$. 
Figure 12. Scatterplot Matrix

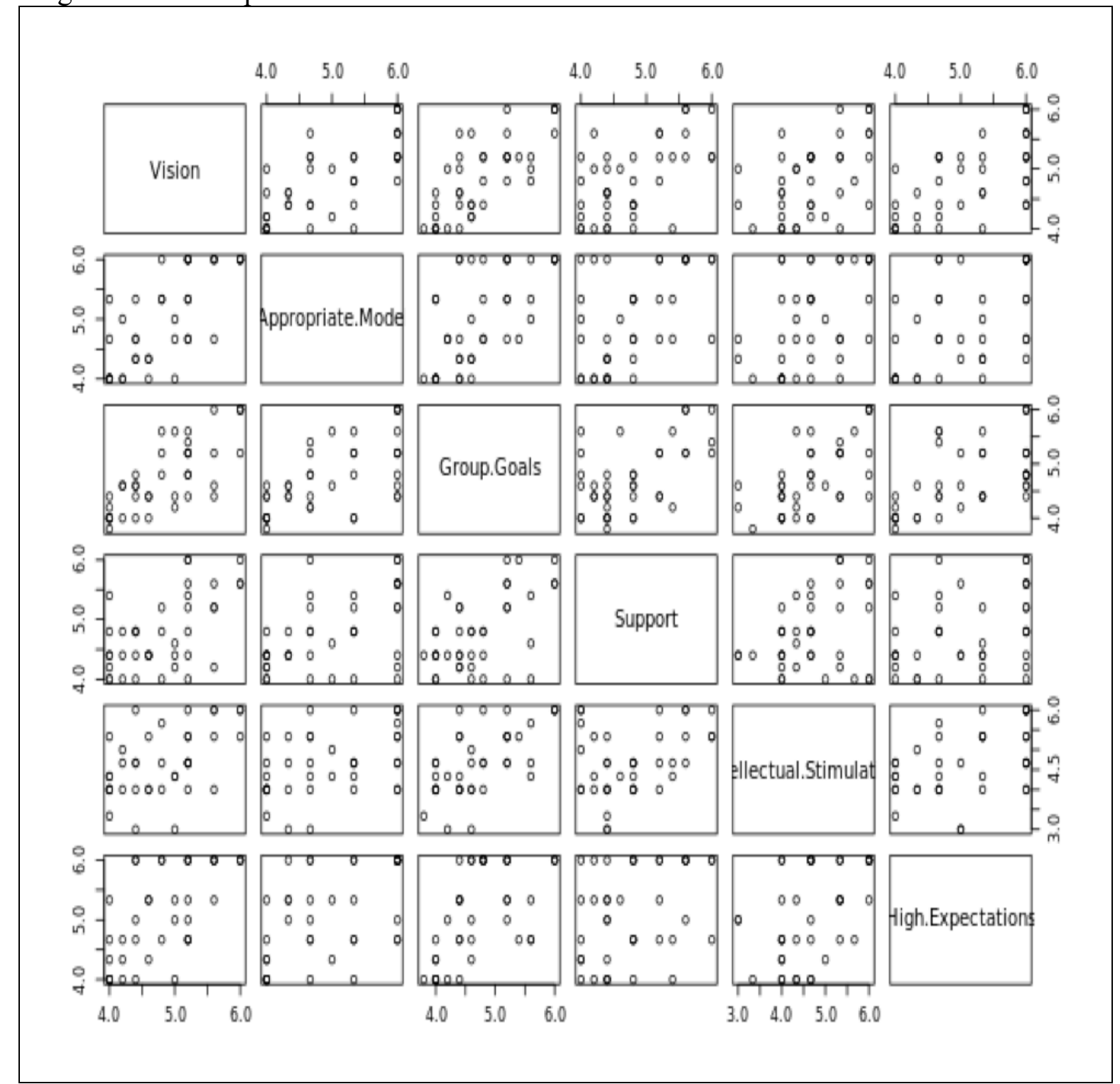

Figure 12. Scatterplot matrix between vision, appropriate model, group goals, support, intellectual stimulation, and high expectations.

Vision and Appropriate Model Correlation. The researcher worked with

StatisticsSolutions staff to run statistical tests of raw data. A dependent sample $t$-test was conducted to assess if there were differences in Vision and Appropriate Model. Prior to analysis, the assumption of normality was assessed using a Shapiro-Wilk test to test the null hypothesis (StatisticsSolutions, 2014). The null-hypothesis of this test is that the 
population is normally distributed (Cohen, Manion, and Morrison, 2011). The result of the test was not significant, $p=.371$, verifying the assumption of normality.

The results of the dependent sample $t$-test were not significant, $t(39)=-1.83, p=$ .074, suggesting that there was not a statistically significant difference between Vision and Appropriate Model. Results of the dependent sample $t$-test are displayed in Table 19. Figure 13 shows the mean of Vision and Appropriate Model.

Table 19

Dependent Sample t-Test for Vision and Appropriate Model

\begin{tabular}{lccccccc}
\hline & & & & \multicolumn{2}{c}{ Vision } & \multicolumn{2}{c}{$\begin{array}{c}\text { Appropriate } \\
\text { Model }\end{array}$} \\
\cline { 5 - 8 } Variable & $t(39)$ & $p$ & Cohen's $d$ & $M$ & $S D$ & $M$ & $S D$ \\
\hline $\begin{array}{l}\text { Vision- } \\
\begin{array}{l}\text { Appropriate } \\
\text { Model }\end{array}\end{array}$ & -1.83 & .074 & 0.29 & 4.85 & 0.64 & 5.0 & 0.79 \\
\hline
\end{tabular}

Figure 13. Vision and Appropriate Model

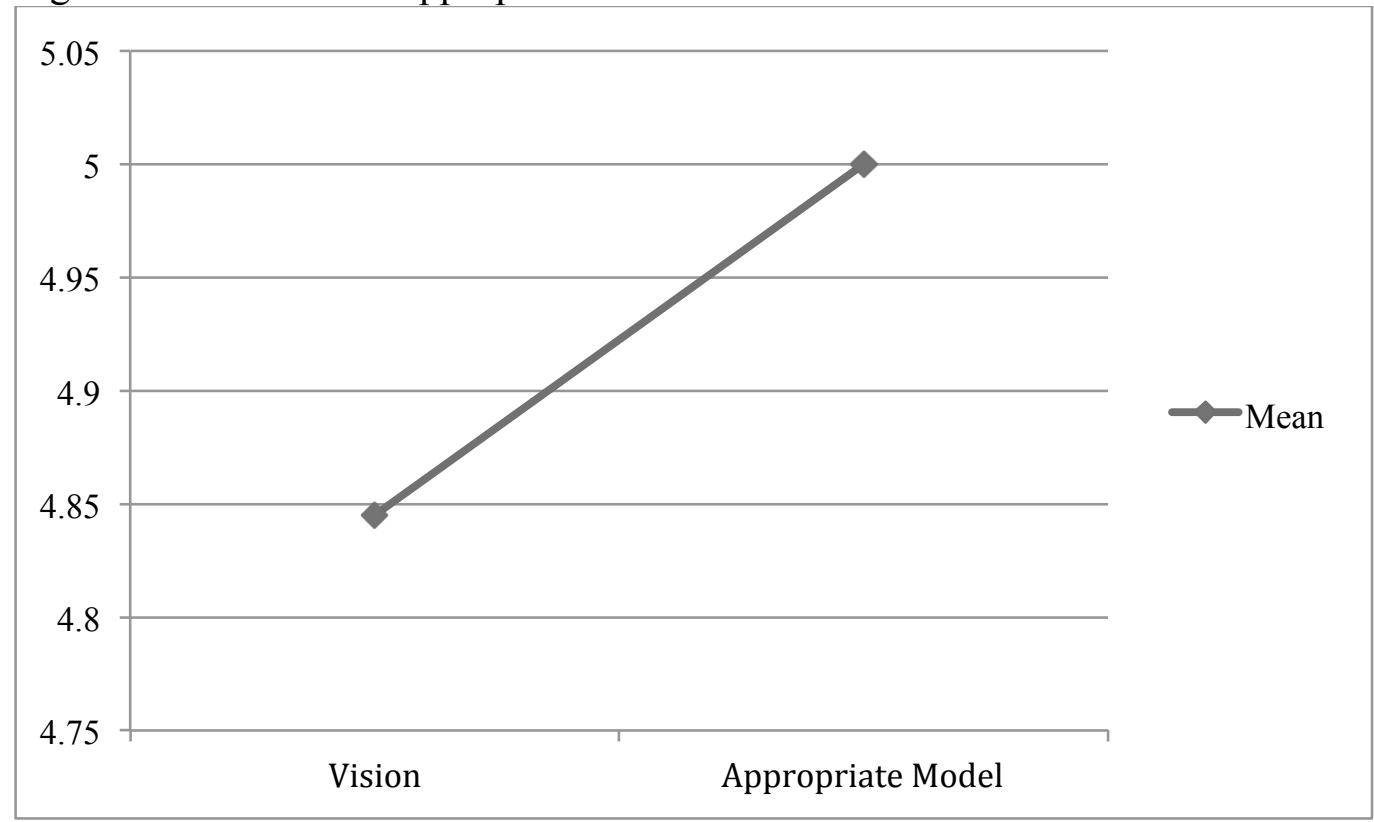

Figure 13. Mean of vision and appropriate model. 
Vision and Group Goals Correlation. The researcher worked with StatisticsSolutions staff to run statistical tests of raw data. A dependent sample $t$-test was conducted to assess if there were differences in Vision and Group Goals. Prior to analysis, the assumption of normality was assessed using a Shapiro-Wilk test to test the null hypothesis (StatisticsSolutions, 2014). The null-hypothesis of this test is that the population is normally distributed (Cohen, Manion, and Morrison, 2011). The result of the test was not significant, $p=.077$, verifying the assumption of normality.

The results of the dependent sample $t$-test were not significant, $t(39)=1.12, p=$ .268 , suggesting that there was not a statistically significant difference between Vision and Group Goals. Results of the dependent sample $t$-test are shown in Table 20.

Figure14 shows the mean of Vision and Group Goals.

Table 20

Dependent Sample t-Test for Vision and Group Goals

\begin{tabular}{lccccccc}
\hline & & & & \multicolumn{2}{c}{ Vision } & \multicolumn{2}{c}{ Group Goals } \\
\cline { 5 - 8 } Variable & $T(39)$ & $p$ & Cohen's $d$ & $M$ & $S D$ & $M$ & $S D$ \\
\hline $\begin{array}{l}\text { Vision- } \\
\text { Group }\end{array}$ & 1.12 & .268 & 0.18 & 4.85 & 0.64 & 4.77 & 0.65 \\
Goals & & & & & & & \\
\hline
\end{tabular}


Figure 14. Vision and Group Goals

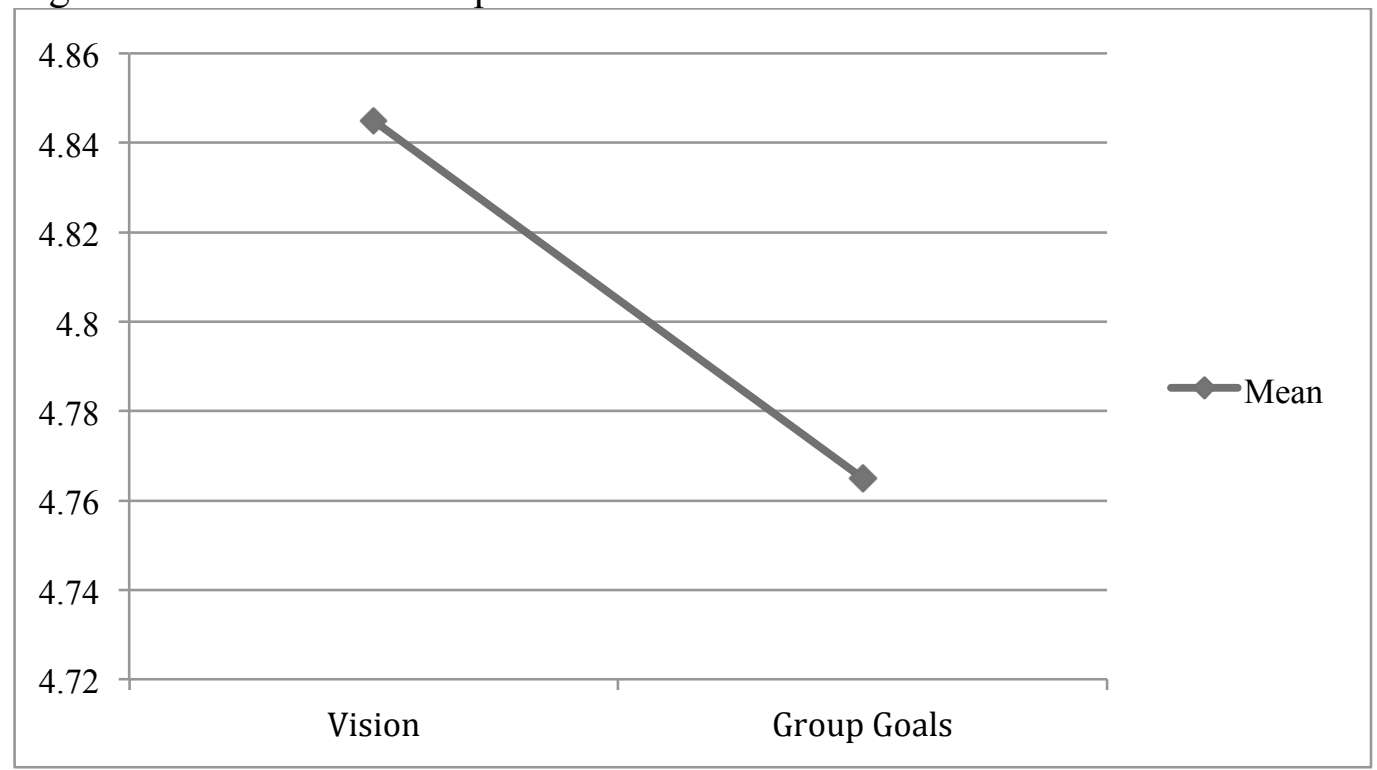

Figure 14. Mean of vision and group goals.

Vision and Support Correlation. The researcher worked with StatisticsSolutions staff to run statistical tests of raw data. A dependent sample $t$-test was conducted to assess differences in Vision and Support. Prior to analysis, the assumption of normality was assessed using a Shapiro-Wilk test to test the null hypothesis (StatisticsSolutions, 2014). The null-hypothesis of this test is that the population is normally distributed (Cohen, Manion, and Morrison, 2011). The result of the test was not significant, $p=.626$, verifying the assumption of normality.

The results of the dependent sample $t$-test were not significant, $t(38)=0.39, p=$ .697 , suggesting that there was not a statistically significant difference between Vision and Support. Results of the dependent sample $t$-test are displayed in Table 21. Figure 15 shows the mean ofVision and Support. 
Leadership Practices

Table 21

Dependent Sample t-Test for Vision and Support

\begin{tabular}{lccccccc}
\hline & & & & \multicolumn{2}{c}{ Vision } & \multicolumn{2}{c}{ Support } \\
\cline { 5 - 8 } Variable & $t(38)$ & $p$ & Cohen's $d$ & $M$ & $S D$ & $M$ & $S D$ \\
\hline $\begin{array}{l}\text { Vision- } \\
\text { Support }\end{array}$ & 0.39 & .697 & 0.06 & 4.82 & 0.62 & 4.78 & 0.62 \\
\hline
\end{tabular}

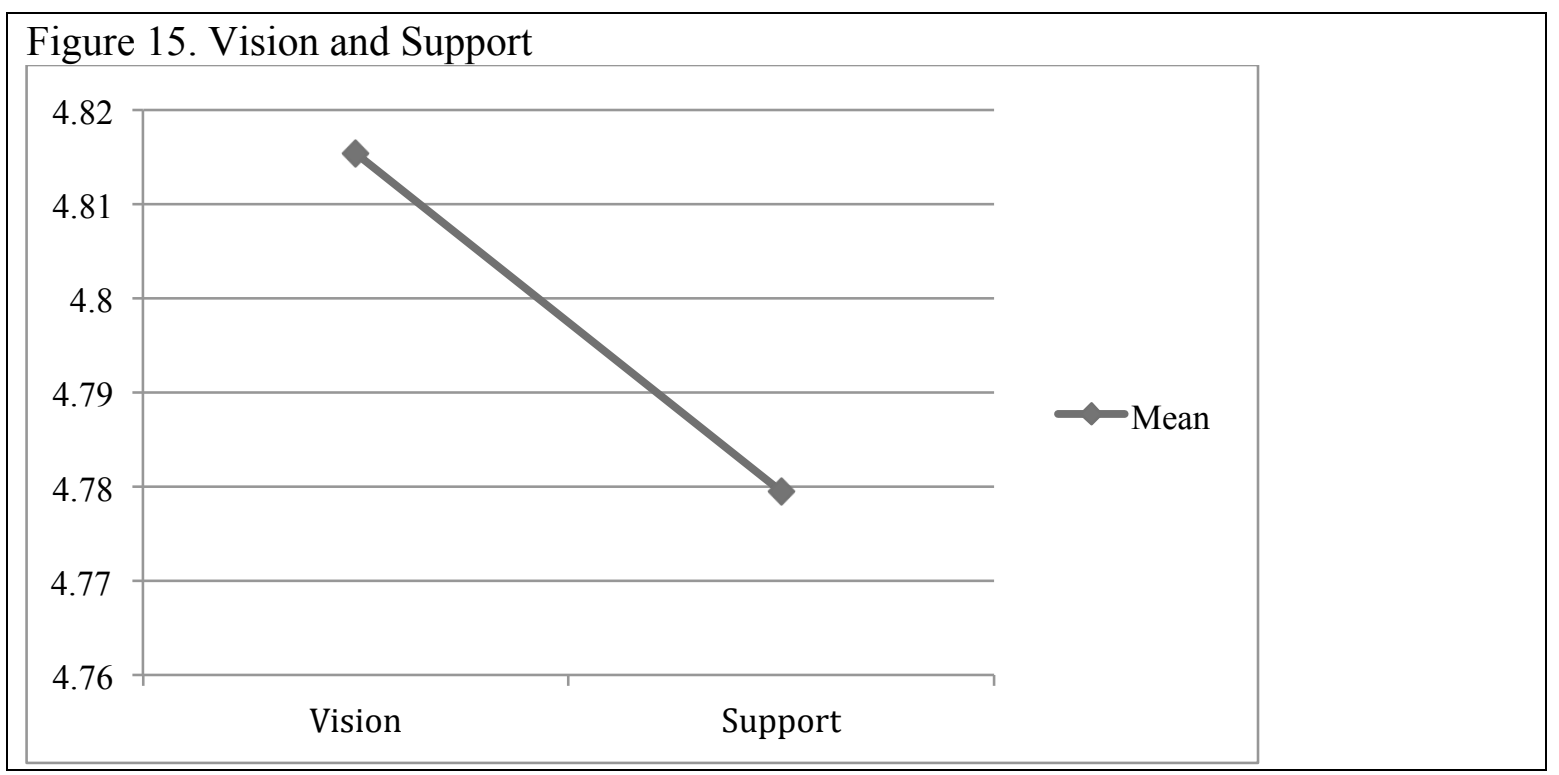

Figure 15. Mean of vision and support.

Vision and Intellectual Stimulation Correlation. The researcher worked with

StatisticsSolutions staff to run statistical tests of raw data. A dependent sample $t$-test was conducted to assess if there were differences in Vision and Intellectual Stimulation. Prior to analysis, the assumption of normality was assessed using a Shapiro-Wilk test to test the null hypothesis (StatisticsSolutions, 2014). The null-hypothesis of this test is that the population is normally distributed (Cohen, Manion, and Morrison, 2011). The result of the test was not significant, $p=.778$, verifying the assumption of normality. 
Leadership Practices

The results of the dependent sample $t$-test were not significant, $t(38)=1.09, p=$ .283 , suggesting that there was not a statistically significant difference between Vision and Intellectual Stimulation. Results of the dependent sample $t$-test are presented in Table 22. Figure 16 shows the mean of Vision and Intellectual Stimulation.

Table 22

Dependent Sample t-Test for Vision and Intellectual Stimulation

\begin{tabular}{lccccccc}
\hline & & & & \multicolumn{2}{c}{ Vision } & \multicolumn{3}{c}{$\begin{array}{l}\text { Intellectual } \\
\text { Stimulation }\end{array}$} \\
\cline { 5 - 9 } & $t(38)$ & $p$ & Cohen's $d$ & $M$ & $S D$ & $M$ & $S D$ \\
\hline $\begin{array}{l}\text { Vision- } \\
\begin{array}{l}\text { Intellectual } \\
\text { Stimulation }\end{array}\end{array}$ & 1.09 & .283 & 0.17 & 4.82 & 0.62 & 4.68 & 0.84 \\
\hline
\end{tabular}

Figure 16. Vision and Intellectual Stimulation

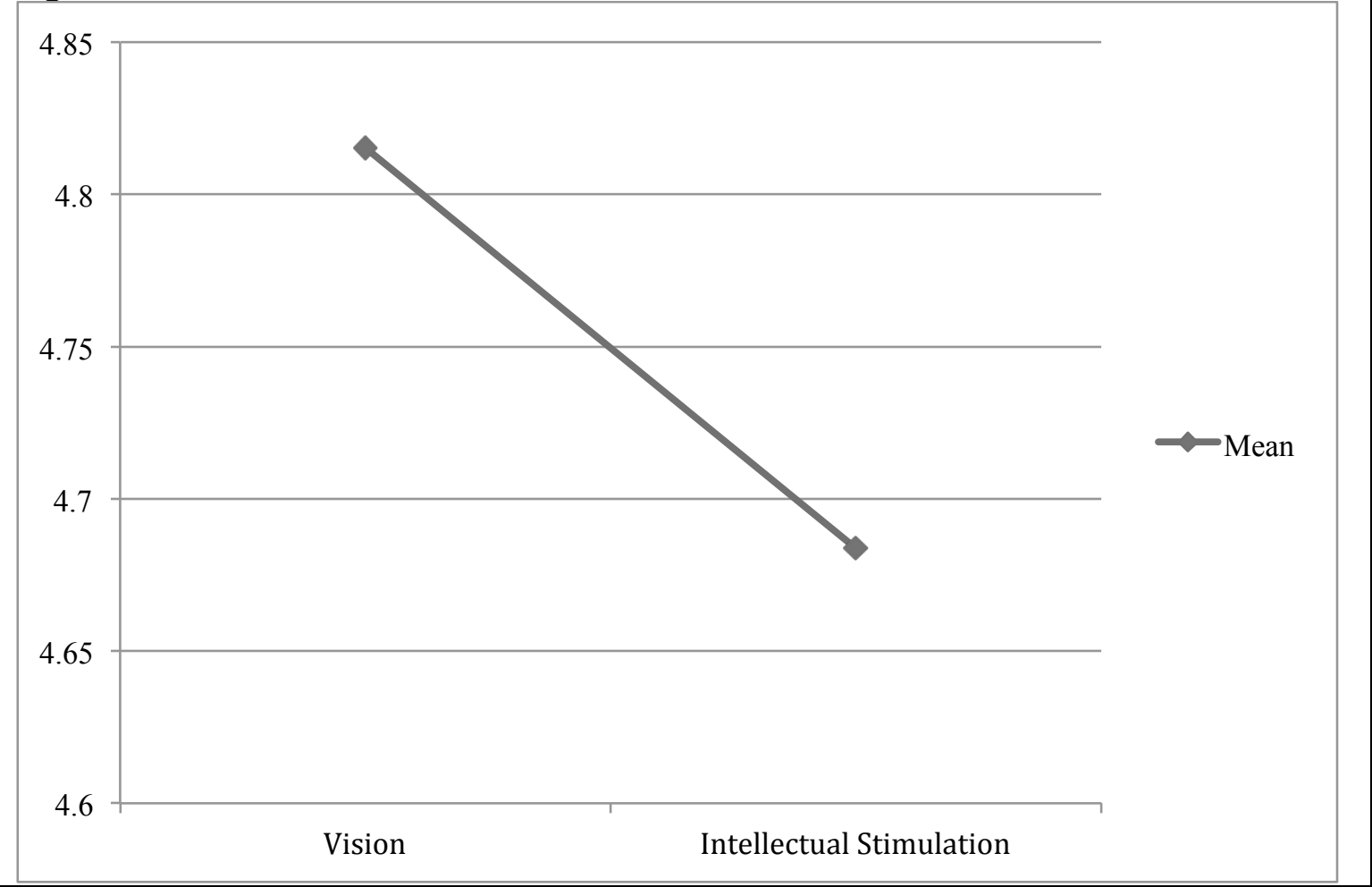

Figure 16. Mean of vision and intellectual stimulation. 
Vision and High Expectations Correlation. The researcher worked with StatisticsSolutions staff to run statistical tests of raw data. A dependent sample $t$-test was conducted to assess if there were differences in Vision and High Expectations. Prior to analysis, the assumption of normality was assessed using a Shapiro-Wilk test. The result of the test was not significant, $p=.317$, verifying the assumption of normality.

The results of the dependent sample $t$-test were significant, $t(38)=-2.88, p=.006$, suggesting that there was a difference in Vision and High Expectations. Vision had a significantly lower mean than High Expectations. According to Cohen (1988), the difference between the two groups had a small effect size. Results of the dependent sample $t$-test are shown in Table 23. Figure 17 shows the mean of Vision and High Expectations.

Table 23

Dependent Sample t-Test for Vision and High Expectations

\begin{tabular}{lccccccc}
\hline & & & & \multicolumn{2}{c}{ Vision } & \multicolumn{2}{c}{ High Expectations } \\
\cline { 5 - 8 } Variable & $t(38)$ & $p$ & Cohen's $d$ & $M$ & $S D$ & $M$ & $S D$ \\
\hline $\begin{array}{l}\text { Vision-High } \\
\text { Expectations }\end{array}$ & -2.88 & .006 & 0.46 & 4.82 & 0.62 & 5.09 & 0.77 \\
\hline
\end{tabular}


Figure 17. Vision and High Expectations

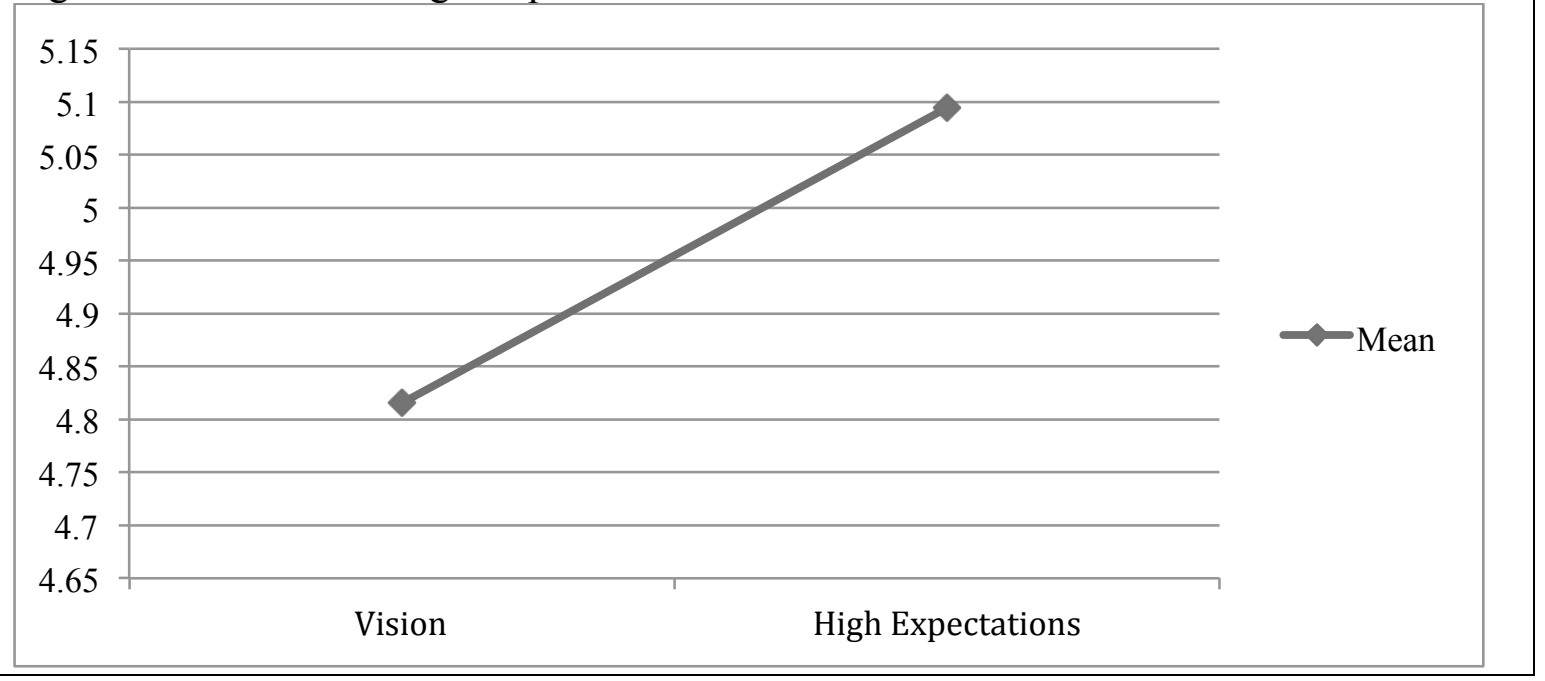

Figure 17. Mean of vision and high expectations.

Appropriate Model and Group Goals Correlation. The researcher worked with StatisticsSolutions staff to run statistical tests of raw data. A dependent sample $t$-test was conducted to assess if there were differences in Appropriate Model and Group Goals. Prior to analysis, the assumption of normality was assessed using a Shapiro-Wilk test. The result of the test was significant, $p=.005$, violating the assumption of normality. However, Howell (2010) suggests that the $t$-test is robust despite violations of normality.

The results of the dependent sample $t$-test were significant, $t(39)=2.39, p=.022$, suggesting that there was a difference in Appropriate Model and Group Goals. Appropriate Model had a significantly higher mean than Group Goals. According to Cohen (1988), the difference between the two groups had a small effect size. Results of the dependent sample $t$-test are presented in Table 24. Figure 18 shows the mean of Appropriate Model and Group Goals. 
Leadership Practices

Table 24

Dependent Sample t-Test for Appropriate Model and Group Goals

\begin{tabular}{|c|c|c|c|c|c|c|c|}
\hline \multirow[b]{2}{*}{ Variable } & \multirow[b]{2}{*}{$t(39)$} & \multirow[b]{2}{*}{$p$} & \multirow[b]{2}{*}{ Cohen's $d$} & \multicolumn{2}{|c|}{$\begin{array}{c}\text { Appropriate } \\
\text { Model }\end{array}$} & \multicolumn{2}{|c|}{ Group Goals } \\
\hline & & & & $M$ & $S D$ & $M$ & $S D$ \\
\hline $\begin{array}{l}\text { Appropriate } \\
\text { Model- } \\
\text { Group } \\
\text { Goals }\end{array}$ & 2.39 & .022 & 0.38 & 5.00 & 0.79 & 4.77 & 0.65 \\
\hline
\end{tabular}

Figure 18. Appropriate Model and Group Goals

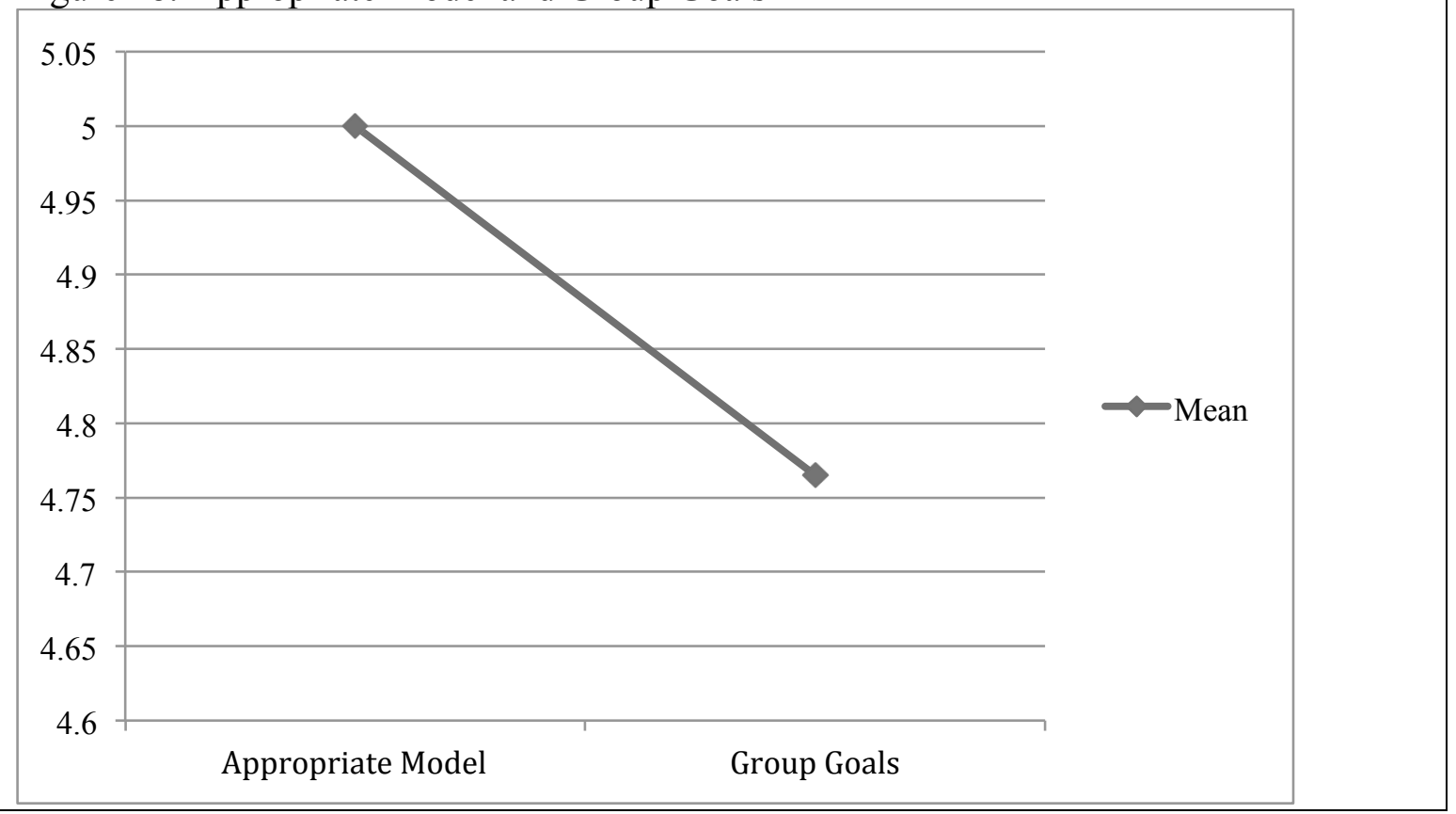

Figure 18. Mean of appropriate model and group goals.

Appropriate Model and Support Correlation. The researcher worked with

StatisticsSolutions staff to run statistical tests of raw data. A dependent sample $t$-test was conducted to assess if there were differences in Appropriate Model and Support. Prior to analysis, the assumption of normality was assessed using a Shapiro-Wilk test. The result of the test was not significant, $p=.114$, verifying the assumption of normality. 
Leadership Practices

The results of the dependent sample $t$-test were not significant, $t(38)=1.73, p=$ .092, suggesting that there was not a statistically significant difference between

Appropriate Model and Support. Results of the dependent sample $t$-test are shown in

Table 25. Figure 19 shows the mean of Appropriate Model and Support.

Table 25

Dependent Sample t-Test for Appropriate Model and Support

\begin{tabular}{lccccccc}
\hline & & & & \multicolumn{2}{c}{$\begin{array}{c}\text { Appropriate } \\
\text { Model }\end{array}$} & \multicolumn{2}{c}{ Support } \\
Variable & $t(38)$ & $p$ & Cohen's $d$ & $M$ & $S D$ & $M$ & $S D$ \\
\cline { 5 - 8 } & & & & & & & \\
Appropriate & 1.73 & .092 & 0.28 & 4.97 & 0.78 & 4.78 & 0.62 \\
$\begin{array}{l}\text { Model- } \\
\text { Support }\end{array}$ & & & & & & & \\
\hline
\end{tabular}

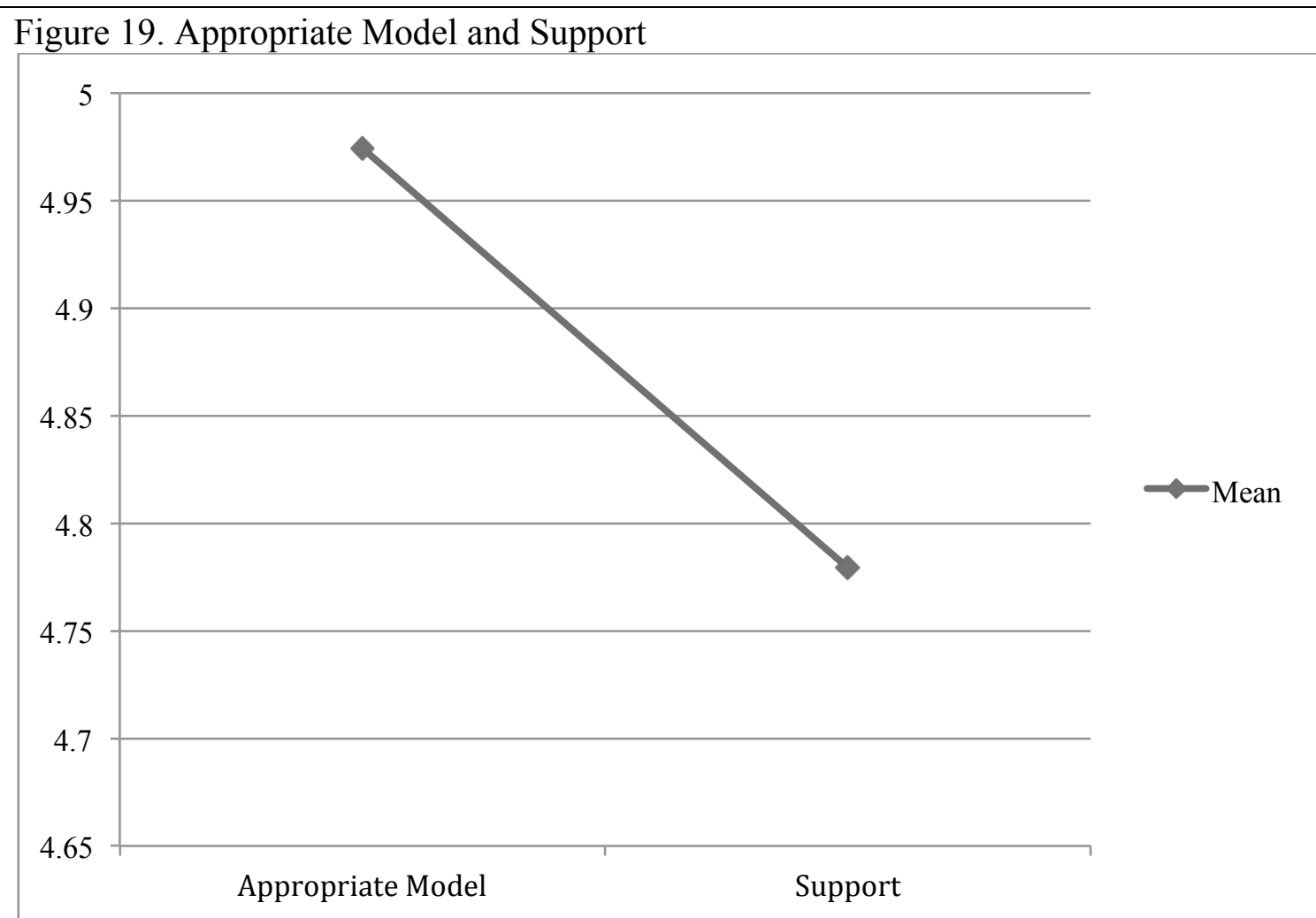

Figure 19. Mean of appropriate model and support. 
Appropriate Model and Intellectual Stimulation Correlation. The researcher worked with StatisticsSolutions staff to run statistical tests of raw data. A dependent sample $t$-test was conducted to assess if there were differences in Appropriate Model and Intellectual Stimulation. Prior to analysis, the assumption of normality was assessed using a Shapiro-Wilk test. The result of the test was not significant, $p=.218$, verifying the assumption of normality.

The results of the dependent sample $t$-test were significant, $t(38)=2.19, p=.035$, suggesting that there was a difference in Appropriate Model and Intellectual Stimulation. Appropriate Model had a significantly higher mean than Intellectual Stimulation. According to Cohen (1988), the difference between the two groups had a small effect size. Results of the dependent sample $t$-test are presented in Table 26. Figure 20 shows the mean of Appropriate Model and Intellectual Stimulation.

Table 26

Dependent Sample t-Test for Appropriate Model and Intellectual Stimulation

\begin{tabular}{|c|c|c|c|c|c|c|c|}
\hline \multirow[b]{2}{*}{ Variable } & \multirow[b]{2}{*}{$t(38)$} & \multirow[b]{2}{*}{$p$} & \multirow[b]{2}{*}{ Cohen's $d$} & \multicolumn{2}{|c|}{$\begin{array}{l}\text { Appropriate } \\
\text { Model }\end{array}$} & \multicolumn{2}{|c|}{$\begin{array}{l}\text { Intellectual } \\
\text { Stimulation }\end{array}$} \\
\hline & & & & $M$ & $S D$ & $M$ & $S D$ \\
\hline $\begin{array}{l}\text { Appropriate } \\
\text { Model- } \\
\text { Intellectual } \\
\text { Stimulation }\end{array}$ & 2.19 & .035 & 0.35 & 4.97 & 0.78 & 4.68 & 0.84 \\
\hline
\end{tabular}




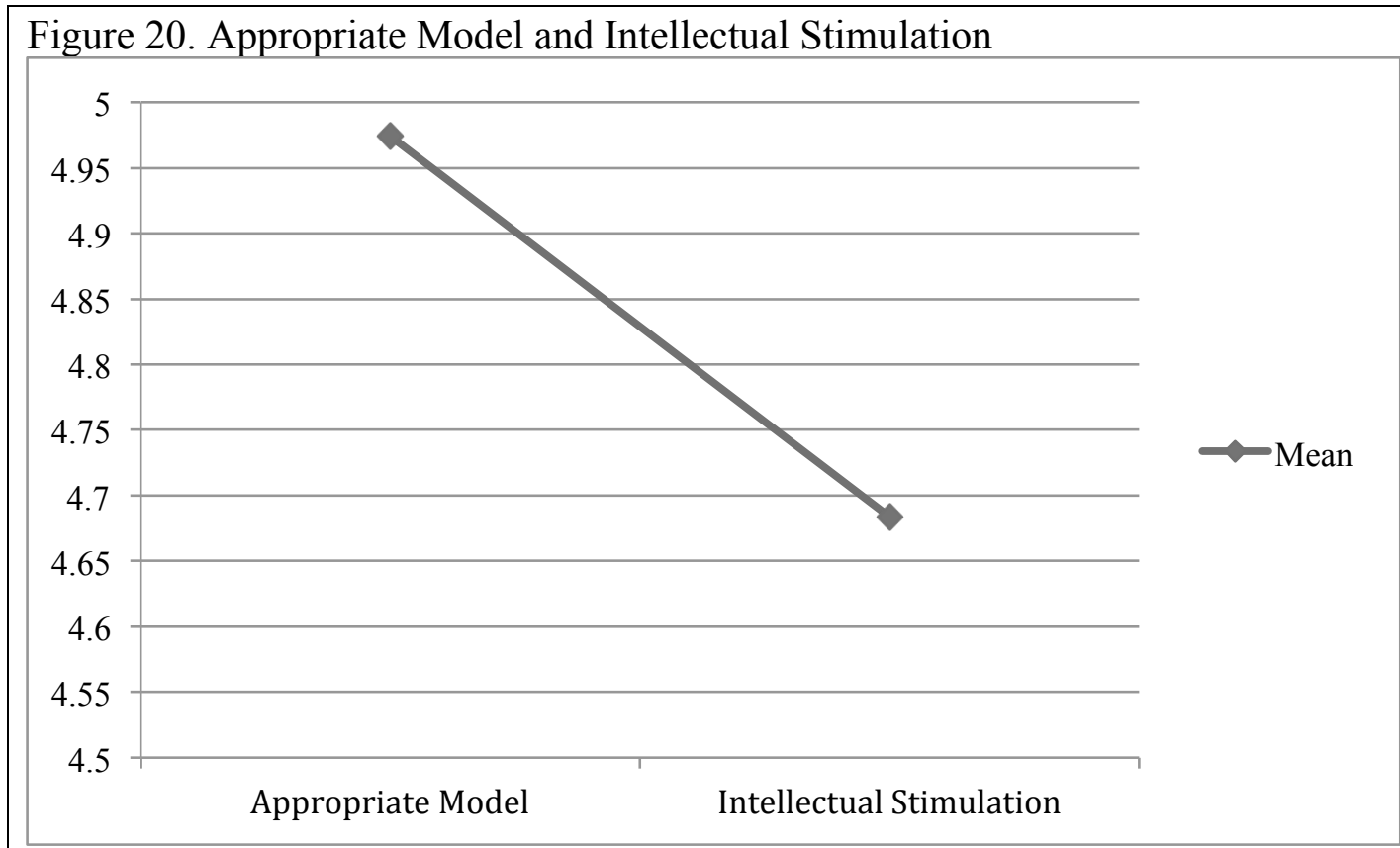

Figure 20. Mean of appropriate model and intellectual stimulation.

Appropriate Model and High Expectations Correlation. The researcher worked with StatisticsSolutions staff to run statistical tests of raw data. A dependent sample $t$-test was conducted to assess if there were differences in Appropriate Model and High Expectations. Prior to analysis, the assumption of normality was assessed using a Shapiro-Wilk test. The result of the test was significant, $p=.023$, violating the assumption of normality. However, Howell (2010) suggests that the $t$-test is robust despite violations of normality.

The results of the dependent sample $t$-test were not significant, $t(38)=-1.02, p=$ .313 , suggesting that there was not a statistically significant difference between Appropriate Model and High Expectations. Results of the dependent sample $t$-test are presented in Table 27. Figure 21 shows the mean of Appropriate Model and High Expectations. 
Leadership Practices

Table 27

Dependent Sample t-Test for Appropriate Model and High Expectations

\begin{tabular}{|c|c|c|c|c|c|c|c|}
\hline \multirow[b]{2}{*}{ Variable } & \multirow[b]{2}{*}{$t(38)$} & \multirow[b]{2}{*}{$p$} & \multirow[b]{2}{*}{ Cohen's $d$} & \multicolumn{2}{|c|}{$\begin{array}{l}\text { Appropriate } \\
\text { Model }\end{array}$} & \multicolumn{2}{|c|}{ High Expectations } \\
\hline & & & & $M$ & $S D$ & $M$ & $S D$ \\
\hline $\begin{array}{l}\text { Appropriate } \\
\text { Model- } \\
\text { High } \\
\text { Expectations }\end{array}$ & -1.02 & .313 & 0.16 & 4.97 & 0.78 & 5.09 & 0.77 \\
\hline
\end{tabular}

Figure 21. Appropriate Model and High Expectations

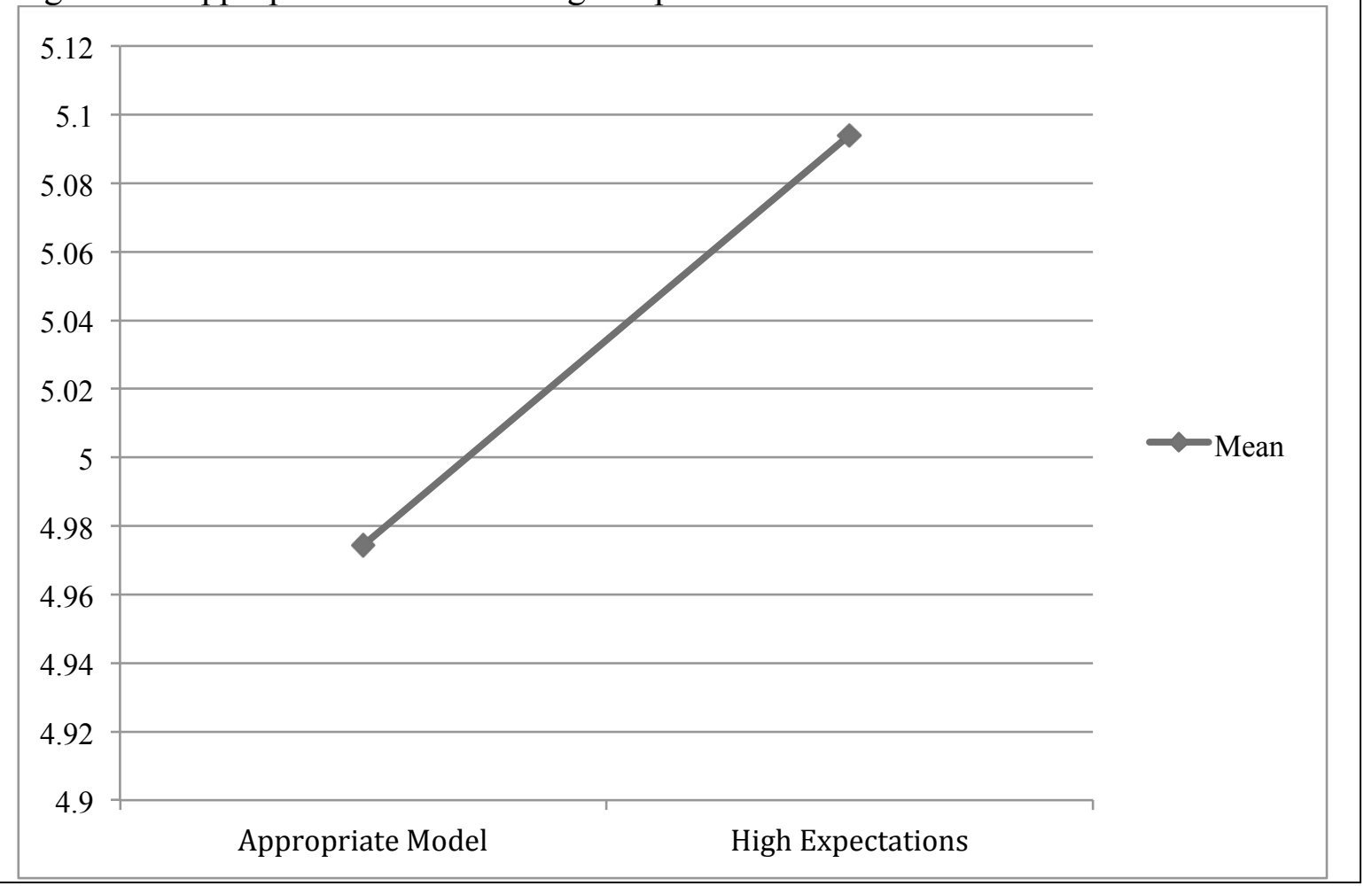

Figure 21. Mean of appropriate model and high expectations.

Group Goals and Support Correlation. The researcher worked with

StatisticsSolutions staff to run statistical tests of raw data. A dependent sample $t$-test was conducted to assess if there were differences in Group Goals and Support. Prior to 
analysis, the assumption of normality was assessed using a Shapiro-Wilk test. The result of the test was not significant, $p=.168$, verifying the assumption of normality.

The results of the dependent sample $t$-test were not significant, $t(38)=-0.49, p=$ .627 , suggesting that there was not a statistically significant difference between Group Goals and Support. Results of the dependent sample $t$-test are presented in Table 28.

Figure 22 shows the mean of Group Goals and Support.

Table 28

Dependent Sample t-Test for Group Goals and Support

\begin{tabular}{lllccccc}
\hline & & & & \multicolumn{2}{c}{ Group Goals } & \multicolumn{2}{c}{ Support } \\
\cline { 5 - 7 } Variable & $t(38)$ & $p$ & Cohen's $d$ & $M$ & $S D$ & $M$ & $S D$ \\
\hline $\begin{array}{l}\text { Group } \\
\text { Goals- } \\
\text { Support }\end{array}$ & -0.49 & .627 & 0.08 & 4.73 & 0.63 & 4.78 & 0.62 \\
\hline
\end{tabular}

Figure 22. Group Goals and Support

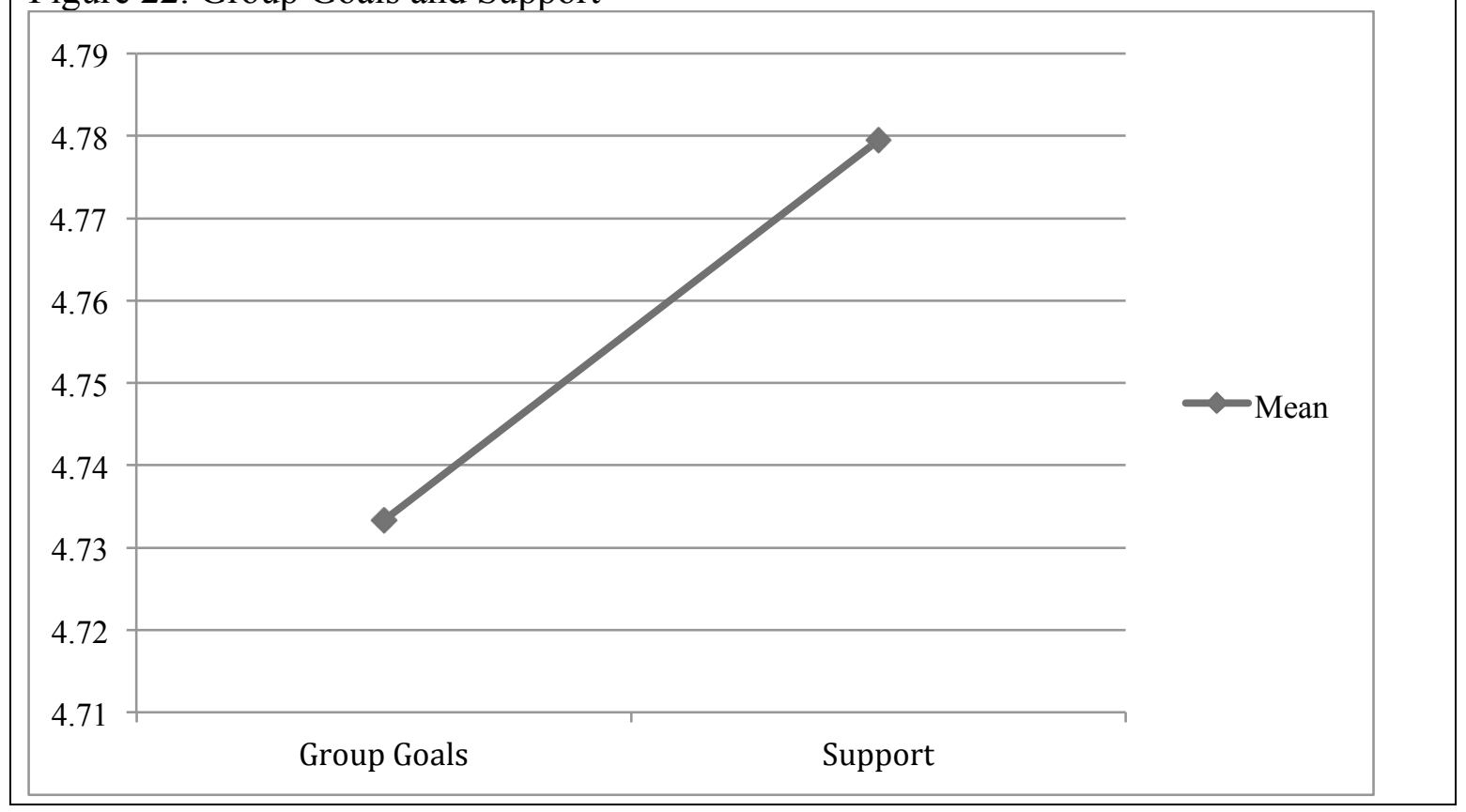

Figure 22. Mean of group goals and support. 
Group Goals and Intellectual Stimulation Correlation. The researcher worked with StatisticsSolutions staff to run statistical tests of raw data. A dependent sample $t$-test was conducted to assess if there were differences in Group Goals and Intellectual Stimulation. Prior to analysis, the assumption of normality was assessed using a ShapiroWilk test. The result of the test was not significant, $p=.426$, verifying the assumption of normality.

The results of the dependent sample $t$-test were not significant, $t(38)=0.47, p=$ .643 , suggesting that there was not a statistically significant difference between Group Goals and Intellectual Stimulation. Results of the dependent sample $t$-test are displayed in Table 29. Figure 23 shows the mean of Group Goals and Intellectual Stimulation.

Table 29

Dependent Sample t-Test for Group Goals and Intellectual Stimulation

\begin{tabular}{|c|c|c|c|c|c|c|c|}
\hline \multirow[b]{2}{*}{ Variable } & \multirow[b]{2}{*}{$t(38)$} & \multirow[b]{2}{*}{$p$} & \multirow[b]{2}{*}{ Cohen's $d$} & \multicolumn{2}{|c|}{ Group Goals } & \multicolumn{2}{|c|}{$\begin{array}{l}\text { Intellectual } \\
\text { Stimulation }\end{array}$} \\
\hline & & & & $M$ & $S D$ & $M$ & $S D$ \\
\hline $\begin{array}{l}\text { Group } \\
\text { Goals- } \\
\text { Intellectual } \\
\text { Stimulation }\end{array}$ & 0.47 & .643 & 0.07 & 4.73 & 0.63 & 4.68 & 0.84 \\
\hline
\end{tabular}




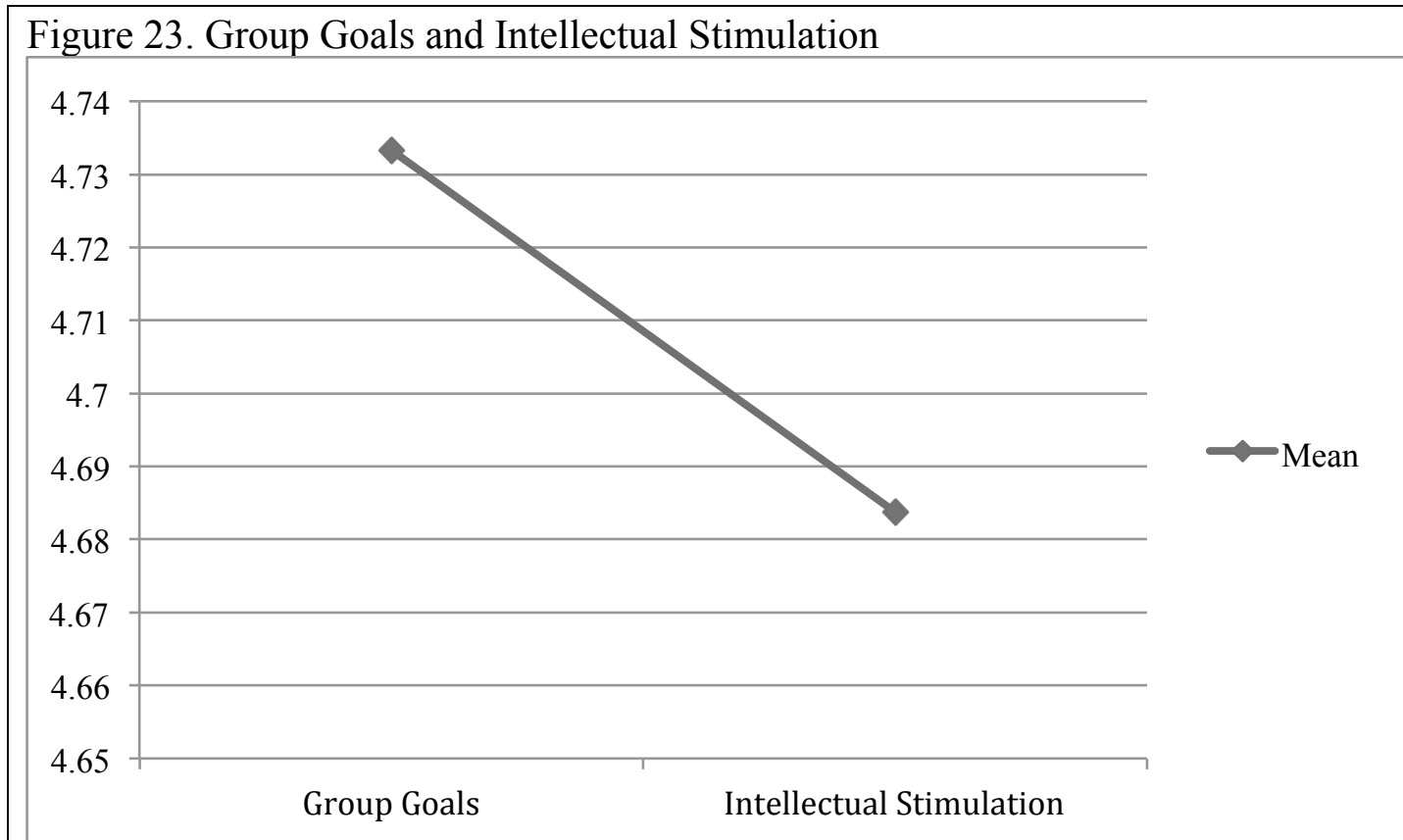

Figure 23. Mean of group goals and intellectual stimulation.

Group Goals and High Expectations Correlation. The researcher worked with

StatisticsSolutions staff to run statistical tests of raw data. A dependent sample $t$-test was conducted to assess if there were differences in Group Goals and High Expectations. Prior to analysis, the assumption of normality was assessed using a Shapiro-Wilk test. The result of the test was not significant, $p=.213$, verifying the assumption of normality.

The results of the dependent sample $t$-test were significant, $t(38)=-3.47, p=.001$, suggesting that there was a difference in Group Goals and High Expectations. Group Goals had a significantly lower mean than High Expectations. According to Cohen (1988), the difference between the two groups had a medium effect size. Results of the dependent sample $t$-test are presented in Table 30. Figure 24 shows the mean of Group Goals and High Expectations. 
Leadership Practices

Table 30

Dependent Sample t-Test for Group Goals and High Expectations

\begin{tabular}{lccccccc}
\hline & & & & \multicolumn{2}{c}{ Group Goals } & \multicolumn{2}{c}{ High Expectations } \\
\cline { 5 - 8 } Variable & $t(38)$ & $p$ & Cohen's $d$ & $M$ & $S D$ & $M$ & $S D$ \\
\hline $\begin{array}{l}\text { Group } \\
\begin{array}{l}\text { Goals- High } \\
\text { Expectations }\end{array}\end{array}$ & -3.47 & .001 & 0.55 & 4.73 & 0.63 & 5.09 & 0.77 \\
\hline
\end{tabular}

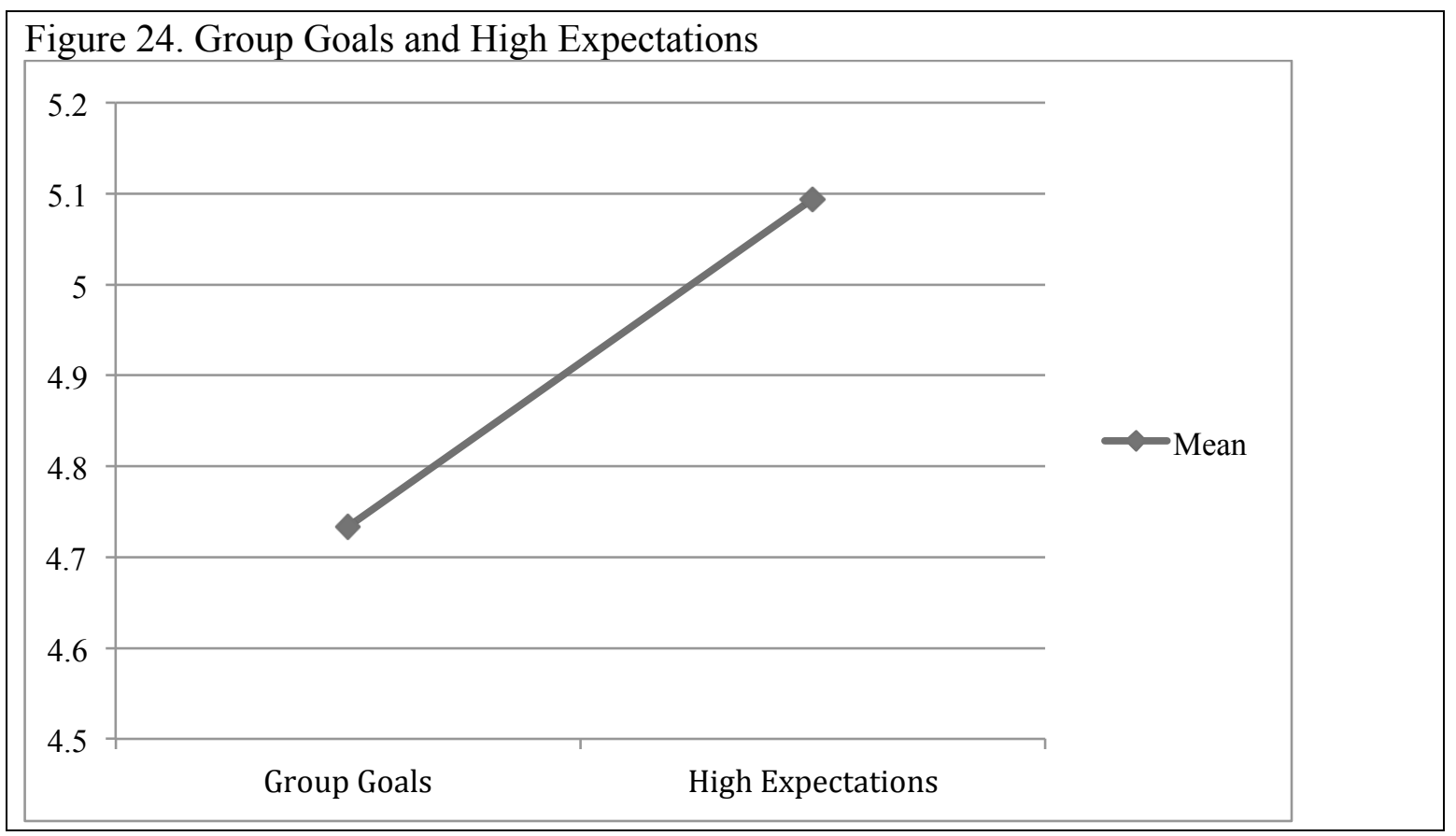

Figure 24. Mean of group goals and high expectations.

Support and Intellectual Stimulation Correlation. The researcher worked with

StatisticsSolutions staff to run statistical tests of raw data. A dependent sample $t$-test was conducted to assess if there were differences in Support and Intellectual Stimulation.

Prior to analysis, the assumption of normality was assessed using a Shapiro-Wilk test.

The result of the test was significant, $p=.033$, violating the assumption of normality. However, Howell (2010) suggests that the $t$-test is robust despite violations of normality. 
Leadership Practices

The results of the dependent sample $t$-test were not significant, $t(38)=0.70, p=$ .489 , suggesting that there was not a statistically significant difference between Support and Intellectual Stimulation. Results of the dependent sample $t$-test are shown in Table 31. Figure 25 shows the mean of Support and Intellectual Stimulation.

Table 31

Dependent Sample t-Test for Support and Intellectual Stimulation

\begin{tabular}{|c|c|c|c|c|c|c|c|}
\hline \multirow[b]{2}{*}{ Variable } & \multirow[b]{2}{*}{$t(38)$} & \multirow[b]{2}{*}{$p$} & \multirow[b]{2}{*}{ Cohen's $d$} & \multicolumn{2}{|c|}{ Support } & \multicolumn{2}{|c|}{$\begin{array}{c}\text { Intellectual } \\
\text { Stimulations }\end{array}$} \\
\hline & & & & $M$ & $S D$ & $M$ & $S D$ \\
\hline $\begin{array}{l}\text { Support- } \\
\text { Intellectual } \\
\text { Stimulation }\end{array}$ & 0.70 & .489 & 0.11 & 4.78 & 0.62 & 4.68 & 0.84 \\
\hline
\end{tabular}

Figure 25. Support and Intellectual Stimulation

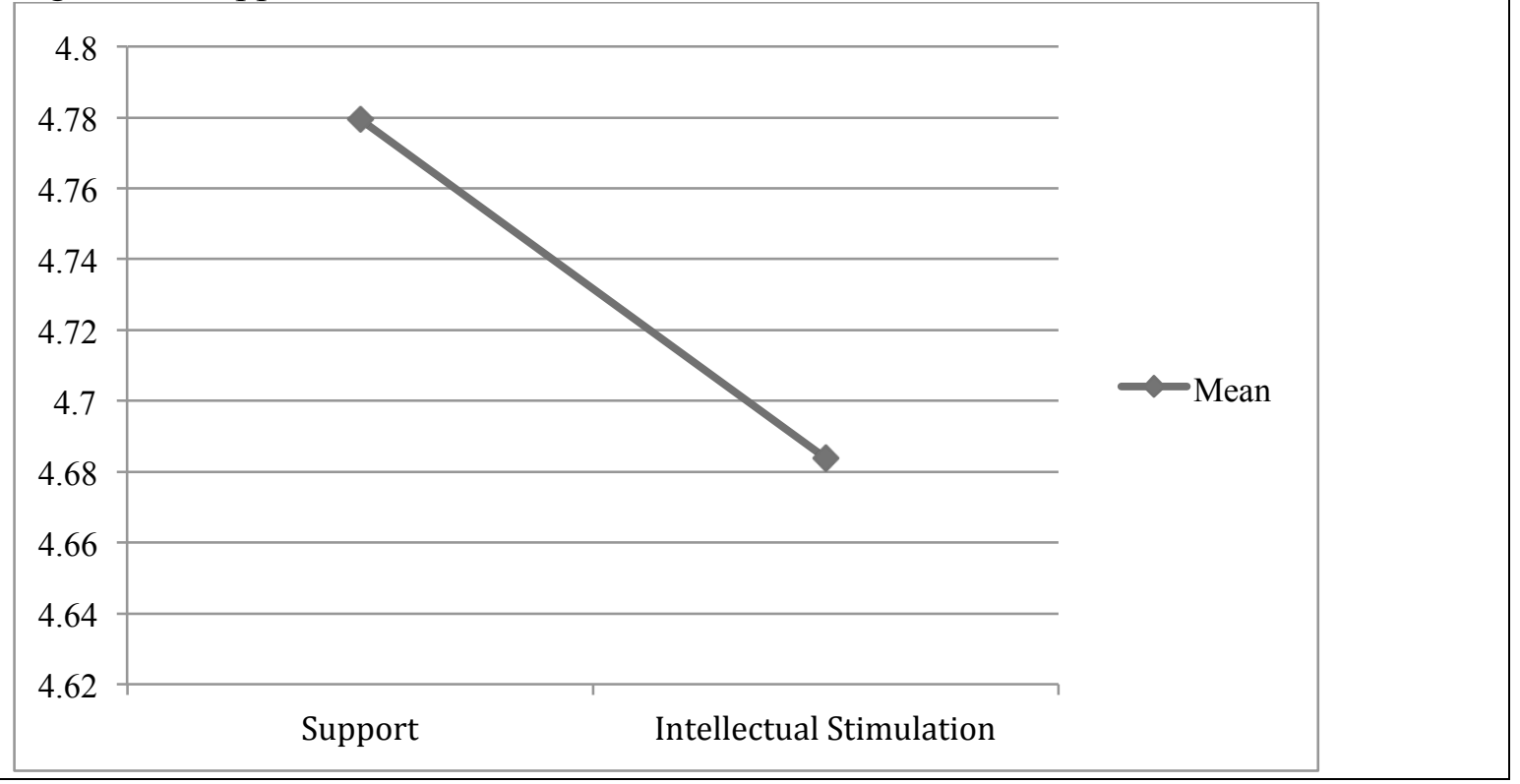

Figure 25. Mean of support and intellectual stimulation.

Support and High Expectations Correlation. The researcher worked with

StatisticsSolutions staff to run statistical tests of raw data. A dependent sample $t$-test was conducted to assess if there were differences in Support and High Expectations. Prior to 
analysis, the assumption of normality was assessed using a Shapiro-Wilk test. The result of the test was not significant, $p=.947$, verifying the assumption of normality.

The results of the dependent sample $t$-test were significant, $t(38)=-2.43, p=.020$, suggesting that there was a difference in Support and High Expectations. Support had a significantly lower mean than High Expectations. According to Cohen (1988), the difference between the two groups had a small effect size. Results of the dependent sample $t$-test are presented in Table 32. Figure 26 shows the mean of Support and High Expectations.

Table 32

Dependent Sample t-Test for Support and High Expectations

\begin{tabular}{lccccccc}
\hline & & & & \multicolumn{2}{c}{ Support } & \multicolumn{2}{c}{ High Expectations } \\
\cline { 5 - 8 } Variable & $t(38)$ & $p$ & Cohen's $d$ & $M$ & $S D$ & $M$ & $S D$ \\
\hline $\begin{array}{l}\text { Support- } \\
\begin{array}{l}\text { High } \\
\text { Expectations }\end{array}\end{array}$ & -2.43 & .020 & 0.39 & 4.78 & 0.62 & 5.09 & 0.77 \\
\hline
\end{tabular}

Figure 26. Support and High Expectations

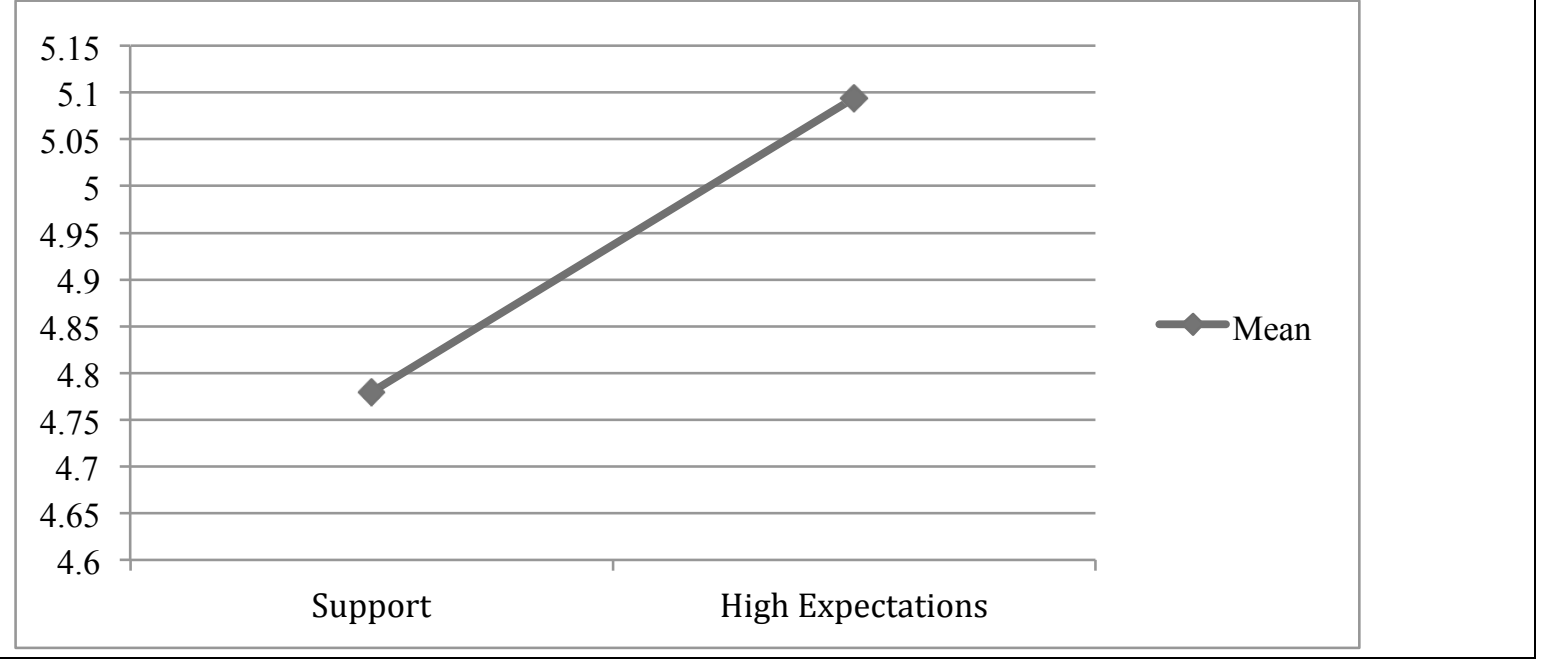

Figure 26. Mean of support and high expectations. 
Intellectual Stimulation and High Expectations Correlation. The researcher worked with StatisticsSolutions staff to run statistical tests of raw data. A dependent sample $t$-test was conducted to assess if there were differences in Intellectual Stimulation and High Expectations. Prior to analysis, the assumption of normality was assessed using a Shapiro-Wilk test. The result of the test was significant, $p=.018$, violating the assumption of normality. However, Howell (2010) suggests that the $t$-test is robust despite violations of normality.

The results of the dependent sample $t$-test were significant, $t(38)=-3.10, p=.004$, suggesting that there was a difference in Intellectual Stimulation and High Expectations. Intellectual Stimulation had a significantly lower mean than High Expectations. According to Cohen (1988), the difference between the two groups had a small effect size. Results of the dependent sample $t$-test are displayed in Table 33. Figure 27 shows the mean of Intellectual Stimulation and High Expectations.

Table 33

Dependent Sample t-Test for Intellectual Stimulation and High Expectations

\begin{tabular}{|c|c|c|c|c|c|c|c|}
\hline \multirow[b]{2}{*}{ Variable } & \multirow[b]{2}{*}{$t(38)$} & \multirow[b]{2}{*}{$p$} & \multirow[b]{2}{*}{ Cohen's $d$} & \multicolumn{2}{|c|}{$\begin{array}{l}\text { Intellectual } \\
\text { Stimulation } \\
\end{array}$} & \multicolumn{2}{|c|}{ High Expectation } \\
\hline & & & & $M$ & $S D$ & $M$ & $S D$ \\
\hline $\begin{array}{l}\text { Intellectual } \\
\text { Stimulation- } \\
\text { High } \\
\text { Expectations }\end{array}$ & -3.10 & .004 & 0.50 & 4.68 & 0.84 & 5.09 & 0.77 \\
\hline
\end{tabular}




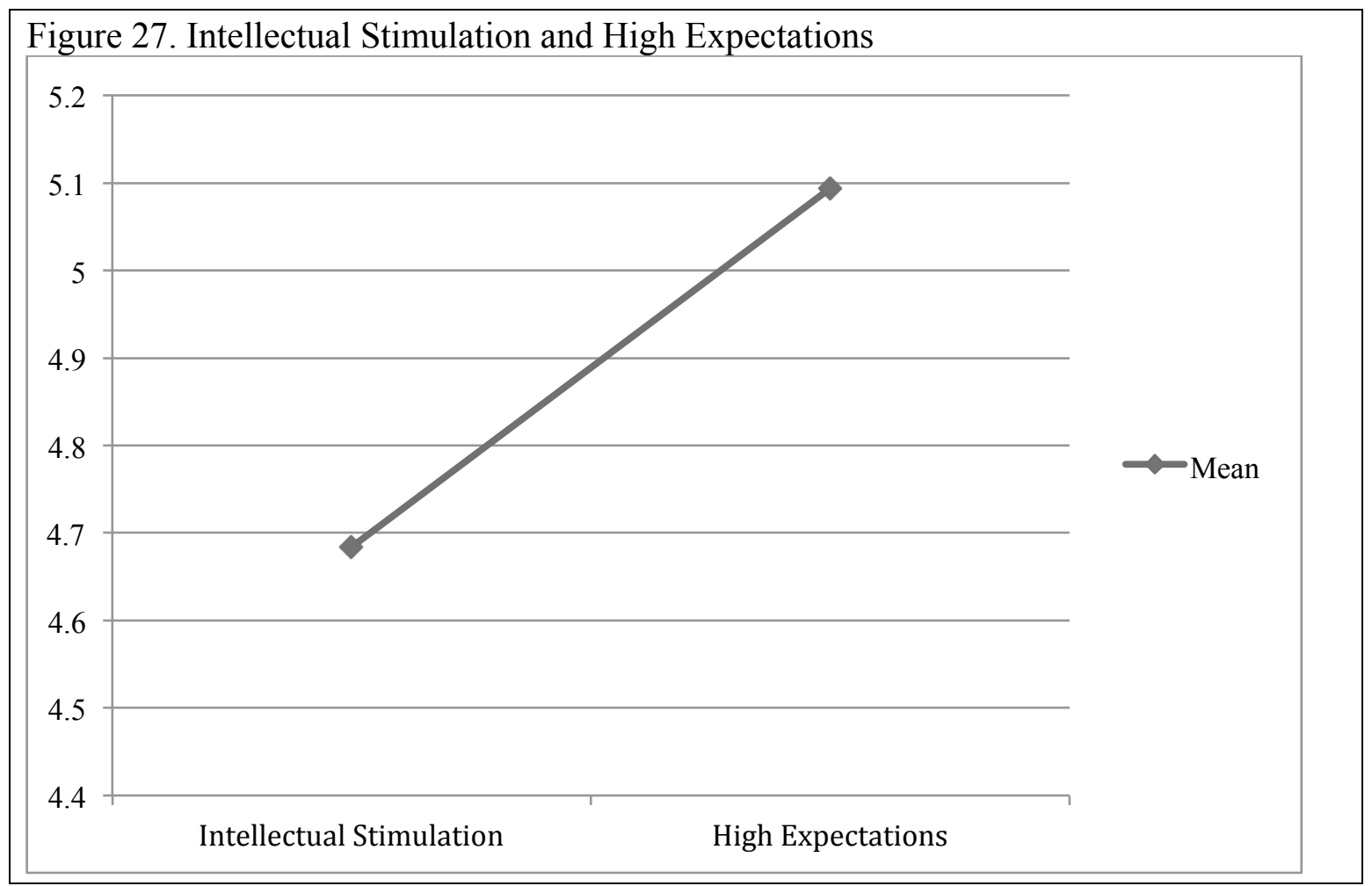

Figure 27. Mean of intellectual stimulation and high expectations.

\section{Synthesis of Quantitative Data}

Even though results of six of the dependent sample $t$-test were significant, suggesting differences between some of the continuous variables, the effect sizes of the correlations were small. This was not an unexpected outcome. If the researcher had conducted a study comparing high performing schools with low performing schools, statistically significant differences may have been observed between the schools on some or all of the continuous variables. However, it is important to acknowledge the significant correlations and the relative value to this study. The continuous variables found to be significant are shown in Table 34. 
Leadership Practices

Table 34

Continuous Variables Found to be Significant Based on a Dependent Sample t-Test

\begin{tabular}{|l|l|l|l|l|c|}
\hline \multicolumn{1}{|c}{ Variables } & \multicolumn{1}{c}{$S D$} & \multicolumn{2}{c|}{ Cohen's $d$} & $\begin{array}{c}\text { Correlation } \\
\text { Coefficient }\end{array}$ \\
\hline Vision & 4.82 & 0.62 & .006 & 0.46 & .64 \\
High Expectations & 5.09 & 0.77 & & & \\
\hline Appropriate Model & 5.00 & 0.79 & .022 & 0.38 & .64 \\
Group Goals & 4.77 & 0.65 & & & \\
\hline Appropriate Model & 4.97 & 0.78 & .035 & 0.35 & .48 \\
Intellectual Stimulation & 4.68 & 0.84 & & & \\
\hline Group Goals & 4.73 & 0.63 & .001 & 0.55 & .58 \\
High Expectations & 5.09 & 0.77 & & & .34 \\
\hline Support & 4.78 & 0.62 & .020 & 0.39 & .47 \\
High Expectations & 5.09 & 0.77 & & & \\
\hline Intellectual Stimulation & 4.68 & 0.84 & .004 & 0.50 & .47 \\
High Expectations & 5.09 & 0.77 & & & \\
\hline
\end{tabular}

$p \leq .050$

These factors are statistically significant which mean the differences are likely to be real differences and are not due to chance. For example, with a larger sample size, it would still be expected to find a low correlation between Support and High Expectations. In contrast to this, the correlation between Vision and Appropriate Model (not significant) might be an anomaly based on the small sample size of this study.

Open-ended Survey Question Responses. The researcher added three openended survey questions to the survey to elicit further information relative to the research questions.

The questions were:

1. How does the principal allocate school and district resources to support programs and instruction effective in improving growth in academic achievement of children in this high poverty school?

2. How do the principal's practices support programs effective in improving growth in academic achievement of children in in this high poverty school? 
3. Is there any other information you would like to add about principal leadership practices or other factors that improve growth in academic achievement for children in this school?

Responses to these questions resulted in qualitative, nonnumeric data that was coded and analyzed by the researcher. These responses yielded the following common themes: 1) allocation of resources to support student achievement; 2) use of data to inform instruction; 3) principals with elementary teaching experience; and 4) teamwork and shared leadership.

Allocation of resources to support student achievement. The principal and teacher responses to Question 1 showed a consistent pattern of understanding that district and school resources should be allocated to the instructional program and academic needs of students. The principals in each of the schools responded to this question and noted that school resources, including professional development, are allocated based on the instructional needs of students. Two of the principals reflected that teachers and staff are asked for input on resource allocations. Teachers who responded to this question have a clear understanding about how and why the principal allocates resources, including time, district allocations, and donations as shown by the following comments from different teachers in these schools:

She is trying to spread out funds evenly to meet our school improvement goal with the peer observation process. That way, we're all involved, and to just a few members who use the funds to attend outside conferences.

Decisions are based on student need and what will bring the premium results. There is an effort to be fair and to reach as many students with our limited resources as possible. 
Resources are allocated based on greatest need and greatest student impact. The principal will always put the needs and benefits of the students first.

School improvement funds are allocated to professional development activities that will increase student achievement. Principal will advocate for resources from the district if we don't have them; she doesn't always get it but she is willing to ask and make an effort.

The principal allocates financial resources as they are available. She gives the impression that she will do everything in her power to provide necessary resources, especially as it relates to increasing student achievement. Her actions support her passion.

The daily schedules at these three schools were structured to provide core instruction to each student, supported by intervention time that is provided in small groups. The principals and teachers at all three schools identified instructional assistants as one of their most significant resources for meeting the needs of each student. Teacher comments included:

One of the biggest resources we have is our educational assistants. Our principal has designed our daily schedule to keep as many people as possible in classrooms during reading and math instruction.

Assistant time is divided equally and fairly, primary doesn't get all the support or upper grades. We all get what is necessary for our school wide schedule and to keep our systems in place.

Our current Principal saw a need for a two-hour assistant in grade one, due to large class sizes and academic needs of our students. Because of her advocating for our students, funds were allocated for these assistants in each first grade classroom.

As often as possible, the principal hires and shifts around the schedules of assistants to fit high-needs classrooms.

The principal focuses most of our funding on providing instructional assistants to support student growth in reading and math. There is always at least one other adult assisting either the whole class or small groups during these subject areas. It is probably our biggest priority. 
Use of data to inform instruction. A second common theme emerging from the open-ended survey responses was the use of data to inform instruction. Teacher reflections provided the greatest insight into this theme, including the powerful statement that follows:

We are a very data driven school. I have been teaching for 20 years, nine years at this school and four years with my current principal. I have taught under a total of three amazing principals who were all very different, and who all supported me and made me a better teacher. I believe I have experienced the most stress and frustration under our current principal - but I don't necessarily think this is a bad thing. The principal challenges me to look at how my teaching is affecting student learning in a very practical and data driven manner.

Other teachers in these schools also reflected on the use of data to inform instruction.

We practice a school wide extra reading half-hour in which students are grouped according to their reading abilities and given instruction corresponding to that. We meet every 4-6 weeks to compare data, and to regroup students as they progress in ability or change needs. We do the same thing with an extra half-hour of math instruction. We meet every 4 weeks to assess and regroup as necessary.

As a district, we are following the RTI model and continually looking at data to inform our instruction and goals for students.

Principals with elementary teaching experience. The third common theme

emerging from the open-ended questions mirrored teacher responses from the focus

groups. The teachers in these three schools felt strongly that elementary schools are best

served by principals with elementary teaching experience. The following statements from the open-ended responses support this theme.

Elementary principals need to have elementary teaching experience. Elementary is a different world than middle and high school. I have worked for two principals in my career that came from the high school. Both were ill equipped to lead staff or work closely in the community in the way that is expected of elementary staff. 
You have to love kids, be resourceful, and keep a good sense of humor to juggle the fragile job of educating families in poverty.

Having just come from the classroom as a former teacher in this district, I feel our principal has a clear understanding of the challenges that teachers face with high poverty level students and large class sizes. Her expectations seem challenging, yet realistic.

Since our principal taught in a classroom for many years, she understands the challenges we face in our classrooms. She does learning walks through classrooms and knows what is going on in each so she is able to support or guide teachers in best practices. She is visible throughout the school and interacts with children and their families in a positive way.

The principal's practices are lead by example and expertise from her own personal experiences as a classroom teacher. She brings to her leadership the classroom perspective.

This theme conveyed teachers' perspectives that their work in the classroom is supported by principal practices that are grounded in the context of the knowledge required and the experiences of elementary school teachers.

Shared leadership and teamwork. The fourth theme that emerged from the openended questions was that of shared leadership and teamwork between the principal and teachers and among the teachers. This theme is evident in principal responses about gaining input from and listening to the voices of teachers and from the teacher responses that follow.

We (principal and teachers) have collaborated as a team and we utilize all assistants in many different ways to help reach our goals for our students.

The principal supports giving us time to work together as grade-level teams during late-starts and/or by taking a day to have a sub so we can plan our reading or math programs (including whole class, small group, and enrichment groups). She looks for consensus on what we, as a staff, need to provide better instruction in the classroom in terms of physical materials, be it reading based science text, chrome books, spelling programs, etc. 
A positive attitude and teamwork approach has turned our building around from how it was with previous principals. We genuinely care for each other as a staff and have those relationships to fall back on.

[The principal] encourages all staff members to have a voice and listens to that voice.

When you can teach in a SAFE, SUPPORTIVE, and COLLABORATIVE environment . . . one where ALL voices are heard and honored . . . one where our talents are allowed to combine and flourish . . . it opens many doors to possibility. Great leaders are the ones who are willing to set their egos aside and help others to reach their potential. Great leaders draw others TOWARD them and not away from them. GREAT Principals are in the classroom, sleeves rolled up, and helping when possible or needed. This is what our Principal does!!!!

These responses from principals and teachers further confirmed the themes of shared leadership and teamwork that emerged from the other data sources.

\section{Document Review}

The researcher completed a document review of available public documents for each of the three schools. The documents included web pages sponsored by the school or district, articles in local newspapers, Oregon school and district report cards, district board reports and minutes, and other documents revealed through a web-based search. In addition, the researcher asked school leadership for any relevant documents such as school improvement plans, staff meeting notes, or other documents that might not have been available online. The researcher carefully reviewed over 100 documents, 30 to 40 documents per school, both before and during data collection. The document review for all three schools consistently provided the following:

- Facts about the school and district;

- Procedural information like testing schedules, picture-taking days, holiday schedules, and bus procedures; 
- Newsletters with descriptions of school activities and where school resources could be obtained; and

- Oregon State Report cards with a message from the principal.

One school was acknowledged at a school board meeting for a national award they received. Another school was recognized at a board meeting for receiving a Level 5 on the Oregon State Report card and for being named a Model school. Only one of the schools had a publically available school improvement plan.

All of the schools maintained a website and/or a Facebook page as a communication tool for parents and the community. It was common to find a message from the principal on those sites. Wording of those messages reflected some of the same themes observed in the interview, focus groups, and open-ended questions. These included:

- The staff at this school is excellent. They are working tirelessly on meeting the emotional, educational, and social needs of each and every student;

- We set high behavioral and academic expectations;

- We strive to establish positive relationships with all students; and

- Dedicated, caring, expert staff is committed to inspiring each student to grow, succeed, and achieve high levels of academic success.

Overall, the initial document review provided the researcher a general sense of school and community demographics, organizational features of the schools and/or districts, and some conversational points for introductory meetings with principals. The researcher reviewed documents after data collection as part of the process of data 
triangulation aimed at supporting the study findings. The document review did not confirm or refute the findings in other sections of the study, nor did it add any new information.

\section{Synthesis of results}

This study found themes in the data, relative to principal leadership practices in these three high poverty K-5 Model schools, consistent with research suggesting that successful leadership can play a role in improving student learning (Leithwood et al., 2004; Louis et al., 2010; Marzano et al., 2005; Waters et al., 2003). Through analysis of the data from multiple sources, the researcher identified themes that showed consistency across all participant groups and were supported by the results of the quantitative survey and open-ended questions. The researcher identified these themes based on analysis of the data from the principal interviews, a quantitative survey with three open-ended questions, teacher focus groups at each school, and parent/guardian focus groups at each school.

The themes elicited from the principal interviews are displayed in Table 35.

Table 35

Themes of Principal Responses by School

\begin{tabular}{|l|c|c|c|c|c|c|}
\hline $\begin{array}{c}\text { Elementary } \\
\text { School }\end{array}$ & $\begin{array}{c}\text { Address } \\
\text { Biases }\end{array}$ & $\begin{array}{c}\text { High } \\
\text { Expectations }\end{array}$ & $\begin{array}{c}\text { Positive } \\
\text { Support }\end{array}$ & $\begin{array}{c}\text { Meet } \\
\text { Basic } \\
\text { Needs }\end{array}$ & $\begin{array}{c}\text { Shared } \\
\text { Leadership }\end{array}$ & $\begin{array}{c}\text { Personal } \\
\text { Attributes }\end{array}$ \\
\hline Atlas & $\checkmark$ & $\checkmark$ & & $\checkmark$ & $\checkmark$ & $\checkmark$ \\
\hline Brighton & & $\checkmark$ & $\checkmark$ & $\checkmark$ & & $\checkmark$ \\
\hline Camden & $\checkmark$ & $\checkmark$ & $\checkmark$ & & $\checkmark$ & $\checkmark$ \\
\hline
\end{tabular}


Leadership Practices

The themes revealed through the teacher focus groups regarding principal leadership practices are displayed in Table 36. These themes intersect with the principal responses relative to Meeting Basic Needs, Shared Leadership, and Personal Attributes.

Table 36

Themes of Teacher Responses by School

\begin{tabular}{|l|c|c|c|c|c|}
\hline $\begin{array}{c}\text { Elementary } \\
\text { School }\end{array}$ & $\begin{array}{c}\text { Meet Basic } \\
\text { Needs }\end{array}$ & Caring & $\begin{array}{c}\text { Elementary } \\
\text { Teaching } \\
\text { Experience }\end{array}$ & $\begin{array}{c}\text { Shared } \\
\text { Leadership }\end{array}$ & $\begin{array}{c}\text { Personal } \\
\text { Attributes }\end{array}$ \\
\hline Atlas & $\checkmark$ & $\checkmark$ & $\checkmark$ & $\checkmark$ & $\checkmark$ \\
\hline Brighton & $\checkmark$ & $\checkmark$ & $\checkmark$ & $\checkmark$ & $\checkmark$ \\
\hline Camden & $\checkmark$ & $\checkmark$ & $\checkmark$ & $\checkmark$ \\
\hline
\end{tabular}

The common themes among the parents/guardians intersected with principal and teacher responses relative to Meeting Basic Needs and Personal Attributes. Additional themes of Care,Positive Support, and Pride in Local School were revealed and are displayed in Table 37.

Table 37

Themes of Parent/Guardian Responses by School

\begin{tabular}{|l|c|c|c|c|c|}
\hline $\begin{array}{c}\text { Elementary } \\
\text { School }\end{array}$ & $\begin{array}{c}\text { Meet Basic } \\
\text { Needs }\end{array}$ & Care & $\begin{array}{c}\text { Positive } \\
\text { Support }\end{array}$ & $\begin{array}{c}\text { Pride in Local } \\
\text { School }\end{array}$ & $\begin{array}{c}\text { Personal } \\
\text { Attributes }\end{array}$ \\
\hline Atlas & $\checkmark$ & $\checkmark$ & & $\checkmark$ & $\checkmark$ \\
\hline Brighton & $\checkmark$ & $\checkmark$ & $\checkmark$ & $\checkmark$ & $\checkmark$ \\
\hline Camden & $\checkmark$ & $\checkmark$ & $\checkmark$ & $\checkmark$ & $\checkmark$ \\
\hline
\end{tabular}


Themes revealed through principal and teacher responses to three open-ended survey questions added two additional themes to the study. These themes were allocation of resources and the use of data. The common themes revealed through analysis of the open-ended survey questions are shown in Table 38.

Table 38

Themes of Open-ended Survey Questions by Respondents and School

\begin{tabular}{|l|c|c|c|c|c|}
\hline \multicolumn{2}{|c|}{$\begin{array}{c}\text { Elementary School and } \\
\text { Respondents }\end{array}$} & $\begin{array}{c}\text { Allocation of } \\
\text { Resources }\end{array}$ & Use of Data & $\begin{array}{c}\text { Elementary } \\
\text { Teaching } \\
\text { Experience }\end{array}$ & $\begin{array}{c}\text { Shared } \\
\text { Leadership \& } \\
\text { Teamwork }\end{array}$ \\
\hline Atlas & PR & $\checkmark$ & $\checkmark$ & & $\checkmark$ \\
\cline { 2 - 6 } & T & $\checkmark$ & $\checkmark$ & $\checkmark$ & $\checkmark$ \\
\hline Brighton & PR & $\checkmark$ & $\checkmark$ & & $\checkmark$ \\
\cline { 2 - 7 } & T & $\checkmark$ & $\checkmark$ & $\checkmark$ & $\checkmark$ \\
\hline Camden & PR & $\checkmark$ & $\checkmark$ & $\checkmark$ & $\checkmark$ \\
\cline { 2 - 7 } & T & $\checkmark$ & $\checkmark$ & $\checkmark$ & \\
\hline
\end{tabular}

PR (Principal), T (Teacher)

A synthesis of common themes relative to principal leadership practices as revealed through principal interviews, principal and teacher responses to open-ended questions in the survey, and teacher and parent/guardian responses to the focus group questions is displayed in Table 37. Common themes most consistently reported were 1) High Expectations, 2) Meeting Basic Needs, 3) Shared Leadership and Teamwork, 4) Use of Data, and 5) Personal Attributes of the principal. These common themes and others specific to one or more of the data sources are shown in Table 39. 
Leadership Practices

Table 39

All Common Themes by Respondents and School

\begin{tabular}{|c|c|c|c|c|c|c|c|c|c|c|c|}
\hline $\begin{array}{l}\text { Elementary } \\
\text { and Respo }\end{array}$ & $\begin{array}{l}\text { hool } \\
\text { ents }\end{array}$ & 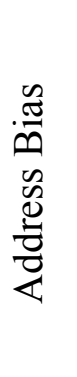 & 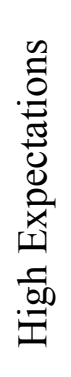 & 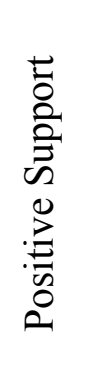 & 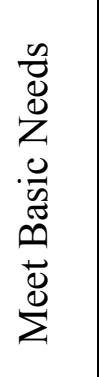 & 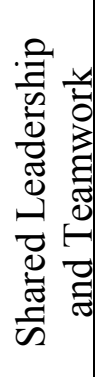 & $\underset{U}{\mathscr{U}}$ & 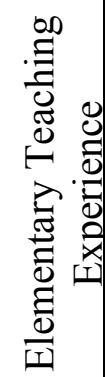 & 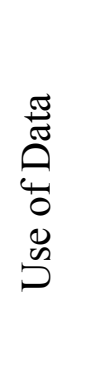 & 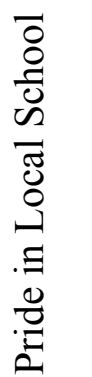 & 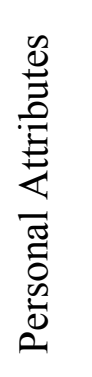 \\
\hline Atlas & PR & r & & & $\checkmark$ & $\checkmark$ & & & $\checkmark$ & & $\checkmark$ \\
\hline Elementary & $\mathrm{T}$ & & & & $\checkmark$ & $\checkmark$ & & $\checkmark$ & $\checkmark$ & & $\checkmark$ \\
\hline & PA & & & & $\checkmark$ & & & & & $\checkmark$ & $\checkmark$ \\
\hline Brighton & PR & s & & $\checkmark$ & $\checkmark$ & $\checkmark$ & & & $\checkmark$ & & $\checkmark$ \\
\hline Elementary & $\mathrm{T}$ & & & & $\checkmark$ & $\checkmark$ & & $\checkmark$ & $\sqrt{ }$ & & $\checkmark$ \\
\hline & PA & & & $\checkmark$ & $\checkmark$ & & & & & $\checkmark$ & $\checkmark$ \\
\hline Camden & PR & r & & $\checkmark$ & $\sqrt{ }$ & $\checkmark$ & & & $\checkmark$ & & $\checkmark$ \\
\hline Elementary & $\mathrm{T}$ & & & & $\checkmark$ & $\checkmark$ & & $\checkmark$ & $\checkmark$ & & $\checkmark$ \\
\hline & PA & & & $\checkmark$ & $\checkmark$ & & & & & $\checkmark$ & $\checkmark$ \\
\hline
\end{tabular}

PR (Principal), T (Teacher), PA (Parent/Guardian)

Data concern. As can be true in schools in general, and sometimes frequently in high poverty schools, one of the schools had experienced three different principals over the past six years. The principal new to the school this year exhibited many of the characteristics of the principal who had been in their school longer, and the teachers' reflections of this principal were positive. The Oregon report card data that resulted in the school being identified as a Model school by ODE is a reflection of the time the previous principal was leading the school. As the researcher reviewed the data to verify themes that appeared to be consistent across schools, it became important to go back to the 
teachers for further clarification about leadership skills the previous principals exhibited.

From the responses received, it was evident that one principal was charismatic, worked hard to drive up student success and set the bar/expectations high. One teacher remarked "The principal united our staff and began the systems we have going that have helped students be successful. That principal's leadership was well-informed, supportive of staff, and always put kids first." Teacher comments about the principal there during the time the school qualified as a Model school included that there was a lack of elementary experience and a significant focus on "the numbers." This principal was very data driven according to one teacher. The teachers who responded to my follow-up questions reflect on the school's success due to the charismatic principal and the teachers' desires to continue the work started with that principal.

\section{Interpretation of findings}

This study examined the phenomena of principal leadership practices of three high-poverty K-5 elementary schools in Oregon identified as Model schools by ODE through the analysis of qualitative and quantitative data (Lunenburg \& Irby, 2008, p. 96). This study was guided by a central research question (Creswell, 2003, p. 105): What principal leadership practices can be observed in high poverty K-5 Model schools that have improved growth in academic achievement of children attending these schools? Related questions were designed to narrow the focus of the study while still leaving open the questioning (Creswell, 2003). The related questions for this study were as follows:

1. How do principal practices support programs improving growth in academic achievement of children in high poverty K-5 Model schools? 
2. How do principals allocate school and district resources to support programs and instruction improving growth in academic achievement of children in high poverty K5 Model schools?

3. How do principals share leadership in high poverty K-5 Model schools where growth in academic achievement of children is improved?

4. What other practices do principals put to use in high poverty K-5 Model schools that have improved academic achievement of children?

The researcher posed the research questions not to prove or disprove that principal practices have a direct impact on student academic growth but to explore principal practices within the context of three K-5 elementary schools in Oregon that have improved academic growth of children in high poverty schools. The principal leadership practices emerging from the data in this study are supported by empirical research about leadership practices and/or characteristics that influence student academic achievement (Hallinger, 2005; Hallinger, Bickman, \& Davis, 1996; Hallinger \& Heck, 1998; Hattie, 2009; Jacobson et al., 2004; Leithwood \& Jantzi, 2012; Leithwood \& Louis, 2012; Leithwood et al., 2004; Lyman \& Villani, 2004; Marks \& Printy, 2003; and, Water, Marzano, \& McNulty, 2003). Principal practices and attributes reflective of transformational leadership, instructional leadership, and balanced leadership were revealed.

The researcher conceptualized the position of principal leadership relative to school program characteristics, shared leadership, resource allocation, and other factors that might be revealed in the study. Based on this framework, the themes that emerged from the data suggest elements of a principal's leadership practices appear to have influenced school operations, program implementation, and teacher work in ways that 
contributed to the academic success of children in these three high poverty K-5 elementary schools.

\section{Limitations of the study}

The limitations of this study were based on the sample population and the availability of data. First, the sample population was high poverty K-5 elementary schools in Oregon identified by ODE as Model schools in 2012, 2013, and/or 2014. This purposive sampling procedure decreased the generalizability of findings to other high poverty elementary schools in Oregon or in other states (Creswell, 2003). The researcher's decision to include only three richly researched cases in the study presented a limitation on confidence in analytic generalizations (Miles et. al., 2014).

Next, Oregon Model school identifications were based on the results of instruments that ODE has deemed valid and reliable. Oregon Statewide Assessments (OAKS), aligned with state standards, were used to measure the progress of students from 3 rd grade to 8 th grade, and $11^{\text {th }}$ grade (ODE, n.d.a.). Due to the specific focus and purpose of summative assessments, OAKS can only be used as part of a collection of evidence regarding the academic needs of individual students (ODE, n.d.a.). In addition, standardized assessments are not inherently responsive to the cultural heritages and personal experiences of underserved populations of students (Gay, 2010).

Next, data was collected from documents, quantitative surveys, interviews, and focus groups in order to triangulate the outcomes of the principal interview analyses from each data source. Only those documents that were readily and publicly made available to staff, parents or guardians, and the community were analyzed. The surveys, interviews 
and focus groups were completed by a group of principals and teachers who volunteered to participate and parents or guardians in the selected schools who were self-selected. Their perspectives were not necessarily representative of the perspective of all teachers and parents/families in the selected schools. In addition, schools are dynamic environments in which the students, teachers, and administrators can change from one year to the next.

Finally, this case study, like all case studies, had the potential for validity errors (Peterson, 2012). To improve validity, the researcher posed "how" research questions that influenced the use of strategies to address external validity (Yin, 2014). The researcher used triangulation of data sources, data types, and methods, and examined reflexivity to minimize methodological threats to interpretation of the data (Yin, 2014). 


\section{CHAPTER 5}

\section{SYNTHESIS, DISCUSSION, AND CONCLUSIONS}

Chapter 4 presented analysis of the data related to the central research question for this study: What principal leadership practices can be observed in high poverty K-5 Model schools that have improved growth in academic achievement of children attending these schools? Chapter 5 synthesizes the study, discusses the findings, identifies implications for educational practice in schools and districts, makes recommendations for additional research, and offers concluding remarks.

\section{Synthesis of the Study}

As the number of children living in poverty continues to increase in Oregon, the impact of NCLB and the accountability for schools to ensure academic success for all children continues to present significant challenges to principals and teachers to provide equitable access to learning no matter what issues children may bring to school. Examination of empirical research shows persistent evidence that principal leadership impacts student success in school (Hallinger \& Heck, 1996; Hallinger, Bickman, \& Davis, 1996; Hattie, 2009; Leithwood et al., 2006; Waters, Marzano, \& McNulty, 2003).

This study examined three K-5 Title I elementary schools in Oregon that demonstrated success in improving student academic growth in spite of high rates of poverty of students and of their respective communities. The researcher examined leadership practices of the principal in the three schools through the lens of the central research question: What principal leadership practices can be observed in high poverty K5 Model schools that have improved growth in academic achievement of children 
attending these schools? The researcher examined principal practices regarding support of programs and instruction, allocation of resources, shared leadership, and other practices as identified by teachers, parents, and publicly available documents. This study identified themes common for principal leadership practices in each of three Model schools effective in improving growth in academic achievement of children attending these high poverty schools.

An ecological framework shaped the theoretical perspective for this study. Children living in poverty face lack of proper housing, families that are unemployed or underemployed, poor or nonexistent medical care, poor and sometimes dangerous environmental factors, and lack of access to social benefits. The ecological framework used by Duncan and Murnane (2011) to explore the relationships between income inequality, families, neighborhoods and local labor markets, leading to the potential for residential segregation by income, limited political influence, and the depletion of other community resources seen as impacting school quality informed the perspective of the researcher. It is impossible for schools to compensate for all of these factors; however, it is possible for schools to invest the resources necessary to help children succeed academically. Principal leadership practices, program characteristics, shared leadership, resource allocation and other factors function within the context of school and community systems to support student growth in high poverty schools (Figure 3).

A multiple-case mixed method approach was employed in this study. Data sources included in-depth interviews with the principals, focus groups with teachers and parents, quantitative surveys from principals and teachers with open-ended questions, and 
document review. Three Model schools identified to participate in the study were representative of other K-5 Title I elementary schools in Oregon regarding school size and percentage of students eligible for FRPL.

\section{Discussion of the Findings}

The three K-5 Title I elementary schools in this study each achieved a rating of Level 5 on the Oregon Report Card in one or more years from 2012 to 2014. These high poverty schools were identified as examples of successful student outcomes as demonstrated by OAKS state assessments and other achievement factors identified in the Oregon State Report Cards (ODE, 2012). The overall report card rating is intended to summarize particular successes and challenges of a school. It is based on a combination of up to five factors. Three of these factors come from standardized test scores in reading and math: student achievement, student growth, and the growth of underserved subgroups. These schools were among K-5 schools in Oregon with the highest rate of student poverty as determined by eligibility for FRPL.

The schools in this study demonstrated success in improving the academic achievement of students by increasing overall academic achievement scores on OAKS assessments and by improving student growth in student subgroups, thereby achieving a Level 5 on the Oregon Report Card rating and being identified as a Model school. This study looked at leadership practices evident in the schools as reported by principals, teachers, and parents/guardians. Themes identified were consistent with research-based leadership theories shown to have a positive effect on student achievement (Hallinger, 2005; Jantzi \& Leithwood, 1996; Leithwood et al., 2004; Waters et al., 2003). 
This study identified themes of leadership practices including 1) high expectations, 2) meeting children's basic needs, 3) shared leadership and teamwork, 4) use of data, and 5) personal attributes of the principal. Other themes considered important to one or more groups of respondents but not necessarily to all included 1) caring, 2) positive support, 3) addressing biases about children and families in poverty, 4) principal's elementary teaching experience, and 5) pride in the local school. As such, the findings of this study support the knowledge base in educational leadership regarding principal leadership as a factor in schools that impact the academic growth of children (Hallinger, 2005; Hallinger, Bickman, \& Davis, 1996; Hallinger \& Heck, 1998; Hattie, 2009; Jacobson et al., 2004; Leithwood \& Jantzi, 2012; Leithwood \& Louis, 2012; Leithwood et al., 2004; Lyman \& Villani, 2004; Marks \& Printy, 2003; and, Water, Marzano, \& McNulty, 2003).

The results of the quantitative survey appear to positively support some of the themes of principal practices identified in the interviews and focus groups. The leadership characteristic of High Expectations had the highest mean response value of all the leadership characteristics from the survey and High Expectations was one of the themes most consistently reported by teachers and principals in the qualitative interviews and focus groups. The leadership characteristic of Appropriate Model had the second highest mean response value in the survey results and themes of leading by doing and providing good models emerged as Personal Attributes of the principals from respondents in the qualitative interviews and focus groups. Vision was a characteristic that had the third highest mean response value in the survey. Within this leadership characteristic 
category, two questions on the survey elicited responses regarding Shared Leadership.

Shared Leadership was one of the themes that was consistently reported in the qualitative responses by teachers and principals.

While this study did not attempt to identify one specific leadership model or style demonstrated by one or all of the principals in these schools, evidence of transformational leadership styles can be seen. The themes revealed in the data are consistent with the transformational leadership characteristics Jantzi and Leithwood (1996) described as factors in the PLQ, primarily those of holding high performance expectations, identifying and articulating a vision, and providing an appropriate model.

One of the most revealing themes identified in this study that suggests the presence of transformational leadership characteristics is the extent to which principals and teachers cited examples of shared leadership. Bass and Riggio (2006) suggest one of the paradoxes of transformational leadership, that of giving power away to others and getting better leadership results because of it, when they state:

A core element of transformational leadership is the development of followers to enhance their capabilities and their capacity to lead. What is often overlooked is how transformational leaders help develop leaders to be better contributors to the group effort-more creative, more resistant to stress, more flexible and open to change, and more likely to one day become transformational leaders themselves (pp. 55-56).

While concepts of transformational leadership were of interest to the researcher in seeking to better understand the principal leadership practices in these high poverty K-5 Model schools that are improving academic achievement of the students in the schools, it is important to acknowledge that theories or models such as transformational leadership, 
transactional leadership, or instructional leadership do not necessarily occur in isolation from one another and the presence of one does not exclude the possibility of the influences of the others.

The case of the school in the study that experienced different leaders with reportedly different leadership styles and yet achieved the same outcome as the other two schools caused the researcher to wonder about the context within which different leadership styles were experienced by teachers. Did the transformational characteristics of the principal described by teachers set the stage in the school for ongoing, continuous improvement? If the principal who followed this principal was more of a transactional leader and the achievement outcomes were sustained and further improved, resulting in the school identified as a Model school, what more do we need to know about the context in which that achievement was improved? This information could suggest that one leadership style could be a precursor to another, or occur in the same person at different times given the context of the organization, or that unknown interactions between the principals and teachers contributed to the positive outcomes.

There are three findings from this study that have the potential to extend the knowledge base in educational leadership. One of those findings was a theme that emerged consistently from teacher responses. The teachers working in these three K-5 elementary schools all reported an appreciation of the principals' prior experience as an elementary school teacher. This is a finding that warrants additional research. Another finding, from principal responses only, was a theme of addressing biases and assumptions about children and families living in poverty. In addition, while not emerging as a 
consistent theme, the fact that each of the principals in the study came from a background of poverty or a background similar to the schools in which they work warrants a better understanding of the impact this might have on their abilities to move student achievement in high poverty schools forward.

\section{Implications for Practice}

The results of this study suggest implications for several areas of educational leadership. First, the study suggests district implications for the hiring, support, and succession planning for principals in high poverty schools. Districts may want to look for evidence of leadership characteristics pertaining to Vision, Appropriate Model, and High Expectations in candidates they hire as principals in high poverty schools. Next, the results of the study suggest implications of personal attributes of principals that are observed as meaningful by teachers and parents, including being focused, supportive, and having knowledge and understanding of the community and students they serve. In addition, the study has potential implications for the allocation of resources by the state, districts, and by principals in high poverty schools, especially as they are evidenced in support of curriculum and instruction that serve the needs of students at all levels of learning. Finally, the results of the study have implications for districts and principals regarding community practices in high poverty communities.

\section{Recommendations for Further Research}

The findings from this study suggest several lines of study for further research. These could include conducting the study in additional settings, expanding the sample size of specific respondent groups, conducting comparative studies between schools with 
differing student outcomes, seeking more information on specific findings of the study such as the principal's teaching background and experience, and modifying the qualitative and quantitative instruments to reflect the findings of this study. An in-depth study of the schools that experienced different leaders with different styles could provide more information for understanding the nuances of different leadership styles as they apply in the same setting. These areas have the potential to refine the theoretical framework of the study, strengthen the implications for practice, and increase the generalizability of this study's findings.

\section{Concluding Remarks}

The schools in this study elicit pride from staff, parents and other community members. Teachers tend to stay in these schools and live in the communities. Generations of families have lived in the communities and attended the schools. Some families move within the school boundaries so their children can attend the schools. One of the schools is the most recently built school in the county. Another school came close to closure until the community rallied to keep it open. The teachers at one of the schools report they have changed and transformed their practices as the community has changed around the school, all the while maintaining a high level of expectations for the academic performance of children.

Parents and family members work hard in these communities to feed their children and to ensure they get to school. The families that have resources do not hesitate to support those who are struggling, and children are not made to feel like they are different or less than anyone else in the school. The schools are the centers of their 
communities and principals and teachers are highly regarded. There remains the belief in these parents that education is important for the futures of their children.

Many of the teachers represented in this study have taught in these schools for a number of years, and in spite of the challenges they face in helping each child to reach their potential, they plan to stay. The reality for many high poverty schools is a high turnover of teachers, so the stability and commitment of these teachers is important to acknowledge.

The principal practices evident in the three schools in this study were similarly identified in some measure by principals, teachers, and parents/guardians. They are practices that are consistently identified in the research as those found in leadership of schools that are successful in improving academic achievement for all children (Hallinger, 2005; Hallinger, Bickman, \& Davis, 1996; Hallinger \& Heck, 1998; Hattie, 2009; Jacobson et al., 2004; Leithwood \& Jantzi, 2012; Leithwood \& Louis, 2012; Leithwood et al., 2004; Lyman \& Villani, 2004; Marks \& Printy, 2003; and, Water, Marzano, \& McNulty, 2003). It was evident to the researcher that it takes courage and persistence, as well as leadership knowledge and skills, to improve academic achievement of children in these high poverty schools. Though it is important to remain cautious about making generalizations from a limited number of cases, the findings from this study lend support to the claim that there exists a set of core leadership practices that contribute to student achievement in high poverty schools. 


\section{REFERENCES}

American Psychological Association. (2007). Publication manual of the American psychological association ( $6^{\text {th }}$ ed.). Washington, DC: American Psychological Association.

American Psychological Association, Presidential Task Force on Educational Disparities. (2012). Ethnic and racial disparities in education: Psychology's contributions to understanding and reducing disparities. Retrieved from http://www.apa.org/ed/resources/racial-disparities.aspx

Apple, M. W. (2013). Can education change society? New York, NY: Routledge.

Applefield, J. M., Huber, R. L., \& Moallem, M. (2000, December). Constructivism in theory and practice: Toward a better understanding. High School Journal, 84(2), 35-53. Retrieved from http://people.uncw.edu/browse/page/7

Association for Supervision and Curriculum Development (1996, December). Finding common ground in an Era of Fragile Support. In Public Education and Democratic Society, (7), December INFO brief. Retrieved from http://www.ascd.org/publications/newsletters/policypriorities/dec96/num07/toc.aspx

Astington, J. W., \& Pelletier, J. (1996). The language of mind: Its role in teaching and learning. In D. R. Olson, \& N. Torrance (Eds.), The handbook of education and human development: New models of learning, teaching and schooling, pp. 593619. Cambridge, MA: Blackwell Publishers, Ltd.

Aud, S., Wilkinson-Flicker, S., Kristapovich, P., Rathbun, A., Wang, X., \& Zhang, J. (2013). The Condition of Education 2013 (NCES 2013-037). U.S. Department of Education, National Center for Education Statistics. Washington, DC. Retrieved from http://nces.ed.gov/pubs2013/2013037.pdf

Avolio, B. J. (1999). Full leadership development: Building the vital forces in organizations. Thousand Oaks, CA: Sage Publications.

Barth, P., Haycock, K., Jackson, H., Mora, K., Ruiz, P., Robinson, S., \& Wilkins, A. (Eds.), (1999). Dispelling the myth: High poverty schools exceeding expectations. Washington, DC: The Education Trust.

Bass, B. M. (1990, Winter). From transactional to transformational leadership: Learning to share the vision. Organizational Dynamics, 18(3), 19-31. Retrieved from http://www.sciencedirect.com/science/article/pii/009026169090061S 
Bass, B. M. \& Riggio, R. E. (2006). Transformational leadership $\left(2^{\text {nd }}\right.$ ed.). New York, NY: Taylor \& Francis Group, LLC.

Baxter, P., \& Jack, S. (2008, December). Qualitative case study methodology: Study design and implementation for novice researchers. The Qualitative Report, 13(4), 544-559.

Retrieved from http://www.nova.edu/ssss/QR/QR13-4/baxter.pdf

Beegle, D. M. (2007). See poverty . . Be the difference!: Discover the missing pieces for helping people move out of poverty. Tigard, OR: Communication Across Barriers, Inc.

Beegle, D. M. (2003, October/November). Overcoming the silence of generational poverty. Talking Points, 15(1), 11-20. Retrieved from http://www.combarriers.com/pdf/TP0151Overcoming.pdf

Bennis, W. (1999, July). The end of leadership: Exemplary leadership is impossible without full inclusion, initiatives, and cooperation of followers. Organizational Dynamics, 27(1), 71-80. Retrieved from http://www.sciencedirect.com.proxy.lib.pdx.edu/science/article/pii/S00902616008 $0008 \mathrm{X}$

Bennis, W. G. (1966). Changing organizations. In W. Warner Burke, D. G. Lake, \& J. W. Paine (Eds.), Organization change: A comprehensive reader (pp. 21-34). San Francisco, CA: Jossey-Bass.

Bennis, W. (1984). Transformative power and leadership. In T. J. Sergiovanni \& J. E. Corbally (Eds.), Leadership and organizational culture: New perspectives on administrative theory and practice (pp. 64-71). Urbana, IL: University of Illinois Press.

Bereiter, C., \& Scardamalia, M. (1996). Rethinking learning. In D. R. Olson, \& N. Torrance (Eds.), The handbook of education and human development: New models of learning, teaching and schooling, pp. 485-513. Cambridge, MA: Blackwell Publishers, Ltd.

Bloom, B. S. (Ed.), (1959). Taxonomy of educational objectives: The classification of educational goals. New York, NY: Longmans, Green \& Company.

Bogdan, R. C., \& Biklen, S. K. (1998). Qualitative research for education: An introduction to theory and methods ( $3^{\text {rd }}$ ed.). Boston, MA: Allyn \& Bacon.

Bolman, L. G., \& Deal, T. E. (2008). Reframing organizations: Artistry, choice, and leadership $\left(4^{\text {th }} e d\right.$.). San Francisco, CA: Jossey-Bass. 
Branch, G. F., Hanushek, E. A., \& Rivkin, S. G. (2013, Winter). School leaders matter: Measuring the impact of effective principals. Education Next, 13(1), 62-69. Retrieved from http://hanushek.stanford.edu/publications/school-leaders-mattermeasuring-impact-effective-principals

Bruner, J. (1960). The process of education. Cambridge, MA: Harvard University Press.

Bulach, C., Boothe, D., \& Pickett, W. (2006, August 21). Analyzing the Leadership Behavior of School Principals. Retrieved from the Connexions Web site: http://cnx.org/content/m13813/1.1/

Burke, W. W., Lake, D. G., \& Paine, J. W. (Eds.), (2009). Organization change: A comprehensive reader. San Francisco, CA: Jossey-Bass.

Burnes, B. (2004). Kurt Lewin and the planned approach to change: A reappraisal. In W. W. Burke, D. G. Lake, \& J. W. Paine (Eds.), Organization Change: A comprehensive reader (pp. 226-253). San Francisco, CA: Jossey-Bass.

Burns, K. (2012). The dustbowl (Television special shown on Public Broadcasting Service). Washington, DC: WETA, and The Dust Bowl Film Project, LLC.

Carter, S. C. (2000). No excuses: Lessons from 21 high-performing, high poverty schools. Washington, DC: The Heritage Foundation.

Case, R. (1996). Changing views of knowledge and their impact on educational research and practice. In D. R. Olson, \& N. Torrance (Eds.), The handbook of education and human development: New models of learning, teaching and schooling, pp. 75-99. Cambridge, MA: Blackwell Publishers, Ltd.

Cauthen, N. K., \& Fass, S. (2008, May). 10 important questions about child poverty \& family economic hardship. National Center for Children in Poverty. New York, NY: Columbia University.

Chamberlin, J. G. (2001). Upon whom we depend: The American poverty system. New York, NY: Peter Lang Publishing.

Chenoweth, K., \& Theokas, C. (2012). Getting it done: Leading academic success in unexpected schools. Cambridge, MA: Harvard Education Press.

Children's Defense Fund (2012). The state of America's children handbook. Retrieved from http://www.childrensdefense.org/child-research-data-publications/data/soac2012-handbook.pdf 
Chin, R., \& Benne, K. D. (1967). General strategies for effecting changes in human systems. In W. W. Burke, D. G. Lake, \& J. W. Paine (Eds.), Organization Change: A comprehensive reader (pp. 89-117). San Francisco, CA: Jossey-Bass.

Clegg, S. R. (1990). Modern organizations: Organization studies in the postmodern world. London: Sage Publications.

Cohen, J. (1988). Statistical power analysis for the behavioral sciences (2nd ed.). Hillsdale, NJ: Erlbaum.

Cohen, Manion, \& Morrison (2011). Research methods in education ( $7^{\text {th }}$ ed.). New York, NY: Routledge.

Coleman, J. (1968). The concept of equality of educational opportunity. Harvard Educational Review 38(1), 7-23.

Coley, R. J., \& Baker, B. (2013). Poverty and education: Finding the way forward. Princeton, NJ: Educational Testing Service. Retrieved from www.ets.org/research

Comer, J. P. (1988, November). Educating poor minority children. Scientific American, $259(5), 42-48$.

Cremin, L. A. (2013). Horace Mann. Encyclopædia Brittanica. Inc. Retrieved on October 27, 2013 from http://www.britannica.com/EBchecked/topic/362466/Horace-Mann

Creswell, J. W. (1994). Research design: Qualitative \& Quantitative Approaches. Thousand Oaks, CA: Sage Publications.

Creswell, J. W. (2003). Research design: Qualitative, quantitative, and mixed methods approaches $\left(2^{\text {nd }}\right.$ ed.). Thousand Oaks, CA: Sage Publications.

Cunningham, P. (2007, January). Early years teachers and the influence of Piaget: Evidence from oral history. Early Years: An International Research Journal, 26(1), 5-16, DOI: 10.1080/09575140500507769

Darling-Hammond, L. (1997). The right to learn: A blueprint for creating schools that work. San Francisco, CA: Jossey-Bass, Inc.

Deal, T. (1990, May). Reframing reform. Educational Leadership, 47(8), 6-12. Retrieved from http://www.ascd.org/ASCD/pdf/journals/ed_lead/el_199005_deal.pdf

Delpit, L. (2006). Other people's children: Cultural conflict in the classroom. New York, NY: The New Press. 
Department of Health and Human Services (2014, January). Annual update of the HHS poverty guidelines. Federal Register, 79(14), 3593-3594.

Dewey, J. (1949). Experience and education. New York, NY: The MacMillan Company.

Dewey, J. (1963). The school and society (Rev. ed.). Chicago, IL: The University of Chicago Press.

Downs, R. B. (1974). Horace Mann: Champion of public schools. New York, NY: Twayne Publishers, Inc.

Duncan, A. (2013, August 27). Remarks at School Without Walls on anniversary of March on Washington. Retrieved from http://www.ed.gov/news/speeches/arneduncan-remarks-school-without-walls-anniversary-march-washington

Duncan, G. J., \& Magnuson, K. (2011). The nature and impact of early achievement skills, attention skills, and behavior problems. In G. J. Duncan \& R. J. Murnane (Eds.), Whither opportunity? Rising inequality, schools, and children's life chances (pp. 47-69). New York, NY: Russell Sage Foundation.

Duncan, G. J., \& Murnane, R. J. [Eds.], (2011). Whither opportunity? Rising inequality, schools, and children's life chances. New York, NY: Russell Sage Foundation.

Duncan, G. J., \& Murnane, R. J. (2014). Restoring opportunity: The crisis of inequality and the challenge for American education. Cambridge, MA: Harvard Education Press.

Edmonds, R. (1979, October). Effective schools for the urban poor. Educational Leadership, 37(1), 15-24. Retrieved from http://www.ascd.org/ASCD/pdf/journals/ed_lead/el_197910_edmonds.pdf

Edwards, N. (1949, Winter). Social forces in American education. History of Education Society 1(2), 70-77.

Elementary and Secondary Education Act of 1965, Pub. L. No. 89-10, 79 Stat. 27, 1965. Retrieved from http://eric.ed.gov/?id=ED017539

Elmore, R. F. (2000, Winter). Building a new structure for school leadership. Washington, DC: The Albert Shanker Institute.

Etzioni, A. (1964). Modern organizations. Englewood Cliffs, NJ: Prentice-Hall, Inc. 
Erickson, F. (1986). Qualitative methods in research on teaching. In M. C. Wittrock (Ed.), Handbook of research on teaching ( $3^{\text {rd }}$ ed.), pp. 199-161. New York, NY: Macmillan.

Field, R. (2005). John Dewey. Internet Encyclopedia of Philosophy (July 14). Retrieved from http://www.iep.utm.edu/dewey/

Filler, L. (Ed.), (1965). Horace Mann on the crisis in education. Yellow Springs, OH: Antioch Press.

Ford, D. Y. (2010). Recruiting and retaining gifted students from diverse ethnic, cultural, and language groups. In J. A. Banks, \& C. A. Banks (Eds.), (2010). Multicultural education: Issues and perspectives (7 ed.) (pp. 371-391). Hoboken, NJ: John Wiley \& Sons, Inc.

Fraenkel, J. R., \& Wallen, N. E. (1996). How to design and evaluate research in education ( $3^{\text {rd }}$ Ed.). New York, NY: McGraw-Hill, Inc.

Freire, P. (1985). The politics of education: Culture, power, and liberation (D. Macedo, Trans.). Westport, CN: Bergin \& Garvey. Kindle edition.

Fullan, M. (1997). What's worth fighting for in the principalship? New York, NY: Teachers College Press.

Fullan, M. (2005). Leadership \& sustainability. Thousand Oaks, CA: Corwin Press.

Gamoran, A. (Ed.), (2007). Standards-based reform and the poverty gap: Lessons for no child left behind. Washington, D.C.: The Brookings Institution.

Gamoran, A. (2007). Introduction: Can standards-based reform help reduce the poverty gap in education? In A. Gamoran (Ed.), Standards-based reform and the poverty gap: Lessons for no child left behind (pp. 3-16). Washington, D.C.: The Brookings Institution.

Gardner, H. (1993). Frames of mind: The theory of multiple intelligences. New York, NY: Basic Books.

Gay, G. (2010). Culturally responsive teaching: Theory, research, and practice $\left(2^{\text {nd }}\right.$ Ed.). New York, NY: Teachers College Press.

Gelbrich, J. (1999). American Education -- The Second Half of the 20th Century: PostWorld War II and Beyond. In Foundational Perspectives in Education (Module I: History and Philosophy of Education, Part 8). Retrieved from http://oregonstate.edu/instruct/ed416/ae8.html 
Giroux, H. A. (1985). Introduction. In P. Freire, The politics of education: Culture, power, and liberation. Westport, CN: Bergin \& Garvey. Kindle edition.

Giroux, H. A. (1988). Critical pedagogy, cultural politics, and the discourse of experience. In H. A. Giroux, Teachers as intellectuals: Toward a critical pedagogy of learning, pp. 86-107. Granby, MA: Bergin \& Garvey Publishers, Inc.

Giroux, H. A. (2008, Winter). Education and the crisis of democracy: Confronting authoritarianism in a post-9/11 America. Journal of Educational Controversy, 3(1). Retrieved from http://www.wce.wwu.edu/Resources/CEP/eJournal/v003n001/a006.shtml

Gorski, P. (2008, April). The myth of the culture of poverty. Educational Leadership, 65(7), 32-36.

Gorski, P. C. (2013). Reaching and teaching students in poverty: Strategies for erasing the opportunity gap. New York, NY: Teachers College Press.

Gould, R. (2007, April-June). An ecological approach to national education reform: Recommendations for the reauthorization of no child left behind. Youth Law News, 28(2), 7-10, 29-30.

Gredler, M. E. (2012, October). Understanding Vygotsky for the classroom: Is it too late? Educational Psychology Review, 24, 113-131. Published online by Springer Science+Business Media, LLC.

Griffin, S. W., \& Green, R. L. (2013). Transforming high poverty, underperforming schools: Practices, processes, and procedures. National Forum of Applied Educational Research Journal, 26(1 \& 2), 77-93.

Hallinger, P. (2005). Instructional leadership and the school principal: A passing fancy that refuses to fade away. Leadership and Policy in Schools, 4, 221-239.

Hallinger, P., Bickman, L., \& Davis, K. (1996, May). School context, principal leadership, and student reading achievement. The Elementary School Journal, 96(5), 527-549.

Hallinger, P. \& Heck, R. (1998). Exploring the principal's contribution to school effectiveness: 1980-1995. School Effectiveness and School Improvement, 9(2), 157-191. 
Hallinger, P. \& Heck, R. (1996, February). Reassessing the principal's role in school effectiveness: A review of empirical research, 1980-1995. Educational Administration Quarterly, 32(1), 5-44.

Haskins, R. (2012, June). Combating poverty: Understanding new challenges for families. Testimony presented at the meeting of the U. S. Senate Committee on Finance.

Hattie, J. A. C. (2009). Visible learning: A synthesis of over 800 meta-analyses relating to achievement. New York, NY: Routledge.

Heifetz, R., Grashow, A., \& Linsky, M. (2009). The practice of adaptive leadership: Tools and tactics for changing your organization and the world. Boston, MA: Harvard Business Press.

Heifetz, R. A., \& Linsky, M. (2002). Leadership on the line: Staying alive through the dangers of leading. Boston, MA: Harvard Business School Publishing.

Hout, M. \& Cumberworth, E. (2014). The poverty and inequality report. Stanford, CA: Stanford Center on Poverty and Inequality.

Hout, M., \& Janus, A. (2011). Educational mobility in the United States since the 1930s. In G. J. Duncan \& R. J. Murnane (Eds.), Whither opportunity? Rising inequality, schools, and children's life chances (pp. 165-185). New York, NY: Russell Sage Foundation.

Howell, D. C. (2010). Statistical methods for psychology (7th ed.). Belmont CA: Wadsworth Cengage Learning.

Jacobson, S. L., Brooks, S., Giles, C., Johnson, L., \& Ylimaki, R. (2004, December). Successful leadership in three high poverty urban elementary schools: An examination of three urban elementary schools. Retrieved from http://gse.buffalo.edu/gsefiles/documents/alumni/Fall08_Commissioned_Report_ NYS_Ed_Dept.pdf

Jacobson, S. L. (2008). Leadership for success in high poverty elementary schools. Journal of Educational Leadership, Policy and Practice, 23(1), pp. 3-17.

Jantzi, D., \& Leithwood, K. (1996, October). Principal leadership questionnaire. Educational Administration Quarterly, 533-534.

Jensen, E. (2009). Teaching with poverty in mind: What being poor does to kids' brains and what schools can do about it [Kindle edition]. Retrieved from www.amazon.com 
Jiang, Y., Ekono, M., \& Skinner, C. (2015, January). Basic facts about low-income children: Children 6-12 years, 2013. National Center for Children in Poverty, Columbia University Mailman School of Public Health. Retrieved from www.nccp.org

Kannapel, P. J., \& Clements, S. K. (2005, February). Inside the black box of highperforming high poverty schools. Lexington, KY: The Prichard Committee for Academic Excellence.

Kornrich, S. \& Furstenberg, F. (2011). Investing in Children: Changes in Parental Spending on Children, 1972 to 2007. Paper retrieved from http://paa2011.princeton.edu/papers/110077

Kozol, J. (1992). Savage inequalities: Children in America's Schools. New York, NY: Crown Publishers, Inc.

Leana, C. R. (2011, Fall). The missing link in school reform. Stanford Social Innovation Review.

Retrieved from

http://www.ssireview.org/articles/entry/the_missing_link_in_school_reform

Leithwood, K. (2012). Core practices: The four essential components of the leader's repertoire. In K. Leithwood \& K. S. Louis, Linking leadership to student learning (pp. 57-67). Retrieved from http://www.eblib.com

Leithwood, K., Begley, P. T., \& Cousins, J. B. (1992). Developing expert leadership for future schools. London: The Falmer Press.

Leithwood, K., Harris, A., \& Hopkins, D. (2008, January). Seven strong claims about successful school leadership. School Leadership \& Management, 28(1), 27-42. Retrieved from http://dx.doi.org/10.1080/13632430701800060

Leithwood, K., \& Jantzi, D. (2012). Collective leadership: The reality of leadership distribution within the school community. In K. Leithwood \& K. S. Louis, Linking leadership to student learning (pp. 11-24). Retrieved from http://www.eblib.com

Leithwood, K., \& Louis, K. S. (2012). Linking leadership to student learning. San Francisco, CA: John Wiley \& Sons, Inc.

Retrieved from http://www.eblib.com 
Leithwood, K. A., Louis, K. S., Anderson, S., \& Wahlstrom, K. (2004). How leadership influences student learning: Review of research. Minneapolis, MN: Center for Applied Research, University of Minnesota.

Leithwood, K. A., \& Riehl, C. (2003, Autumn). What we know about successful school leadership. Philadelphia, PA: Laboratory for Student Success, Temple University. Retrieved from http://www.dcbsimpson.com/randd-leithwood-successfulleadership.pdf

Levine, A. (2005, March). Educating school leaders. New York, NY: The Education Schools Project. Retrieved from http://www.edschools.org/pdf/Final313.pdf

Liontos, L. B. (1992, August). Transformational leadership. Eugene, OR: ERIC Clearinghouse on Educational Management. Retrieved from http://www.vtaide.com/png/ERIC/Transformational-Leadership.htm

Louis, K. S., Leithwood, K., Wahlstrom, K. L., \& Anderson, S. E. (2010, July). Learning from leadership: Investigating the links to improved student learning (Final Report of Research to the Wallace Foundation). St. Paul, MN: Center for Applied Research and Educational Improvement, University of Minnesota.

Louis, K. S., \& Wahlstrom, K. (2012). Shared and instructional leadership: When principals and teachers successfully lead together. In K. Leithwood \& K. S. Louis, Linking leadership to student learning (pp. 25-41). Retrieved from http://www.eblib.com

Lunenburg, F. C., \& Irby, B. J. (2008). Writing a successful thesis or dissertation: Tips and strategies for students in the social and behavioral sciences. Thousand Oaks, CA: Corwin Press, Inc.

Lyman, L. L., \& Villani, C. J. (2004). Best leadership practices for high poverty schools. Lanham, MA: Scarecrow Press, Inc.

Macartney, S. (2011, November). Child poverty in the United States 2009 and 2010: Selected race groups and Hispanic origin. American Community Survey Briefs, United States Census Bureau.

Mann, H. (1848). Twelfth Annual Report to the Secretary of the Massachusetts State Board of Education. Retrieved from http://www.intellectualtakeout.org/content/quotes-horace-mann-andamerican-education-reform 
Marks, H. M., \& Printy, S. M. (2003, August). Principal leadership and school performance: An integration of transformational and instructional leadership. Education Administration Quarterly, 39(3), 370-397. Retrieved from http://palmbeachschools.org/dre/documents/schoolleaderMarksn.pdf

Marzano, R. J., Waters, T., \& McNulty, B. A. (2005). School leadership that works: From research to results. Aurora, CO: McREL.

Maslow, A. H. (1943). A theory of human motivation. Psychological Review, 50, 370396.

Maxcy, S. J. (1991). Educational leadership: A critical pragmatic perspective. New York, NY: Bergin \& Garvey.

Maxwell, J. A., and Loomis, D. M. (2003). Mixed methods design: An alternative approach. In A. Tashakkori \& C. Teddlie (Eds.), Handbook of mixed methods in social and behavioral research (241-271). Thousand Oaks, CA: Sage Publications.

McLeod, S. A. (2007). Vygotsky - Simply Psychology. Retrieved from http://www.simplypsychology.org/vygotsky.html

McCoy, J. V. (2011). A multiple case study of principals' instructional leadership in "Level 5 " schools of excellence for improvement (Doctoral dissertation). Retrieved from ProQuest Dissertations and Theses database (UMI No. 3482388).

Mees, G. W. (2008, May). The relationships among principal leadership, school culture, and student achievement in Missouri middle schools (Doctoral dissertation). Retrieved from https://www.nassp.org/portals/0/content/59554.pdf

Meier, D. (2013, September 17). A new school year: Democracy \& schools (Education Week blog). Retrieved from http://blogs.edweek.org/edweek/BridgingDifferences/2013/09/deborah_meier_returns_to_bridg.html

Messerli, J. (1971). Horace Mann: A biography. New York, NY: Alfred A. Knopf, Inc.

Middle Level Leadership Center (2009). School improvement surveys. University of Missouri. Retrieved from http://mllc.org/

Miles, M. B., Huberman, A. M., \& Saldaña, J. (2014). Qualitative data analysis: A methods sourcebook ( $3^{\text {rd }}$ Ed.). Los Angeles, CA: Sage Publications, Inc. 
Mishel, L., Bivens, J., Gould, E., \& Shierholz, H. (2012, November). Poverty. In The State of Working America, $12^{\text {th }}$ Edition, pp. 419-460. Economic Policy Institute: Cornell University Press.

Mora-Whitehurst, R. (2013, July-September). The relationship between elementary principals' visionary leadership and students' reading performance. The Educational Forum, 77(3), 315-328.

Mortimore, P., \& Sammons, P. (1987, September). New evidence on effective elementary schools. Educational Leadership, 45(1), 4-8. Retrieved from http://www.ascd.org/ASCD/pdf/journals/ed_lead/el_198709_mortimore.pdf

National Center for Education Statistics (2011). The Nation's Report Card: Reading 2011 (NCES2012-457). Institute of Education Sciences, U.S. Department of Education, Washington, D.C.

National Center for Children in Poverty (n.d.a.). New York: Columbia University Mailman School of Public Health. Accessed at http://nccp.org/

National Center for Education Statistics (2011). The Nation's Report Card: Math 2011 (NCES2012-458). Institute of Education Sciences, U.S. Department of Education, Washington, D.C.

National Commission of Excellence in Education. (1983). A nation at risk: The imperative for educational reform. Washington, DC: U.S. Government Printing Office.

Nelson III, C. A., \& Sheridan, M. A. (2011). Lessons from neuroscience research for understanding causal links between family and neighborhood characteristics and educational outcomes. In G. J. Duncan \& R. J. Murnane (Eds.), Whither opportunity? Rising inequality, schools, and children's life chances (pp. 27-46). New York, NY: Russell Sage Foundation.

Nieto, S. (2005, Spring). Public education in the twentieth century and beyond: High hopes, broken promises, and an uncertain future. In M. Charner-Laird, M. L. Donaldson, \& S. Hong (Eds.), Education past and present: Reflections on research, policy, and practice, Harvard Educational Review, 75(1), 43-64.

No Child Left Behind Act of 2001, Pub. L. No. 107-110, 115 Stat. 1425 (2002). Retrieved from http://www2.ed.gov/policy/elsec/leg/esea02/index.html

Novak, J. D. (1977). A theory of education. Ithaca, NY: Cornell University Press. 
Oliver, M. L., \& Shapiro, T. M. (1995). Black wealth/White wealth: A new perspective on racial inequality. New York, NY: Routledge.

Oregon Center for Public Policy (2013, September). A graphic view of poverty in Oregon. Retrieved from http://www.ocpp.org/2013/09/19/graphic-view-povertyoregon/

Oregon Department of Education (2009). Improving basic programs (Title 1-A), Brief 24, Volume 1. Retrieved from http://www.ode.state.or.us/pubs/eii/titleiabrief.pdf

Oregon Department of Education (2012). State standards and tests. Retrieved from http://www.ode.state.or.us/wma/teachlearn/testing/admin/2011-12-tam.pdf

Oregon Department of Education (2012). Oregon statewide report card 2011-12. Retrieved from http://www.ode.state.or.us/data/annreportcard/rptcard2012.pdf

Oregon Department of Education. (2012). Oregon's ESEA flexibility waiver application (abridged). Approved July 18, 2012. Retrieved from http://www.ode.state.or.us/initiatives/nclb/docs/oregons_completed_esea_flexibili ty_request_abridged.pdf

Oregon Educational Act for the $21^{\text {st }}$ Century (1991). Retrieved from http://www.oregonlaws.org/ors/329.005

Oregon School Boards Association (2013). Oregon's NCLB waiver. Retrieved from http://www.osba.org/Resources/Article/Improving_Education/SAG/NCLBWaiver .aspx

Ornstein, A. C., \& Levine, D. U. (1989). Foundations of education (4 ${ }^{\text {th }}$ ed.). Boston, MA: Houghton Mifflin Company.

Perrow, C. (1986). Complex organizations: A critical essay (3 $3^{\text {rd }}$ ed.). New York: McGraw-Hill, Inc.

Peterson, D. S. (2012). Latino student success in Oregon high schools (Doctoral dissertation). UMI Number 3495806.

Piaget, J. (1969). Science of education and the psychology of the child. (D. Coltman, Trans., 1970). New York, NY: Orion Press.

Public education in Oregon (2013). In Oregon Blue Book. Retrieved on July 11, 2013 from http://bluebook.state.or.us/education/educationintro.htm 
Ramírez, M. I. (2011). Results for all: Identifying promising leadership practices that school administrators believe impact student performance in Pennsylvania (Doctoral Dissertation). Retrieved from ProQuest Dissertations and Theses database (UMI No. 3492298).

Reardon, S. F. (2011). The widening academic achievement gap between the rich and the poor: New evidence and possible explanations. In G. J. Duncan \& R. J. Murnane (Eds.), Whither opportunity? Rising inequality, schools, and children's life chances (pp. 91-115). New York, NY: Russell Sage Foundation.

Reardon, S. F. (2013). The widening income achievement gap. Educational Leadership $70(8), 10-16$.

Reardon, S. F. (2014). Education. In M. Hout \& E. Cumberworth, The poverty and inequality report, 53-59. Retrieved from http://www.stanford.edu/group/scspi/sotu/SOTU_2014_CPI.pdf

Reeves, D. G. (2009). Leading change in your school: How to conquer myths, build commitment, and get results. Alexandria, VA: ASCD.

Rice, J. K. (2010, April). Principal effectiveness and leadership in an era of accountability: What research says (Brief 8). Retrieved from Urban Institute, National Center for Analysis of Longitudinal Data in Education Research website: http://www.urban.org/UploadedPDF/1001370_principal_effectiveness.pdf

Robbins, T., Stagman, S., \& Smith, Sheila (2012, October). Young children at risk: National and state prevalence of risk factors. National Center for Children in Poverty. New York, NY: Columbia University. Retrieved from www.nccp.org

Rousmaniere, K. (2013). The principal's office: A social history of the American school principal. Albany, NY: State University of New York Press.

Rowan, B. (2011). Intervening to improve the educational outcomes of students in poverty: Lessons from recent work in high poverty schools. In G. J. Duncan and R. J. Murnane (Eds.), Whither opportunity? Rising inequality, schools, and children's life chances (pp. 523-537). New York, NY: Russell Sage Foundation.

Rumberger, R. W. (2007, June). Parsing the data on student achievement in high poverty schools. 88 North Caroline Law Review 1293. Retrieved from https://litigationessentials.lexisnexis.com/webcd/app?action=DocumentDisplay\&crawlid=1\&doct ype $=$ cite $\&$ docid $=85+$ N.C.L. + Rev. $+1293 \&$ srctype $=$ smi\& $\& r c i d=3 B 15 \& k e y=e c 766 f$ fca8171cc7373c0c9c6e1fccf1 
Ryan, H. D. (2007). An examination of the relation between teacher efficacy and teachers' perceptions of their principals' leadership behaviors (Doctoral Dissertation). UNT Digital Library. http://digital.library.unt.edu/ark:/67531/metadc3620/. Accessed April 16, 2015.

Sagor, R. D. (1992, February). Three principal who make a difference. Educational Leadership, 49(5), 13-18.

Sandefur, G. D., \& Wells, T. (1999). Does family structure really influence educational attainment? Social Science Research, 28, 331-357. Retrieved from http://www.idealibrary.com

Schuell, T. (2013, July). Theories of learning. Retrieved from http://www.education.com/reference/article/theories-of-learning/

Sergiovanni, T. (1990). Value-added leadership: How to get extraordinary performance in schools. San Diego, CA: Harcourt Brace Jovanovich, Publishers.

Sergiovanni, T. (1996). Leadership for the schoolhouse: How is it different? Why is it important? San Francisco, CA: Jossey-Bass Publishers.

Sergiovanni, T. (2000). The lifeworld of leadership: Creating culture, community, and personal meaning in our schools. San Francisco, CA: Jossey-Bass Publishers.

Shafritz, J. M., and Ott, J. S. (1992). Classics of organization theory (3rd ed.). Belmont, CA: Wadsworth, Inc.

Shields, C. M. (2010, September). Transformative leadership: Working for equity in diverse contexts. Educational Administration Quarterly, 46(4), 558-589. Retrieved from http://eaq.sagepub.com

Siemens, G. (2004, December). Connectivism: A learning theory for the digital age. Retrieved from http://www.elearnspace.org/Articles/connectivism.htm

Skinner, B. F. (1954, Spring). The science of learning and the art of teaching. Harvard Educational Review, 24(2), 86-97.

Southern Education Foundation (2013, October). A new majority: Low income students in the South and Nation (Research Report Update). Retrieved from $\mathrm{http}: / /$ www.southerneducation.org/getattachment/0bc70ce1-d375-4ff6-8340f9b3452ee088/A-New-Majority-Low-Income-Students-in-the-South-an.aspx

Statistics Solutions. (2014). Statistics Solutions Pro (Version v1.15.02.16) [Online computer software]. Retrieved from http://ssp.statisticssolutions.com/ 
Stevens, J. (1999). Intermediate statistics (2nd ed.). Mahwah, NJ: Routledge Academic.

Sum, A. \& Khatiwada, I. (2012, March/April). Ignoring those left behind. Challenge: The Magazine of Economic Affairs, 55(2). Retrieved from http://www.challengemagazine.com/extra/005_020.pdf

Taylor, R., Stagman, S., \& Smith, S. (2012, October). Young children at risk: National and state prevalence of risk factors. National Center for Children in Poverty Fact Sheet. New York, NY: Columbia University. Retrieved from www.nccp.org

Tilley, T. B., Smith, S. J., \& Claxton, R. L. (2012, Fall). Success despite socioeconomics: A case study of a high-achieving, high poverty school. Journal of School Public Relations, 33(4), 292-317.

United States Census Bureau. Supplemental measure of poverty remains unchanged. Retrieved on November 6, 2013 from http://www.census.gov/newsroom/releases/archives/poverty/cb13-183.html

United States Department of Agriculture (n.d.a.). National school lunch program. Retrieved from http://origin.www.fns.usda.gov/cnd/Lunch/AboutLunch/ProgramHistory_7.htm

United States Department of Education (n.d.a.). Title I - Improving The Academic Achievement Of The Disadvantaged. Retrieved from http://www2.ed.gov/policy/elsec/leg/esea02/pg1.html

United States Department of Education. (2011). ESEA flexibility waivers. Retrieved from http://www2.ed.gov/policy/elsec/guid/esea-flexibility/index.html

United States Department of Education, National Center for Education Statistics. (2013). The condition of education 2013 (NCES 2013-037). Retrieved from http://nces.ed.gov/pubs2013/2013037.pdf

Vgotsky, L. S. (1978). Mind in society: The development of higher psychological processes. Cambridge, MA: Harvard University Press.

Wagner, T. (2002). Making the grade: Reinventing America's schools. New York, NY: RoutledgeFalmer.

Wahlstrom, K. (2012). An up-close view of instructional leadership: A grounded analysis. In K. Leithwood \& K. S. Louis, Linking leadership to student learning (pp. 68-84). Retrieved from http://www.eblib.com 
Wallace Foundation (n.d.a.). Conducting in-depth interviews (Workbook E). Retrieved from $\mathrm{http} / / / \mathrm{www}$.wallacefoundation.org/knowledge-center/afterschool/collecting-and-using-data/Documents/Workbook-E-Indepth-Interviews.pdf

Wallace Foundation Perspective (2013, January). The school principal as leader: Guiding schools to better teaching and learning. Retrieved from www.wallacefoundation.org

Waters, T., Marzano, R. J., \& McNulty, B. (2003). Balanced leadership: What 30 years of research tells us about the effect of leadership on student achievement (A Working Paper). Denver, CO: Mid-Continent Research for Education and Learning (McREL).

Wielkiewicz, R. M., \& Stelzner, S. P. (2005). An ecological perspective on leadership theory, research and practice. Review of General Psychology, 9(4), 326-331.

Williams, B. (1999). Diversity and education for the $21^{\text {st }}$ century. In D. D. Marsh (Ed.), 1999 ASCD yearbook: Preparing our schools for the $21^{\text {st }}$ century, pp. 89-114. Alexandria, VA: Association for Supervision and Curriculum Development.

Williams, E. E., Jr. (2006). Teachers' perceptions of principal leadership in relation to student achievement (Doctoral dissertation). Retrieved from ProQuest Dissertations and Theses database. (UMI No. 3258821)

Wise, T. (2011). White like me: Reflections on race from a privileged son. Berkeley, CA: Soft Skull Press. Kindle edition.

Woods, E. H. J. (2012). A case study of the perceptions of stakeholders regarding transformational leadership processes and structures implemented in a high poverty, high achieving school (Doctoral Dissertation). Retrieved from ProQuest Dissertation and Theses database (UMI No. 3533987).

Yin, R. K. (2014). Case study research: Design and methods (5 ${ }^{\text {th }}$ Ed.). Thousand Oaks, CA: Sage Publications, Inc. 
Leadership Practices

APPENDIX A

PRINCIPAL LEADERSHIP QUESTIONNAIRE (PLQ) SURVEY 
PLQ: Principal Leadership Questionnaire Survey*

Researchers have studied the connection between school leadership and student performance and have found that not only does school leadership matter, but it is second only to teaching in its impact on student learning (Leithwood, Louis, Anderson, \& Wahlstrom, 2004). The purpose of this study is to explore principal leadership practices in high poverty K-5 Model schools that have improved growth in academic achievement for children. The current measure for identifying Model Schools is the Oregon Assessment of Knowledge and Skills (OAKS), which will be replaced by Smarter Balanced Assessments in 2014-15.

Your school was chosen to participate in this study, " Principal Leadership Practices in High Poverty K-5 Model Schools in Oregon", because it is a high poverty K-5 elementary school in Oregon identified by the Oregon Department of Education as a Model School. This survey will provide the researcher with information regarding your perspective of the principal's leadership skills relative to the improvement in academic achievement of children attending this school. All participant's responses are confidential.

If you have questions about this study, please email the researcher at janice.adams66@yahoo.com or call her at 503.524.9076 or 503.970.5108. If you have questions or concerns regarding the research or the researcher, please contact the researcher's University Supervisor, Deborah Peterson, at 503-725-4716.

If you have questions regarding your legal rights as a research subject, you may call the Portland State University Office of Research Integrity at 503.725.2231. This survey may only be completed by persons 18 years of age and older. By completing this survey you are certifying that you are 18 years of age or older, and that you are voluntarily completing this survey.

\section{Demographic Information}

1. Please check the title below that describes your current position.

a. Principal

b. Other administrator

c. Regular Education Teacher

d. Specialist (ESL, SpED, counselor, etc.)

2. Please choose the range below that best describes the number of years you have been at this school.
a. $0-9$ years
b. 10-19 years
c. $20+$ years 
3. Please indicate your gender/sex.

4. Please check all races/ethnicities that you identify yourself as. Check all that apply.

White

Black, or African-American

Hispanic, Latino, or Spanish Origin

American Indian or Alaskan Native

Asian

Native Hawaiian or other Pacific Islander

Please respond by considering how well each of the following statements applies to your principal. Please use the following scale.

1=Strongly Disagree $2=$ Disagree $3=$ Slightly Disagree $4=$ Slightly Agree $5=$ Agree $6=$ Strongly Agree

5. My principal has both the capacity and the judgment to overcome most obstacles.

6. My principal commands respect from everyone on the faculty.

7. My principal excites faculty with visions of what we may be able to accomplish if we work together as a team.

8. My principal makes faculty members feel and act like leaders.

9. My principal gives the faculty a sense of overall purpose for its leadership role.

10. My principal leads by "doing" rather than simply by telling.

11. My principal symbolizes success and accomplishment within the profession of education.

12. My principal provides good models for faculty members to follow.

13. My principal provides for our participation in the process of developing school goals.

14. My principal encourages faculty members to work toward the same goals.

15. My principal uses problem solving with the faculty to generate school goals.

16. My principal works toward whole faculty consensus in establishing priorities for school goals.

17. My principal regularly encourages faculty members to evaluate our progress toward achievement of school goals.

18. My principal provides for extended training to help develop my knowledge and skills relevant to being a member of the school faculty.

19. My principal provides the necessary resources to support my implementation of the school's program.

20. My principal treats me as an individual with unique needs and expertise.

21. My principal takes my opinion into consideration when initiating actions that affect my work.

22. My principal behaves in a manner thoughtful of my personal needs 
23. My principal challenges me to reexamine some basic assumptions I have about my work in the school.

24. My principal stimulates me to think about what I am doing for the school's students.

25. My principal provides information that helps me think of ways to implement the school's program.

26. My principal insists on only the best performance from the school's faculty.

27. My principal shows us that there are high expectations for the school's faculty as professionals.

28. My principal does not settle for second best in the performance of our work as the school's faculty.

Please respond in writing to the following questions.

29. How does the principal allocate school and district resources to support programs and instruction effective in improving growth in academic achievement of children in this high poverty school?

30. How do the principal's practices support programs effective in improving growth in academic achievement of children in in this high poverty school?

31. Is there any other information you would like to add about principal leadership practices or other factors that improve growth in academic achievement for children in this school?

\section{THANK YOU FOR COMPLETING THIS SURVEY}

Adapted from Jantzi \& Leithwood, Educational Administration Quarterly, (October, 1996) 533-534. Used by authors' permission.

*This survey format was modified to Survey Monkey format and the three open-ended questions were added by this researcher. 
Leadership Practices

APPENDIX B:

SUPERINTENDENT/PRINCIPAL INVITATION LETTER 


\section{SUPERINTENDENT/PRINCIPAL INVITATION LETTER}

\section{Dear Superintendent and Principal,}

Thank you for taking my call last week about the research study I am conducting through the Portland State University doctoral program titled "Principal Leadership Practices in High Poverty K-5 Model Schools in Oregon.” The purpose of this study is to explore principal leadership practices in high poverty K-5 Model schools that have improved growth in academic achievement of children attending these schools? The central research question for the study is: What principal leadership practices can be observed in high poverty K-5 Model schools that have improved growth in academic achievement of children attending these schools? Related research questions are: How do principal practices 1) support effective programs? 2) allocate school and district resources to support effective programs and instruction? and, 3) share leadership? Finally, what other practices do principals implement that result in improving growth in academic achievement of children in high poverty schools?

This study is a multiple case study using mixed methods. The three schools participating in this investigation are drawn from the population of K-5 Title I elementary schools in the state identified as "Model Schools" in 2012, 2013, and/or 2014 under the Oregon ESEA waiver. The document review includes any publicly available documents regarding the schools. Principals will participate in an interview and survey; teachers in a focus group and survey; and parents or guardians in a focus group only. The design of the overall study, including surveys, interviews, and focus groups, and all data management and reporting techniques, is intended to ensure that the probability and the magnitude of harm or discomfort anticipated in the proposed research is not greater in and of itself than those ordinarily encountered in everyday life or during the performance of routine professional responsibilities of the participants. A schedule of anticipated activities and timelines is below.

Schedule of Research Activities and Timelines

\begin{tabular}{|l|l|l|l|}
\hline Activity & Day/Time & Details & $\begin{array}{l}\text { Location and } \\
\text { Refreshments Offered }\end{array}$ \\
\hline $\begin{array}{l}\text { Document } \\
\text { Review }\end{array}$ & Summer 2014 & $\begin{array}{l}\text { Completed by } \\
\text { researcher }\end{array}$ & NA \\
\hline $\begin{array}{l}\text { SurveyMonkey } \\
\text { Survey }\end{array}$ & Fall 2014, & $\begin{array}{l}\text { Complete on-line } \\
\text { Winter 2015 }\end{array}$ & NArvey \\
\hline $\begin{array}{l}\text { Principal } \\
\text { Interview }\end{array}$ & $\begin{array}{l}\text { Fall 2014, } \\
\text { Winter 2015 }\end{array}$ & $\begin{array}{l}\text { The interview will take up to } \\
60 \text { minutes. }\end{array}$ & $\begin{array}{l}\text { All interviews } \\
\text { will be in a location } \\
\text { determined by the } \\
\text { interviewee with light } \\
\text { refreshments }\end{array}$ \\
\hline
\end{tabular}




\begin{tabular}{|l|l|l|l|}
\hline $\begin{array}{l}\text { Teacher Focus } \\
\text { Group }\end{array}$ & $\begin{array}{l}\text { Fall 2014, } \\
\text { Winter 2015 }\end{array}$ & $\begin{array}{l}\text { The focus group will take up to } \\
60 \text { minutes. Focus group } \\
\text { participation is not dependent } \\
\text { completion of survey. }\end{array}$ & $\begin{array}{l}\text { All focus groups will be in } \\
\text { a private room identified } \\
\text { per community with light } \\
\text { refreshments }\end{array}$ \\
\hline $\begin{array}{l}\text { Parent Focus } \\
\text { Group }\end{array}$ & $\begin{array}{l}\text { Fall 2014, } \\
\text { Winter 2015 }\end{array}$ & $\begin{array}{l}\text { The focus group will } \\
\text { take up to 60 } \\
\text { minutes. }\end{array}$ & $\begin{array}{l}\text { All focus groups will be in } \\
\text { a private room identified } \\
\text { per community with light } \\
\text { refreshments }\end{array}$ \\
\hline
\end{tabular}

The findings from this study will provide information on principal practices in high poverty K-5 Model schools that have improved growth in academic achievement of children attending these schools.

Upon final approval from you, I will schedule a meeting to further discuss the details of the study and your participation in it.

Thank you for your consideration of this request.

Sincerely,

Janice M. Adams

PSU Doctoral Candidate

503-970-5108 


\section{APPENDIX C}

LETTERS OF INFORMED CONSENT

1. PRINCIPAL LETTER OF INFORMED CONSENT

2. TEACHER LETTER OF INFORMED CONSENT

3. PARENT/GUARDIAN LETTER OF INFORMED CONSENT 


\section{PRINCIPAL LETTER OF INFORMED CONSENT}

You and your school are invited to participate in a research study conducted by Janice M. Adams from Portland State University, Graduate School of Education Doctoral Program. The study is being conducted in partial fulfillment of the requirements for a doctoral degree under the supervision of PSU faculty member Deborah Peterson, EdD. The study is designed to examine principal leadership practices in three high poverty K-5 Model schools that have improved growth in academic achievement of children attending these schools as perceived by three populations: 1) a population of principals; 2) a population of teachers; and 3) a population of parents or guardians of children in the school. This school was chosen for the study because the Oregon Department of Education (ODE) has identified it as a Model School.

You and your school were selected as a possible participant in this study because the school where you are principal meets the following criteria established by the researcher: 1. The school was identified as a Model school by ODE in 2012, 2013, and/or 2014; 2. More than $70 \%$ of the students in the school are eligible for Free or Reduced Lunch;

3. A range of geographical locales of K-5 Title I elementary schools is represented; and,

4. A range of small ( $<250$ students), medium (250-499 students), and/or large K-5 Title I elementary schools (500+ students) is represented.

Your participation in this study is voluntary. No study participants will be identified by name or described in any manner that would specifically identify them; however, due to the small sample size of the study, there is the potential for others reading the study in the future to possibly draw conclusions about the identity of the participants. The researcher will de-identify all information that could lead to identifying the participating schools, principals, teachers, and parents or guardians. You do not have to take part in the study, and it will not have any affect on your relationship with Portland State University. You may also withdraw from this study at any time without affecting your relationship with Portland State University.

If you choose to participate, you will be asked to complete a 31-question web-based survey relative to principal leadership and an interview about principal leadership practices in the school and the impact on student success. The survey will be administered through a Survey Monkey account held by Janice M. Adams. The interview will be a face-to-face interview with the researcher scheduled at your convenience and will take an hour to complete. Any information that is obtained in connection with this study and that can be linked to you or identify you will be de-identified and kept confidential. Information collected through completed surveys and interviews will be stored electronically on the personal computer of Janice M. Adams, which is not used or accessed by any other user. You may not received any direct benefit from taking part in this study, but the study may help to increase the knowledge base of principal leadership practices that can be observed in high poverty K-5 Model schools that have improved growth in academic achievement of children attending these schools. 
The researcher will answer any questions you may have before, during or after your participation in this study. No individual data will be reported on your answers specifically and codes will be used to main privacy. You will be provided with study products prior to publication in order for you to check accuracy of the descriptions, explanations, and interpretations made by the researcher.

Informed consent of study participants is an important part of the research process. In order for the researcher to obtain your informed consent, you are asked to sign the following form.

By signing this form you are allowing the publication of the results of the study. If you have concerns or problems about your participation in this study or your rights as a research subject, please contact the PSU Human Subjects Research Committee at 503.725.4288 or email them at hsrrc@pdx.edu. If you have any questions about the study itself, you can call the researcher, Janice M. Adams, at 503.524.9076 or email her at janice.adams66@yahoo.com. In addition, you can call the professor advising the researcher, Deborah Peterson, at 503.725-4716.

You can ask the researcher to exclude the data you have provided at any point throughout the research process and the researcher is required to do so. By signing this form, you acknowledge that you are 18 years of age or older and that you have read and understand the above explanations and agree to take part in this study.

Participant's Name (PRINT)

Signature Date Email

I have presented this information to the participant and have obtained his or her voluntary consent. 


\section{TEACHER LETTER OF INFORMED CONSENT}

You are invited to participate in a research study conducted by Janice M. Adams from Portland State University, Graduate School of Education Doctoral Program. The study is being conducted in partial fulfillment of the requirements for a doctoral degree under the supervision of PSU faculty member Deborah Peterson, EdD. The study is designed to examine principal leadership practices in three high poverty K-5 Model schools that have improved growth in academic achievement of children attending these schools as perceived by three populations: 1) a population of principals; 2) a population of teachers; and 3) a population of parents or guardians of children in the school. This school was chosen for the study because the Oregon Department of Education (ODE) has identified it as a Model School.

You were selected as a possible participant in this study because the school where you are a teacher meets the following criteria established by the researcher:

1. The school was identified as a Model school by ODE in 2012, 2013, and/or 2014;

2. More than $70 \%$ of the students in the school are eligible for Free or Reduced Lunch;

3. A range of geographical locales of K-5 Title I elementary schools is represented; and,

4. A range of small (<250 students), medium (250-499 students), and/or large K-5 Title I elementary schools $(500+$ students) is represented.

Your participation in this study is voluntary. No study participants will be identified by name or described in any manner that would specifically identify them; however, due to the small sample size of the study, there is the potential for others reading the study in the future to possibly draw conclusions about the identity of the participants. The researcher will de-identify all information that could lead to identifying the participating schools, principals, teachers, and parents or guardians. You do not have to take part in the study, and it will not have any affect on your relationship with your school, your district, or Portland State University. You may also withdraw from this study at any time without affecting your relationship with Portland State University.

If you choose to participate, you will be asked to complete a 31-question web-based survey relative to principal leadership and to participate in a focus group about principal leadership practices in the school and the impact on student success. The survey will be administered through a Survey Monkey account held by Janice M. Adams. The interview will be a group interview with other teachers and with the researcher, scheduled at your convenience. Any information that is obtained in connection with this study and that can be linked to you or identify you will be de-identified and kept confidential. Information collected through completed surveys and interviews will be stored electronically on the personal computer of Janice M. Adams, which is not used or accessed by any other user. You may not received any direct benefit from taking part in this study other than the light refreshments available during the focus group, but the study may help to increase the 
knowledge base of principal leadership practices that can be observed in high poverty K5 Model schools that have improved growth in academic achievement of children attending these schools.

The researcher will answer any questions you may have before, during or after your participation in this study. No individual data will be reported on your answers specifically and codes will be used to main privacy. You will be provided with study products prior to publication in order for you to check accuracy of the descriptions, explanations, and interpretations made by the researcher.

Informed consent of study participants is an important part of the research process. In order for the researcher to obtain your informed consent, you are asked to sign the following form.

By signing this form you are allowing the publication of the results of the study. If you have concerns or problems about your participation in this study or your rights as a research subject, please contact the PSU Human Subjects Research Committee at 503.725.4288 or email them at hsrrc@pdx.edu. If you have any questions about the study itself, you can call the researcher, Janice M. Adams, at 503.524.9076 or email her at janice.adams66@yahoo.com. In addition, you can call the professor advising the researcher, Deborah Peterson, at 503.725.4716.

You may ask the researcher to exclude the data you have provided at any point throughout the research process and the researcher is required to do so. By signing this form, you acknowledge that you are 18 years of age or older and that you have read and understand the above explanations and agree to take part in this study.

Participant's Name (PRINT)

Signature Date Email

I have presented this information to the participant and have obtained his or her voluntary consent. Date 


\section{PARENT/GUARDIAN LETTER OF INFORMED CONSENT}

You are invited to participate in a research study conducted by Janice M. Adams from Portland State University, Graduate School of Education Doctoral Program. The study is being conducted in partial fulfillment of the requirements for a doctoral degree under the supervision of PSU faculty member Deborah Peterson, EdD. The study is designed to examine principal leadership practices in three high poverty K-5 Model schools that have improved growth in academic achievement of children attending these schools as perceived by three populations: 1) a population of principals; 2) a population of teachers; and 3) a population of parents or guardians of children in the school. This school was chosen for the study because the Oregon Department of Education (ODE) has identified it as a Model School.

You were selected as a possible participant in this study because your child or children attend a school that meets the following criteria established by the researcher:

1. The school was identified as a Model school by ODE in 2012, 2013, and/or 2014;

2. More than $70 \%$ of the students in the school are eligible for Free or Reduced Lunch;

3. A range of geographical locales of K-5 Title I elementary schools is represented; and,

4. A range of small ( $<250$ students), medium (250-499 students), and/or large K-5 Title I elementary schools $(500+$ students) is represented.

Your participation in this study is voluntary. No study participants will be identified by name or described in any manner that would specifically identify them; however, due to the small sample size of the study, there is the potential for others reading the study in the future to possibly draw conclusions about the identity of the participants. The researcher will de-identify all information that could lead to identifying the participating schools, principals, teachers, and parents or guardians. You do not have to take part in the study, and it will not have any affect on your relationship with the school your child attends, your district, or Portland State University. You may also withdraw from this study at any time without affecting your relationship with Portland State University.

If you choose to participate, you will be asked to participate in a focus group about principal leadership practices in the school and the impact on student success. The focus group will be held in a location and at a time convenient to parents or guardians. The focus group will take an hour to complete. Any information that is obtained in connection with this study and that can be linked to you or identify you will be de-identified and kept confidential. Information collected through completed surveys and interviews will be stored electronically on the personal computer of Janice M. Adams, which is not accessed or used by any other user. You may not received any direct benefit from taking part in this study other than the light refreshments that will be available, but the study may help to increase the knowledge base of principal leadership practices that can be observed in 
high poverty K-5 Model schools that have improved growth in academic achievement of children attending these schools.

The researcher will answer any questions you may have before, during or after your participation in this study. No individual data will be reported on your answers specifically and codes will be used to main privacy. You will be provided with study products prior to publication in order for you to check accuracy of the descriptions, explanations, and interpretations made by the researcher.

Informed consent of study participants is an important part of the research process. In order for the researcher to obtain your informed consent, you are asked to sign the following form.

By signing this form you are allowing the publication of the results of the study. If you have concerns or problems about your participation in this study or your rights as a research subject, please contact the PSU Human Subjects Research Committee at 503.725.4288 or email them at hsrrc@pdx.edu. If you have any questions about the study itself, you can call the researcher, Janice M. Adams, at 503.524.9076 or email her at janice.adams66@yahoo.com. In addition, you can call the professor advising the researcher, Deborah Peterson, at 503.725.4716.

You may ask the researcher to exclude the data you have provided at any point throughout the research process and the researcher is required to do so. By signing this form, you acknowledge that you are 18 years of age or older and that you have read and understand the above explanations and agree to take part in this study.

Participant's Name (PRINT)

Signature Date

I have presented this information to the participant and have obtained his or her voluntary consent. Date 
Leadership Practices

APPENDIX D

PRINCIPAL INTERVIEW PROTOCOL 


\title{
PRINCIPAL INTERVIEW PROTOCOL
}

\author{
Script for Opening and Closing Principal Interviews
}

Opening:

Hello! My name is Janice Adams and I am a doctoral student at Portland State University. I am currently studying principal leadership practices in high poverty K-5 Model schools that have improved growth in academic achievement of children attending these schools. Today you have the opportunity to participate in a study about this issue. School A was chosen for this study because it is a high poverty K-5 Title I school identified by the Oregon Department of Education as a Model School.

This portion of the study includes an interview. It consists of 5 questions*. You are invited to have refreshments during this interview. I want to remind you that you can stop the interview or leave at any time. There will be no advantage or disadvantage for your continued participation in the study. I am so pleased you are here. Let's go ahead and get started!

The first question is:

1. What do you think educators need to do to assist children in poverty to succeed academically?

Next,

2. Share with me one success story without which any description of this school would be incomplete? (with a particular child, about learning, with a family, etc.)

3. What three words best describe your leadership? In what ways does your leadership support children's success in school?

4. What do you find to be the most challenging, or the hardest part about leading in a high poverty school?

And finally,

5. What else do I need to consider about principal leadership practices or other factors that improve growth in academic achievement of children in this school?

Closing:

Thank you so much for talking with me today. I will be back on XXXXXX date to share with you what I have learned and to ask you whether I left something out or should add something else. Thank you again. My contact information is on the sheet I am handing you in case you want to have your comments deleted from the study or you have something additional you would like to share with me.

*Interview questions are modified from research conducted by Lyman and Villani (2008) and are used with permission of the author. 
Leadership Practices

APPENDIX E

FOCUS GROUP PROTOCOLS

1. TEACHER FOCUS GROUP

2. PARENT/GUARDIAN FOCUS GROUP 


\title{
TEACHER FOCUS GROUP PROTOCOL
}

\author{
Script for Opening and Closing Teacher Focus Groups
}

Opening:

Hello! My name is Janice Adams and I am a doctoral student at Portland State University. I am currently studying principal leadership practices in three high poverty K-5 Model schools that have improved growth in academic achievement of children attending these schools. Today you have the opportunity to participate in a study about this issue. School A was chosen for this study because it is a high poverty K-5 Title I school identified by the Oregon Department of Education as a Model School.

This portion of the study is a focus group interview that consists of 5 questions*. You are invited to have refreshments during this interview. I want to remind you that you can stop the interview or leave at any time. There will be no advantage or disadvantage for your continued participation in the study. I am so pleased you are here. Let's go ahead and get started!

The first question is:

1. What do you think educators need to do to assist children in poverty to succeed academically?

Next,

2. Share with me one success story without which any description of this school would be incomplete? (with a particular child, about learning, with a family, etc.)

3. What three words best describe the principal's leadership? In what ways does his or her leadership support children's success in school?

4. What do you find to be the most challenging, or the hardest part about teaching in a high poverty school?

And finally,

5. What else do I need to consider about principal leadership practices or other factors that improve growth in academic achievement of children in this school?

Closing:

Thank you so much for talking with me today. I will be back on XXXXXX date to share with you what I have learned and to ask you whether I left something out or should add something else. Thank you again. My contact information is on the sheet I am handing you in case you want to have your comments deleted from the study or you have something additional you would like to share with me.

*Interview questions are modified from research conducted by Lyman and Villani (2008) and are used with permission of the author. 


\title{
PARENT FOCUS GROUP PROTOCOL
}

\author{
Script for Opening and Closing Teacher Focus Groups
}

Opening:

Hello! My name is Janice Adams and I am a doctoral student at Portland State University. I am currently studying principal leadership practices in three high poverty K-5 Model schools that have improved growth in academic achievement of children attending these schools. Today you have the opportunity to participate in a study about this issue. School A was chosen for this study because it is a high poverty K-5 Title I school identified by the Oregon Department of Education as a Model School.

This portion of the study is a focus group interview that consists of 5 questions*. You are invited to have refreshments during this interview. I want to remind you that you can stop the interview or leave at any time. There will be no advantage or disadvantage for your continued participation in the study. I am so pleased you are here. Let's go ahead and get started!

The first question is:

1. What do you think educators need to do to assist children in poverty to succeed academically?

Next,

2. Share with me one success story without which any description of this school would be incomplete? (with a particular child, about learning, with a family, etc.)

3. What three words best describe the principal's leadership? In what ways does his or her leadership support children's success in school?

4. What do you find to be the most challenging, or the hardest part about teaching in a high poverty school?

And finally,

5. What else do I need to consider about principal leadership practices or other factors that improve growth in academic achievement of children in this school?

Closing:

Thank you so much for talking with me today. I will be back on XXXXXX date to share with you what I have learned and to ask you whether I left something out or should add something else. Thank you again. My contact information is on the sheet I am handing you in case you want to have your comments deleted from the study or you have something additional you would like to share with me.

*Interview questions are modified from research conducted by Lyman and Villani (2008) and are used with permission of the author. 
Leadership Practices

APPENDIX F

PARENT/GUARDIAN FOCUS GROUP

FLYER 


\section{PARENT/GUARDIAN FOCUS GROUP FLYER}

The purpose of this study is to explore principal leadership practices in three high poverty K-5 Model schools that have improved growth in academic achievement of children attending these schools. Data will be collected through document reviews, surveys, interviews, and focus groups. Your school was chosen for this study because it was as identified as a Model School by the Oregon Department of Education (ODE). As a parent/guardian, you are invited to take part in a focus group. You may withdraw from the study at any time or you can withdraw data you supply at any time before the study is published.

Researcher Contact Information
Janice M. Adams
Portland State University
Doctoral Student
janice.adams66@yahoo.com
503.524.9076

University Advisor
Deborah Peterson, EdD
503.725.4716

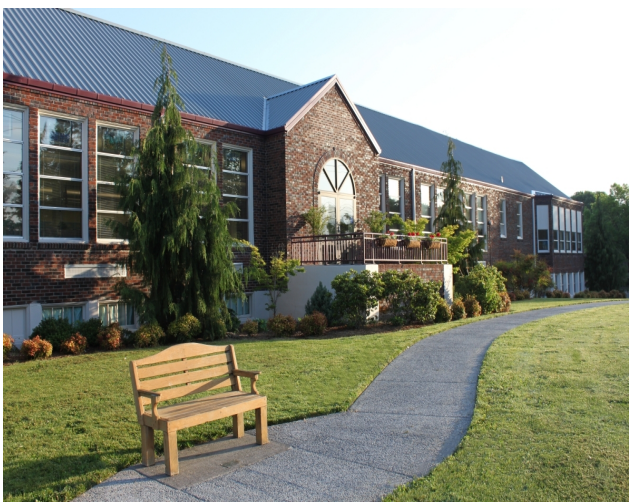

Date for Focus Group

Location for Focus Group

\begin{tabular}{|c|c|c|c|}
\hline Activity & Day/Time & Details & $\begin{array}{l}\text { Location and } \\
\text { Refreshments Offered }\end{array}$ \\
\hline $\begin{array}{l}\text { Principal } \\
\text { Interview }\end{array}$ & $\begin{array}{l}\text { Fall } 2014 \text { or } \\
\text { Winter } 2015\end{array}$ & $\begin{array}{l}\text { The interview will } \\
\text { take up to } 60 \text { minutes. }\end{array}$ & $\begin{array}{l}\text { All interviews } \\
\text { will be in a location } \\
\text { determined by the interviewee with } \\
\text { light refreshments }\end{array}$ \\
\hline $\begin{array}{l}\text { Teacher Focus } \\
\text { Group }\end{array}$ & $\begin{array}{l}\text { Fall } 2014 \text { or } \\
\text { Winter } 2015\end{array}$ & $\begin{array}{l}\text { The focus group will } \\
\text { take } 60 \text { minutes. Focus } \\
\text { group participation is not } \\
\text { dependent upon } \\
\text { completion of survey. }\end{array}$ & $\begin{array}{l}\text { All focus groups will be in a } \\
\text { private room identified per } \\
\text { community with light refreshments }\end{array}$ \\
\hline $\begin{array}{l}\text { Parent Focus } \\
\text { Group }\end{array}$ & $\begin{array}{l}\text { Fall } 2014 \text { or } \\
\text { Winter } 2015\end{array}$ & $\begin{array}{l}\text { The focus group will } \\
\text { take up to } 60 \text { minutes. }\end{array}$ & $\begin{array}{l}\text { All focus groups will be in a } \\
\text { private room identified per } \\
\text { community with light refreshments }\end{array}$ \\
\hline
\end{tabular}

